\title{
A Review on Binderless Tungsten Carbide: Development and Application
}

Cite as

Nano-Micro Lett.

(2020) 12:13

Received: 17 October 2019

Accepted: 20 November 2019

Published online: 30 December 2019

(C) The Author(s) 2019

\author{
Jialin Sun $^{1 凶}$, Jun Zhao ${ }^{2}$, Zhifu Huang ${ }^{1 凶},{\text { Ke } \text { Yan }^{3}{ }^{凶} \text {, Xuehui Shen }}^{4}$, Jiandong Xing ${ }^{1}$, \\ Yimin Gao ${ }^{1}$, Yongxin Jian ${ }^{1}$, Hejie Yang ${ }^{1}$, Bo Li ${ }^{1}$ \\ $\triangle$ Jialin Sun, jialinsun@xjtu.edu.cn; Zhifu Huang, hzf@xjtu.edu.cn; Ke Yan, yanke@mail.xjtu.edu.cn \\ 1 State Key Laboratory for Mechanical Behavior of Materials, School of Materials Science and Engineering, \\ Xi' an Jiaotong University, Xi' an 710049, People's Republic of China \\ 2 Key Laboratory of High Efficiency and Clean Mechanical Manufacture of MOE, School of Mechanical \\ Engineering, Shandong University, Jinan 250061, People's Republic of China \\ 3 Key Laboratory of Education Ministry for Modern Design and Rotor-Bearing System, Xi'an Jiaotong \\ University, Xi' an 710049, People's Republic of China \\ 4 School of Mechanical and Automotive Engineering, Qilu University of Technology, Jinan 250353, \\ People's Republic of China
}

\section{HIGHLIGHTS}

- Establish processing-composition-microstructure-property relationships governing binderless tungsten carbide (BTC).

- Highlight the densification improving strategies and toughening methods for BTC.

- Provide key challenges as well as the outlook for superior peformance associated with BTC.

ABSTRACT WC-Co alloys have enjoyed great practical significance owing to their excellent properties during the past decades. Despite the advantages, however, recently there have been concerns about the challenges associated with the use of Co, i.e. price instability, toxicity and properties degeneration, which necessitates the fabrication of binderless tungsten carbide (BTC). On the other hand, BTC or BTC composites, none of them, to date has been commercialized and produced on an industrial scale, but only used to a limited extent for specialized applications, such as mechanical seals undergoing high burthen as well as high temperature electrical contacts. There are two challenges in developing BTC: fully densifying the sintered body together with achieving a high toughness. Thus, this review applies towards comprehensively

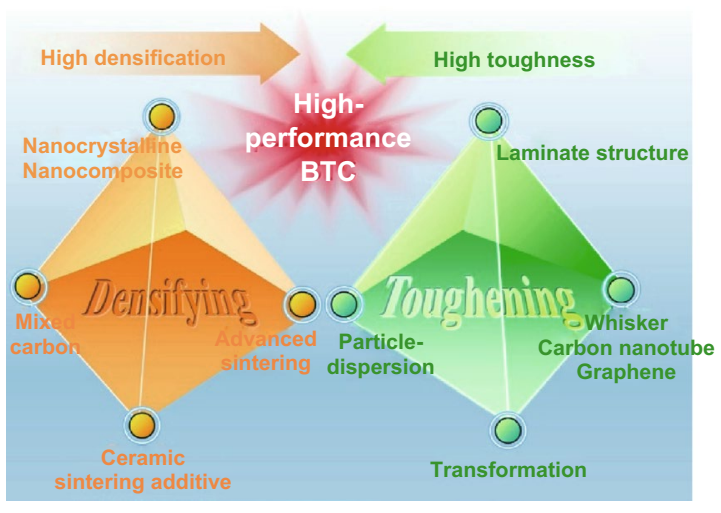
summarize the current knowledge of sintering behavior, microstructure, and mechanical properties of BTC, highlighting the densification improving strategies as well as toughening methods, so as to provide reference for those who would like to enhance the performance of BTC with better reliability advancing them to further wide applications and prepare the material in a way that is environment friendly, harmless to human health and low in production cost. This paper shows that the fabrication of highly dense and high-performance BTC is economically and technically feasible. The properties of BTC can be tailored by judiciously selecting the chemical composition coupled with taking into careful account the effects of processing techniques and parameters.

KEYWORDS Binderless tungsten carbide; Sintering; Densification; Toughening; Mechanical properties 


\section{Introduction}

Cemented carbides enjoy great practical significance and have been extensively applied as rock drill buttons, pressing dies, cutting tools, and other abrasion-resistant engineering parts due to their combinations of considerable toughness, strength, and wear resistance [1-5]. The tungsten carbide phase endows the alloy excellent hardness as well as superior wear resistance, while the binder phase is responsible for strength and toughness of the composite materials.

Cobalt (Co) is the mostly employed binder phase during the conventional sintering process due to a combination of fundamental synergistic reasons including its favorable wettability on tungsten carbide, interfacial bonding strength between WC and Co, the plasticity of Co phase in the composite, and its own strength and wear resistance [6,7]. However, its usage yields the deteriorations in hardness and oxidation/corrosion resistance along with elevated temperature performance owing to the inferior chemical characteristics of cobalt to the carbide phase. Furthermore, thermal stress is ease of generation because of the thermal expansion coefficients misfit [8-10]. When machining metal with high plasticity as pure iron using conventional WC-Co cemented carbide, chip tends to adhere on the rake face of cutting tool, resulting in serious adhesive wear due to the existence of cobalt with low melting point. This issue is exacerbated when cobalt resources may face depletion and economic crises for cobalt occurred because of the excessive development for growing application of cobalt for rechargeable accumulators (batteries) and in superalloys for high-performance jet turbines as illustrated in Table 1 [11]. Additionally, the acute pulmonary toxicity including on macrophage toxicity of WC and Co mixture has been proved to be higher than that of single WC and Co, making sintered WC-Co cemented carbides classified as carcinogenic to humans by International Agency for Research on Cancer (IARC) [12, 13].

On account of the reason above, considerable studies have paid overwhelming attention to the development of BTC. As pioneered by Kanemitsu [14] in 1982, BTC, also named binderless cemented carbide, is tungsten carbide free of any metallic binder including cobalt, iron, and nickel. As shown in Fig. 1, because of the absence of metal binder, BTC composites, possessing attractive properties as exceptional hardness as well as excellent wear/corrosion/oxidation resistance, can be fascinating materials serving in extremely tough environments. However, while initially appealing, none of them, to date, has been commercialized and produced on an industrial or commercial scale. BTCs are only used to a limited extent for specialized applications, such as mechanical seals undergoing high burthen, optical glass lens molds, nozzles for abrasive water jet as well as high-temperature electrical contacts. The production of high-performance BTC is even more challenging. The bottleneck lies in the difficulties encountered in consolidating and toughening BTC. More precisely, it is difficult to consolidate pure tungsten carbide to a full density through conventional sintering, due to its strong energy covalent chemical bonds and high melting point together with low self-diffusion coefficients. Furthermore, WC abnormal grain growth and the formation of sub-carbide $\mathrm{W}_{2} \mathrm{C}$ are also unavoidable. As a consequence, BTC composites usually exhibit such disadvantages such as unsatisfactory flexural strength and fracture toughness. In the backdrop of this problem, the development of BTC demands material design solving the twin problems of densification and brittleness.

Table 1 Overview of different uses of cobalt [11]

\begin{tabular}{|c|c|c|c|c|c|}
\hline Product group & Form & Fraction of supply (\%) & $\begin{array}{l}\text { Trend in use and since } \\
\text { when }\end{array}$ & Recycling & $\begin{array}{l}\text { Value } \\
\text { added to } \\
\text { product }\end{array}$ \\
\hline Super-alloys & Metallic & 22 & Increases 1995 & Yes & High \\
\hline Cutting tools & Metallic & 11 & Increases 1960 & Partly & Medium \\
\hline Magnets & Metallic & 12 & Increases 1990 & Partly & High \\
\hline Other applications & Metallic & 11 & Constant - & No & Low \\
\hline Batteries & Chemical & 22 & Increases 2000 & Yes & Medium \\
\hline Chemicals, catalyst & Chemical & 9 & Increases 1960 & No & Low \\
\hline Resins, pigments & Chemical & 13 & Constant - & No & Low \\
\hline
\end{tabular}



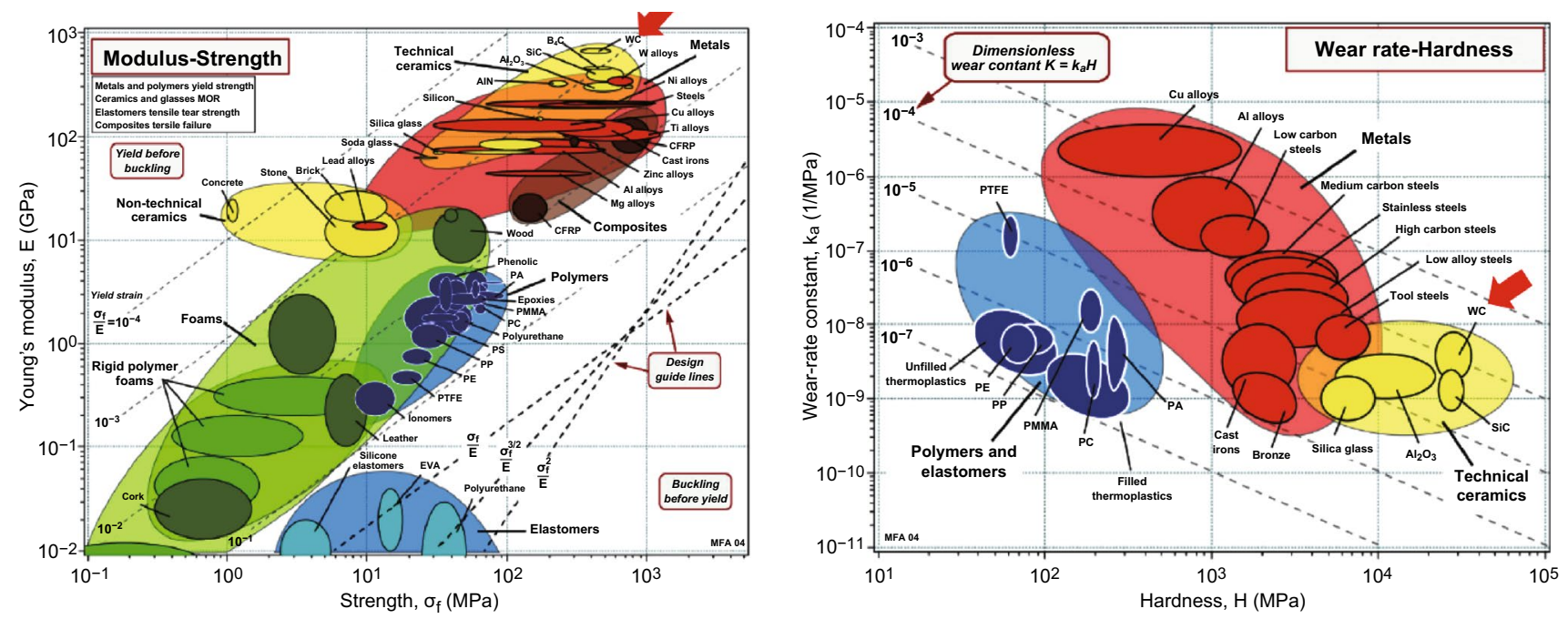

Fig. 1 Ashby diagrams for materials. Left: Young's modulus versus strength, right: wear-rate constant versus hardness. The red arrows point to tungsten carbides [15]. Figure panels reproduced from Ref. [15] with permission from Michael F. Ashby copyright 2009. (Color figure online)

The advanced sintering techniques, such as spark plasma sintering (SPS), reactive spark plasma sintering (RSPS), high-frequency induction-heated sintering (HFIHS) as well as pulsed current active sintering (PCAS), are successfully employed in laboratory scale preparing dense BTC. Particularly, SPS is currently the most applied sintering methods to consolidate BTC or BTC composites. Besides, some sintering additive may act as carbide binder ( $\mathrm{TiC}, \mathrm{TaC}$, and $\mathrm{SiC})$ or oxide binder $\left(\mathrm{Al}_{2} \mathrm{O}_{3}, \mathrm{ZrO}_{2}\right.$, and $\left.\mathrm{Y}_{2} \mathrm{O}_{3}\right)$, which significantly improve the sinterability of tungsten carbide. On the other hand, with a deep understanding of brittle fracture, various toughening methods, for example transformation toughening, have been proposed to reduce the brittleness and enhance the strength and toughness of BTC.

Though BTC has been developed in various research groups during the past decades, there are still no comprehensive reviews of the processing-composition-microstructure-property relationships governing the material. In light of this, the present article aims to understand the fundamentals of sintering, toughening, and mechanical properties of BTC through a comprehensive review and a systematic examination of the processing, composition, microstructure, and mechanical properties, so as to provide adequate references for those who want to improve the performance of cemented carbides with better reliability and prepare the material in a way that is cost-effective, environmentally friendly, and benign to human health. The following review will be divided into three major sections: methods improving the sinterability of BTC including the design of mixed carbon content, chemical composition as well as advanced sintering techniques; strategies of toughening BTCs including particle dispersion toughening, transformation toughening, whisker toughening, carbon nanotube toughening, graphene toughening, and laminated structure toughening together with synergistic toughening; and mechanical properties of BTC including hardness versus fracture toughness coupled with wear resistance.

\section{Densification of Binderless Tungsten Carbide}

Full densification is a prerequisite for BTC achieving its intrinsic properties. However, BTC, owing to the absence of any metallic binders, cannot be prepared by classical liquid-phase sintering but consolidated through solid-state sintering with higher temperature, i.e., above $1800{ }^{\circ} \mathrm{C}$, as well as external pressure because of its low self-diffusion coefficients and strong covalent bonds [16-19]. Thus, it is essential to understand the fundamental of solid-state sintering. Solid-state sintering refers to a diffusional transport of matter through a particular path, which is driven by the reduction in surface free energy of the particle, activated by temperature, and dictated by chemical potential gradients associated with defect concentration in the solid. It can 
be divided into three stages [20,21]. The initial stage features interface formation as well as neck growth between primary particles. It ends when the grain begins to growth. The intermediate stage features extensive grain boundary formations. Pores are still connected with each other in this stage. The final stage begins when pores become isolated. This stage features a fast grain growth with slight densification enhancement. Only four mechanisms are operative in solid-state sintering, and those are grain boundary diffusion, surface diffusion, vapor transport, and lattice diffusion [22]. With respect to solid-state sintering of BTC, grain boundary diffusion may play the critical role in the densification process. During the past decades, some efforts have been made to develop new sintering techniques as well as methodologies improving the sinterability of BTC, so as to obtain a fully dense BTC.

In 1957, Agte et al. [23] firstly attempted to fabricate pure WC employing conventional sintering techniques; however, the result was unsatisfactory. In 1990s, the availability of ultra-fine even nanopowders possessing increased surface energy, and some sintering actives shed light on the preparation of BTC through conventional sintering methods. It is revealed that the densification of nanocrystalline WC-Co powder took place mostly in solid state [24], suggesting that cobalt may not act significantly in the densification process of nanocrystalline WC-Co. Richter et al. [25-27] originally reported on the production of completely densified pure WC using vacuum or pressurized gas sintering owing to the utilization of ultra-fine WC starting powder. The author was appreciated by the EPMA Award of Merit for New Materials in the year of 2000 for developing an ultra-fined BTC with high hardness and wear resistance without any or very low amounts of grain growth inhibitor addition [28, 29]. Recently, some fast sintering techniques such as SPS featuring rapid heating and rapid sintering at relatively lower temperature further facilitated the fabrication of BTC. Fully densified BTC with fine grains is ultimately preferred and is critical to maximize properties. In the following, we critically analyze the major challenges involved in the densification of BTC, including various approaches required to overcome the sintering difficulty of BTC, and then effectively utilize the sintering factors to advantage the consolidation of BTC.

\subsection{Mixed Carbon Content}

Mixed carbon content has been of great concern to manufacturers of cemented carbide components since the $1950 \mathrm{~s}$ [30, 31]. Adding free carbon into WC can improve the densification process and reduce or eliminate the formation of brittle phase $\mathrm{W}_{2} \mathrm{C}$ in samples obtained by SPS at $1800{ }^{\circ} \mathrm{C}$ for 6 min under the pressure of $70 \mathrm{MPa}$ as shown in Fig. 2a. It is suggested that carbon addition is required to reduce oxide impurities as passivation layers located on the surface of WC grains and create the unifying phase compositions, ultimately obtaining single-phase WC materials. Gubernat et al. $[33,34]$ produced dense single-phase WC polycrystals by hot-pressing sintering with carbon addition. It was found that graphite nanolayers were formed on inter-granular boundaries in carbon-added WC sinters, which significantly improved the thermal conductivity of the polycrystals. The thermal conductivity of sintered WC samples without carbon addition was around $100 \mathrm{~W} /(\mathrm{m} \mathrm{deg})$, whereas that of obtained WC specimens with carbon addition was close to $200 \mathrm{~W} /(\mathrm{m} \mathrm{deg})$. However, excessive carbon addition can easily lead to the abnormal grain growth (AGG) of WC as well as the formation of graphite phase inducing cavities and pores in the sintered products [16, 35-38] preventing the full densification, implying that strictly controlling carbon content is essential in the design and fabrication of BTC.

As for conventional cemented carbides as $\mathrm{WC}-\mathrm{Co}$ cemented carbides, there exists a carbon window, carbon content below which $\eta$-phase forms, whereas carbon content above which graphite phase precipitates. Unfortunately, no carbon range but only at a critical value carbon content can deleterious eta phase generation and graphite precipitation be avoided with respect to binderless cemented carbides [39]. Zhang et al. [39] synthesized pure WC employing SPS by tailoring carbon addition to the starting powders. In case of WC with an initial powder size of $0.2 \mu \mathrm{m}$, the sintered product was a single WC phase only with a $0.4 \mathrm{wt} \%$ carbon mixed. $\mathrm{WC}_{1-\mathrm{x}}$ phase formed regarding mixed carbon content below $0.4 \mathrm{wt} \%$, while free carbon appeared concerning mixed carbon content above $0.4 \mathrm{wt} \%$. The main phase changed into $\mathrm{WC}_{1-\mathrm{X}}$ and $\mathrm{W}_{2} \mathrm{C}$ for samples without carbon addition. The authors stated that higher mixed carbon content was required for fine-grained BTC with a correct 

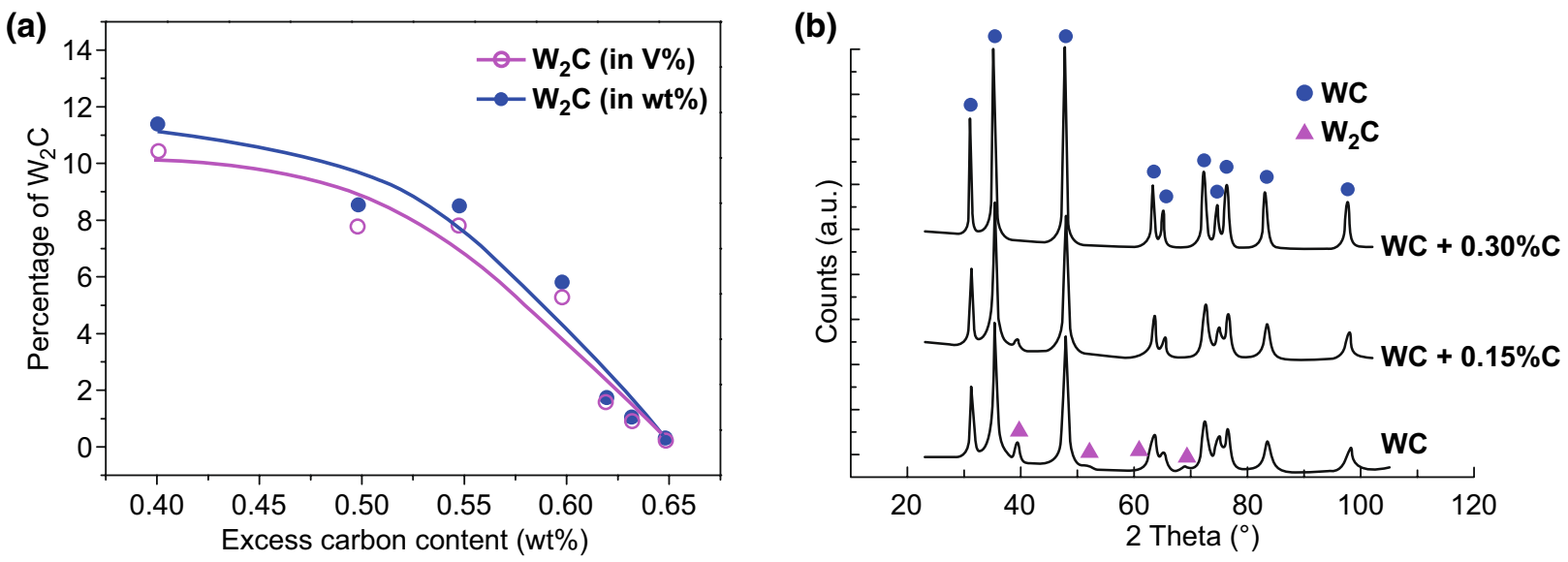

(c)
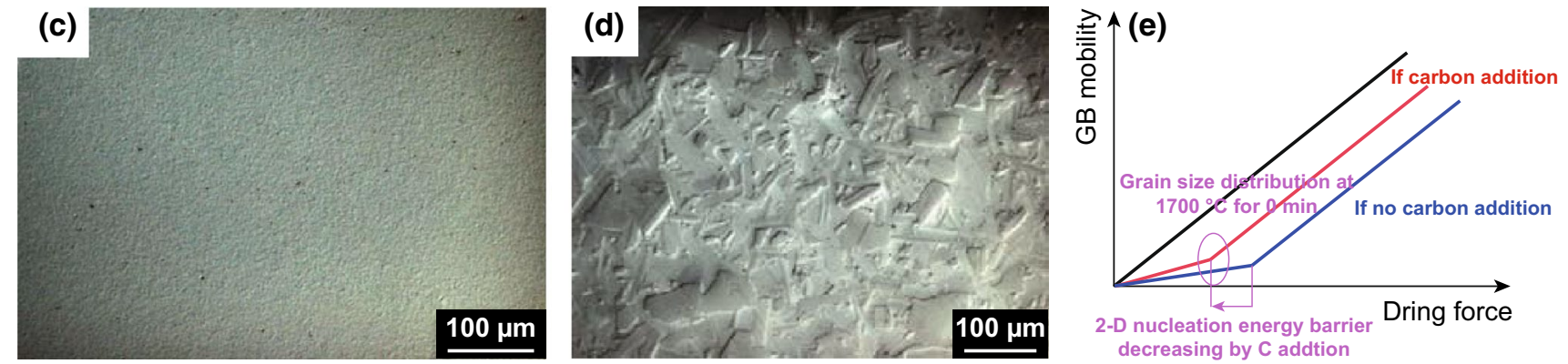

Fig. 2 a Percentage of impurity phase $\mathrm{W}_{2} \mathrm{C}$ phase in sintered sample obtained by SPS at $1800{ }^{\circ} \mathrm{C}$ for 6 min under the pressure of $70 \mathrm{MPa}$ as a function of $\mathrm{C}$ addition in powders [32]. $\mathbf{b}$ XRD patterns of WC micro and WC ball milled with carbon addition, $\mathbf{c}$ WC $+0.15 \% \mathrm{C}$ and $\mathbf{d}$ $\mathrm{WC}+0.3 \% \mathrm{C}$ SPS $2200{ }^{\circ} \mathrm{C}$ without holding time [40]. e Schematic of abnormal grain growth due to addition of C [41]. Figure panels reproduced from Ref. [32] with permission from Taylor \& Francis copyright 2015, Ref. [40] with permission from Elsevier copyright 2008, Ref. [41] with permission from Elsevier copyright 2003

phase in comparison with conventional cemented carbides as WC-Co. For one thing, more oxygen was absorbed by WC powders with fine grade (with larger-surface-to-volume ratio). Besides, higher sintering temperature (about $1800{ }^{\circ} \mathrm{C}$ ) contributed to a complete oxide reduction process. Girardini et al. [40] prepared WC with commercially available microWC powders employing SPS with a sintering temperature of $2200{ }^{\circ} \mathrm{C}$ and no holding time. With $0.15 \mathrm{wt} \%$ carbon addition, the sintered samples appeared no AGG (Fig. 2c), but the $\mathrm{W}_{2} \mathrm{C}$ phase was detected as shown in Fig. $2 \mathrm{~b}$, implying that the added carbon was insufficiently used for complete oxide reduction. With $0.3 \mathrm{wt} \%$ carbon addition, the $\mathrm{W}_{2} \mathrm{C}$ phase was avoided (Fig. 2b); however, no improved mechanical properties were obtained as a result of the occurrence of AGG as illustrated in Fig. 2d. Single-phase WC products can be obtained through adding carbon, but AGG occurred once the carbon content exceeded the stoichiometric amount required for the reduction of oxides. In other words, carbon addition reduces or eliminates the brittle phase $\mathrm{W}_{2} \mathrm{C}$, and this leads to an enhancement in mechanical properties as fracture toughness; however, at the same time carbon contributes to the AGG and this second effect depresses the mechanical properties as hardness and flexural strength of the material.

As for this, the densification and grain growth behavior of binderless WC are sensitively dependent on the $\mathrm{C}$ content within WC. It is rather challenging to strictly control the carbon content during the fabricating process, and the correlation between carbon content and AGG must be carefully taken into account for the design and fabrication of BTC.

Cha et al. [41] reported that $\mathrm{W}_{2} \mathrm{C}$ formation was attributed to the carbon loss through interaction of carbon with surface oxides. Carbon addition was necessary for reduction of oxide impurities located mainly as passivation layers on the surface of WC grains. It is proposed that the densification and grain growth behavior of BTC are sensitively dependent on the C content within tungsten carbide. WC with an initial powder size of $0.57 \mu \mathrm{m}$ could be sintered to densification by addition 
of $0.3 \mathrm{wt} \%$ free carbon. The authors also demonstrated the mechanism for carbon addition-induced AGG as shown in Fig. 2e. From their perspective, the carbon addition can not only increase the driving force of grain growth, but also decrease the two-dimensional nucleation energy barrier in WC; as a consequence, the two-dimensional nucleation insufficiently restricts the grain growth due to the sufficiently large driving force for grain growth. Zhao et al. [42] prepared highly dense BTC with a grain size of around $0.4 \mu \mathrm{m}$ by the SPS method. The authors found that the carbon addition-induced AGG occurred only when the sintering temperature was above $1650{ }^{\circ} \mathrm{C}$. To avoid AGG, specimens were consolidated at a lower temperature $1500{ }^{\circ} \mathrm{C}$ with a holding time $5 \mathrm{~min}$, the density was around 99\%, and no AGG occurred. On the other hand, based on the well-known equations as Eqs. 1-6, it is suggested that the excess carbon in WC can be moderated by introducing proper contents of $\mathrm{WO}_{3}$ and $\mathrm{W}[39,43]$.

In the presence of free carbon:

$\mathrm{W}+\mathrm{C} \rightarrow \mathrm{WC}$

$\mathrm{WO}_{3}+4 \mathrm{C} \rightarrow \mathrm{WC}+3 \mathrm{CO}(\mathrm{g})$

$2 \mathrm{WO}_{3}+5 \mathrm{C} \rightarrow 2 \mathrm{WC}+3 \mathrm{CO}_{2}(\mathrm{~g})$

In the absence of free carbon:

$\mathrm{W}+\mathrm{WC} \rightarrow \mathrm{W}_{2} \mathrm{C}$

$\mathrm{WO}_{3}+7 \mathrm{WC} \rightarrow 4 \mathrm{~W}_{2} \mathrm{C}+3 \mathrm{CO}(\mathrm{g})$

$4 \mathrm{WO}_{3}+16 \mathrm{WC} \rightarrow 10 \mathrm{~W}_{2} \mathrm{C}+6 \mathrm{CO}_{2}(\mathrm{~g})$

In summary, carbon control is very essential for BTC achieving maximum densification and performance levels. Strict design of additives including carbon, $\mathrm{WO}_{3}$, and $\mathrm{W}$ together with careful control of thermal processing process is of great importance to the carbon content in the final product.

\subsection{Nanocrystalline Tungsten Carbide and Its Composites}

Based on various sintering models, from the two sphere ones for the initial sintering stage to the microstructural model for the intermediate sintering stage, sintering temperature strongly depends on the grain size, that is, finer initial powder grain size is helpful in lowering the sintering temperature or starting temperature as well as shortening the sintering process, especially for nanopowders as illustrated in Fig. 3a [44-51]. It is demonstrated that nanosized WC-Co powders start to densify at $600{ }^{\circ} \mathrm{C}$, while submicron-sized powders begin at $1100{ }^{\circ} \mathrm{C}$ and regular micro-sized powders at $1320^{\circ} \mathrm{C}$ (WC-Co liquidus point) [52-54], conforming the profound effect of grain size on the onset of sintering of WC-Co cemented carbides. Muginstein [55] reported that submicron-sized WC powders begin to densify at $1200{ }^{\circ} \mathrm{C}$, while nanopowders at $500{ }^{\circ} \mathrm{C}$, suggesting that grain size also acted significantly during the sintering of BTC. Furthermore, according to the interfacial energy considerations, there exists a critical pore coordination number, only below which pores will shrink and disappear; otherwise, pores will be stable and not shrink during the sintering process. The grain growth of nanocrystalline particles is helpful in lowering the coordination number of pores and then contributing to the densification process. Also, in general, the average pore size is strongly associated with the average particle size, so nanocrystalline particles may lead to nanosized pores with higher mobility, in turn accelerating the densification process.

Kim [56] and Chvildeev [57, 58] investigated in detail the effect of initial WC particle size on the densification of pure WC by determining the relative densities of sintered BTC with varied initial particle sizes after the same sintering condition. As shown in Fig. 3b, c, the relative density of BTC increased with decreased initial particle size. Therefore, reducing the particles size even down to nanorange is feasible to improve the consolidation process. Girardini et al. [40] compared the densities of micro- and nano-WC with increasing sintering temperature as shown in Fig. 3d. Obviously, there exists a densification delay for micro-WC powder in comparison with nano-WC powder, indicating that nano-WC powder possesses better sintering activity [24, 59-61]. The driving force for densification of WC in general results from a reduction in total surface energy. The internal interface area increased with a decrease in WC grain size, and an enlarged interface area is essential to an enhanced sintering driving force. Based on conventional sintering theories, the sintering driving force can be calculated by Laplace equation (Eq. 7):

$\sigma=\gamma\left(\frac{1}{R_{1}}+\frac{1}{R_{2}}\right)$

where $\gamma$ is the surface energy of the material and $R_{1}$ and $R_{2}$ are the principal radii of the curvature. Obviously, 
(a)

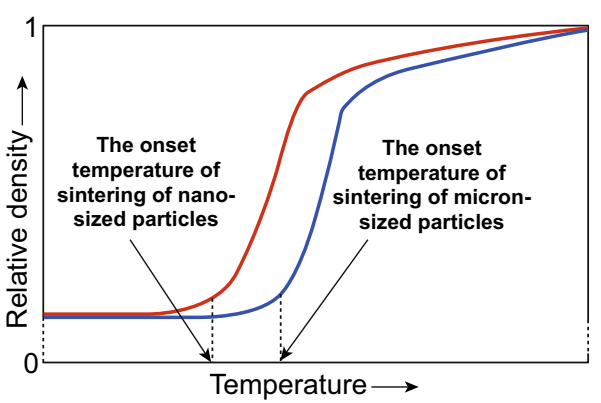

(b)

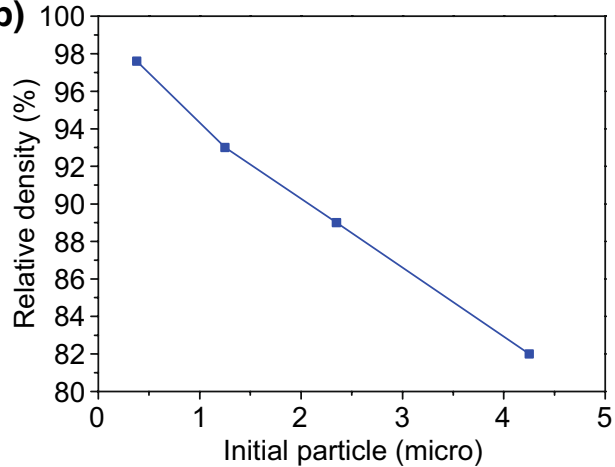

(c)

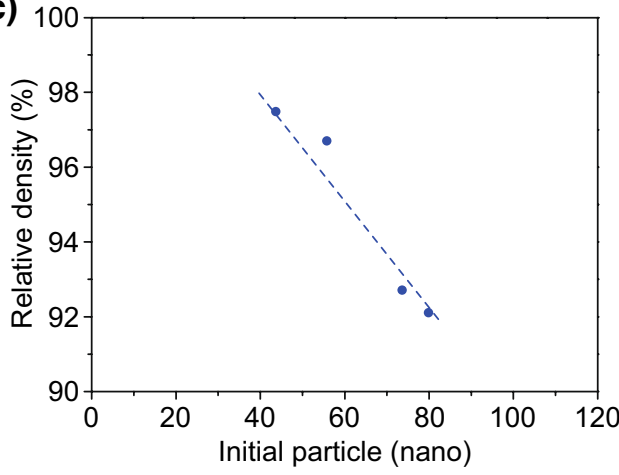

(d)

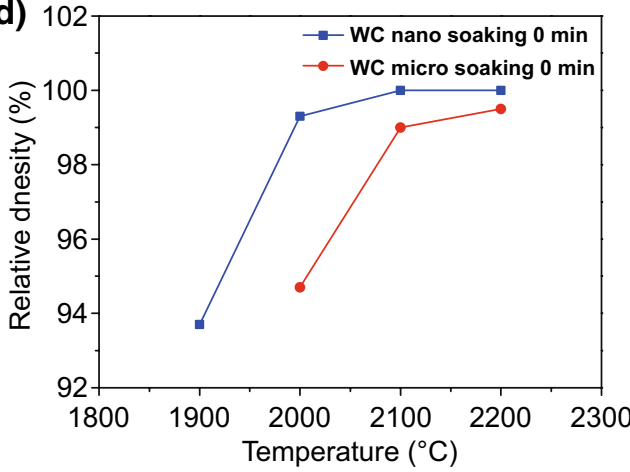

(e) Bridging between agglomerates

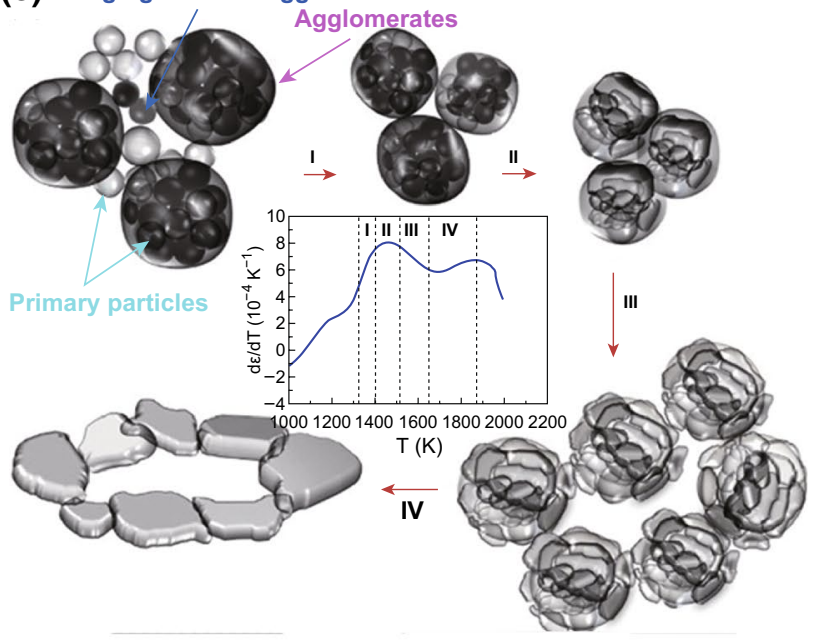

(f)
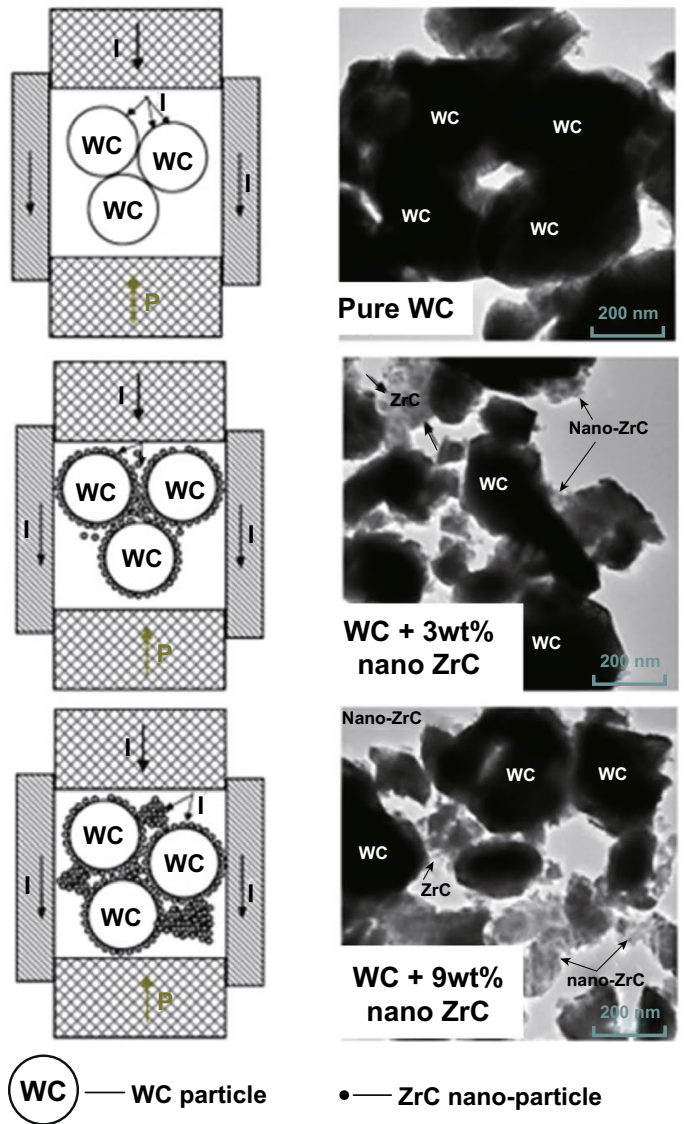

- ZrC nano-particle

Fig. 3 a Schematic diagram illustrating different onset temperatures of sintering of nano- and micro-sized particles [44]. Relative density of pure WC as a function of initial particle size in BTC $\mathbf{b}$ microsize [56] and $\mathbf{c}$ nanosize [57]. $\mathbf{d}$ Relative density of micro and nano WC versus sintering temperature, without holding time [40]. e Schematic of the sintering mechanism of nano WC on the basis of the experimental shrinkage strain rate in a non-isothermal experiment [48]. f Schematic diagrams and corresponding TEM micrographs revealing the contact state of WC and $\mathrm{ZrC}$ nano-particles during sintering [63]. Figure panels reproduced from Ref. [44] with permission from Taylor \& Francis copyright 2008, Ref. [56] with permission from Elsevier copyright 2004, Ref. [57] with permission from Elsevier copyright 2017, Ref. [40] with permission from Elsevier copyright 2008, Ref. [48] with permission from Elsevier copyright 2011, Ref. [63] with permission from Elsevier copyright 2015 
nanocrystalline WC powders possess much higher sintering driving forces in comparison with micro-sized ones, due to their superior surface energy. It is concluded that nanocrystalline WC powders possess better sinterability in comparison with micro-sized ones, due to their high surface energy increasing the sintering driving forces.

By investigating sintering kinetics of nanocrystalline WC powders (100-500 nm), Muginstein [62] defined three sintering stages regarding the nanocrystalline WC powder: (1) initial stage, rearrangement of particles at low temperature $\left(850{ }^{\circ} \mathrm{C}\right)$ with no grain or particle growth; (2) intermediate stage, neck formation between powder particles at $1000-1250{ }^{\circ} \mathrm{C}$ and initial grain growth at $1200{ }^{\circ} \mathrm{C}$; and (3) final stage, pore elimination accompanied by massive grain growth at $1300-1450{ }^{\circ} \mathrm{C}$.

The sintering kinetics of nano-grained WC was studied in detail by Nanda Kumar et al. [48] using commercially available nano-WC powder without any pretreatment with particle sizes measuring $70 \mathrm{~nm}$ (by BET analysis) employing non-isothermal and isothermal sintering. The results illustrated that the agglomeration of nanoparticles was easily to be brought about by surface diffusion resulting in neck growth and grain rotation even at low temperature. The sinterability differences of inter- and intra-agglomerate pore phases introduced substages into the intermediate stage during the sintering process as shown in Fig. 3e. Four substages were defined in the intermediate sintering stage: (1) stage I ( $~ 80 \%$ end density), this stage was located at the end of initial sintering stage/starting of the intermediate sintering stage and covered the temperature from 1027 to $1127{ }^{\circ} \mathrm{C}$. This stage featured a rapid increase in the densification rate, resulting from inter-agglomerate together with intraagglomerate densification. Most bridges between agglomerates disappeared and then clusters impinged on each other. At the end of this stage, the microstructure evolved into most agglomerate and continuous pore; 2 ) stage II ( 83 to $85 \%$ end density), this stage was identified for its constant density. The shrinkage, if any, occurred purely as a function of intra-agglomerate densification. At the end of this stage, the microstructure was characterized by well-demarcated agglomerate boundaries; 3$)$ stage III ( 85\% end density), in this stage, the net shrinkage stain rate decreased owing to inter-agglomerate pore stability as well as a small amount of grain growth within agglomerates; (4) stage IV ( 94\% end density), in this stage, because of temperature driven coupled with the reduction in pore coordination number, the system tried to evolve by massive grain growth within the agglomerates, leading to the breakup of the agglomerate and sintering start of stable inter-agglomerate pores. The pores started to shrink rapidly and surpassed the grain growth rate with the transform of agglomerates into large grains. Thus, in nano-WC system, the grain growth acted to enhance the densification process by changing the pore stability from thermodynamically stable to unstable through decreasing the pore coordination number. Actually, considering the thermodynamics of the sintering process, complete densification cannot be achieved in nano-WC powders without grain growth as one abets the other [48].

Besides reducing the particle size of WC matrix, it is also effective to facilitate the sintering of WC by dispersing some nanosized second-phase additive within micro-sized WC matrix grains or at the grain boundaries of WC matrix. Ren et al. [63] reported that the densification of BTC was significantly improved through adding appropriate amount of $\mathrm{ZrC}$ nano-powder. The densification mechanism was that submicron-sized WC particles were surrounded by nanosized $\mathrm{ZrC}$ particles through the mixing process as shown in Fig. 3f. WC particles tended to gather together to form a large particle regarding pure WC sample. However, with respect to $3 \mathrm{wt} \%$ nano- $\mathrm{ZrC}$-added specimen, submicronsized WC particles were adhered by nano-ZrC particles (Fig. 3f). The adherent nano-powder filled the inter-space resulting from particle rearrangement and plastic deformation of WC grains and then improved the densification process. On the other hand, nanopowders tended to agglomerate as a result of their high specific surface areas. Considering the WC-9 wt\% ZrC samples, the agglomeration of nano$\mathrm{ZrC}$ was serious, consequently leading to the deterioration of densification.

Biswas [64] prepared fully dense WC-6 wt $\% \mathrm{ZrO}_{2}$ composites with the assistance of $\mathrm{ZrO}_{2}$ powders of $27 \mathrm{~nm}$ as second-phase employing SPS (sintering at $1300{ }^{\circ} \mathrm{C}$ for holding $5 \mathrm{~min}$ ). As demonstrated in Table 2, employing the same consolidation technique, sintering temperature required for WC achieving full densification was significantly reduced as a function of nanocrystalline $\mathrm{ZrO}_{2}$ addition. Furthermore, it should be noted that WC can be consolidated utilizing nanosized $\mathrm{ZrO}_{2}$ at a lower temperature $1300{ }^{\circ} \mathrm{C}$ in comparison with WC-Co at $1400{ }^{\circ} \mathrm{C}$ [65], indicating that nano- $\mathrm{ZrO}_{2}$ is an ideal alternative to Co binder as sinter additive. The densification improving mechanism was $\mathrm{ZrO}_{2}$ enhancing 
Table 2 Densification data of $\mathrm{WC}-6 \mathrm{wt} \% \mathrm{ZrO}_{2}$ composites and $\mathrm{WC}-6 \mathrm{wt} \%$ Co cemented carbides sintered via spark plasma sintering (SPS)

\begin{tabular}{|c|c|c|c|c|c|}
\hline Material composition & $\begin{array}{l}\text { Starting powder size } \\
(\mu \mathrm{m})\end{array}$ & $\begin{array}{l}\text { Sintering techniques and tem- } \\
\text { perature }\left({ }^{\circ} \mathrm{C}\right)\end{array}$ & Holding time (min) & Pressure (MPa) & $\begin{array}{l}\text { Relative } \\
\text { density } \\
(\%)\end{array}$ \\
\hline $\mathrm{WC}-6 \mathrm{wt} \% \mathrm{ZrO}_{2}$ [64] & 0.2 & SPS, 1300 & 5 & 30 & 99.9 \\
\hline WC-6 wt\% Co [65] & 0.2 & SPS, 1300 & 5 & 30 & 91.4 \\
\hline WC-6 wt $\%$ Co [65] & 0.2 & SPS, 1400 & 5 & 30 & 100 \\
\hline
\end{tabular}

sintering kinetics as a result of size effect together with high "constriction resistance." Nanosized $\mathrm{ZrO}_{2}$ increased the volume fraction of the interface area due to its higher specific surface area and then resulted in faster mass transport considering grain boundaries providing faster diffusion paths. Nanosized $\mathrm{ZrO}_{2}$ particles enhanced "constriction resistance," because of their nanosize, resulting in higher resistivity coupled with smaller particle-to-particle contact area, based on Eq. 8 [66]:

$R_{\mathrm{c}}(n, a, l)=\frac{\rho f_{\mathrm{s}}}{2 \pi n a} \arctan \left(\frac{\sqrt{l^{2}-a^{2}}}{a}\right)$

where $R_{\mathrm{c}}$ is the constriction resistance, $\rho$ is the resistivity of the powder, $a$ is the linear dimension of the inter-particle contact, $f_{\mathrm{s}}$ is the shape factor, $l$ is the nearest distance between the contacts, and $n$ is approximately the number of squares with sides $2 l$. Thus, voltage drop took place over a small distance around the nano- $\mathrm{ZrO}_{2}$ contact area. Highresistance localized area with a rather high Joule heating was formed, resulting in local temperature increase and then a faster mass transport.

\subsection{Ceramic Sintering Additive}

Sintering additives, which are present in solid state only or may form liquid phases, are intentionally added to control the microstructural and dimensional development during sintering. Numerous researches have demonstrated that minor additions of second phase, which increase the grain boundary diffusion and surface diffusion in this system, accelerate the densification process [67]. Therefore, besides the mixed carbon content and carbide grain size, the design of chemical composition is also a logical strategy to enhance the sinterability of tungsten carbide in conventional methods. The low melting point of the metal and possibility of carbonation and oxidation make the selection of the transition-metal carbides ( $\mathrm{TiC}[68,69], \mathrm{TaC}$ [70], and $\mathrm{SiC}$ $[71,72])$ and metal oxides $\left(\mathrm{Al}_{2} \mathrm{O}_{3}[73], \mathrm{ZrO}_{2}[74], \mathrm{Y}_{2} \mathrm{O}_{3}[75\right.$, 76], and $\mathrm{La}_{2} \mathrm{O}_{3}$ [77]) binders more favorable for tailoring the densification process of BTC.

\subsubsection{Titanium Carbide (TiC)}

Titanium carbide ( $\mathrm{TiC}$ ), with a cubic structure ( $\mathrm{Ti}$ atoms on one fcc sublattice and $\mathrm{C}$ atoms on the other), has been recognized as one of the most significant metal carbides for BTC manufacturing, due to its prominent intrinsic properties, such as high melting point $\left(3067^{\circ} \mathrm{C}\right)$, high thermal conductivity $\left(30 \times 10^{6} \mathrm{~S} \mathrm{~cm}^{-1}\right)$, high hardness (TiC has $31 \mathrm{GPa}$ Vickers hardness and WC has $25 \mathrm{GPa}$ ), high elastic modulus (410-450 GPa), high thermodynamic stability together with low friction coefficient and density $\left(4.93 \mathrm{~g} \mathrm{~cm}^{-3}\right)$ [78]. In 1982, Kanemitsu et al. [15] firstly developed a WC-TiC-TaC binderless cemented carbide. Since then, several researches have been performed to improve the sinterability of tungsten carbide through adding $\mathrm{TiC}$ as a carbide binder.

Kim et al. [79] demonstrated the effect of TiC content on the sintering of WC-TiC composites as illustrated in Fig. 4. Initially, all specimens showed volume increases because of the thermal expansion. The onset of shrinkage of pure WC started at about $1200^{\circ} \mathrm{C}$, while that of TiC-added WC composites took place at around $950-1100{ }^{\circ} \mathrm{C}$, suggesting that the content of $\mathrm{TiC}$ had a significant influence on the onset of sintering of WC-based composites. Sintering temperature was decreased significantly with the increasing TiC content. As depicted in Fig. 4b, under the same sintering condition, the density of pure WC sample was about $78 \%$, while that of WC-50 at.\% specimen was $98.5 \%$. Obviously, TiC was beneficial to enhance the relative density of WC-TiC composites. The densification mechanism was that $\mathrm{TiC}$ acted as a carbide binder resulting from the formation of WC-TiC solid solution phase [80-83]. As shown in Fig. 4c, the lattice 

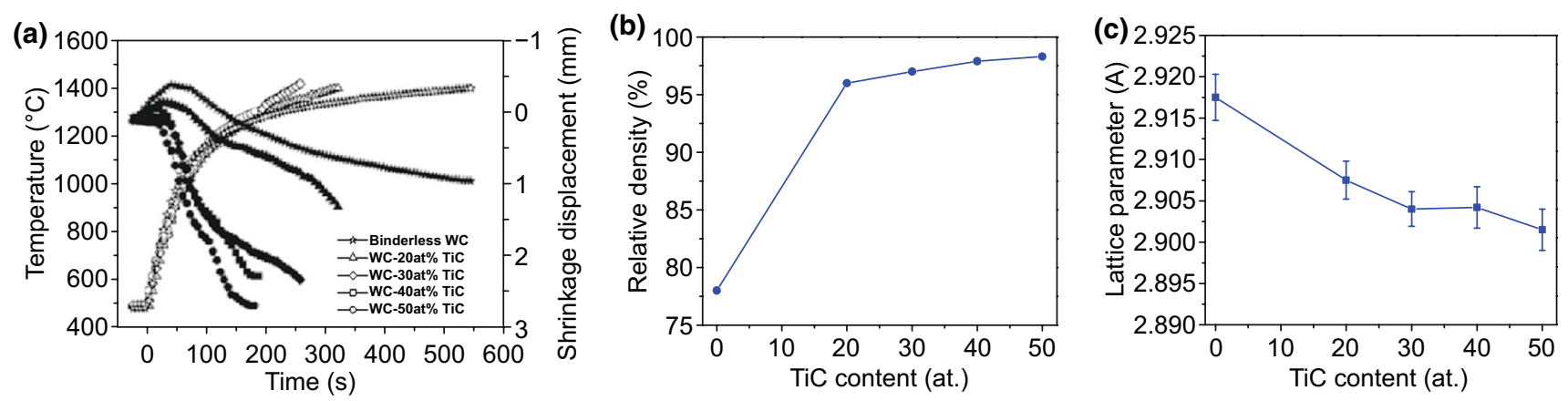

Fig. 4 a Variations of temperature and shrinkage displacement with heating time during high-frequency induction heated sintering of WC $-x$ at.\% TiC hard materials (under $60 \mathrm{MPa}$ pressure, 2800A). b Relative density as a function of TiC content. c Plot of WC phase lattice parameter as a function of TiC content produced by PCAS [79]. Figure panels reproduced from Ref. [79] with permission from Hanyang University copyright 2007

parameter of WC decreased with the increasing contents of TiC addition, confirming the formation of a series of solid solution.

It was thought that the formation of solid solutions between additive and WC could facilitate the densification of WC-based materials. The similar densification mechanism was found in WC-TiC-TaC [80], WC-VC [84], and $\mathrm{WC}-\mathrm{Mo}_{2} \mathrm{C}$ [85] systems. Imasato et al. [80] reported that the addition of $\mathrm{TaC}$ and $\mathrm{TiC}$ facilitated the sintering process of WC because of the formation of (W, Ta, Ti) $\mathrm{C}$ solution phase. Huang et al. [84] suggested that VC addition facilitated densification as a function of $(\mathrm{V}, \mathrm{W}) \mathrm{C}$ solid solution phase formation, so that full densification for WC-VC composites could be achieved at lower temperature or within shorter sintering time in comparison with pure WC.

\subsubsection{Silicon Carbide (SiC)}

Silicon carbide $(\mathrm{SiC})$ possesses a high hardness above 20 GPa together with a relatively high Young's modulus 440 GPa. Furthermore, $\mathrm{SiC}$ is less expensive than WC. Additionally, $\mathrm{SiC}$ is proved to be a toughening phase for many ceramics including WC. So, SiC can be an excellent candidate for improving the sinterability of BTC. It is proposed that the sintering temperature of WC was significantly decreased as a function of $\mathrm{SiC}$ powder and/or $\mathrm{SiC}$ whiskers addition [86-88].

Dense WC-SiC composites were fabricated by Nino et al. [87] employing hot-pressing sintering methods. As demonstrated in Fig. 5a, no dense sintered body was obtained at $1600{ }^{\circ} \mathrm{C}$ for pure WC though hot-pressing applied, indicating that $1800^{\circ} \mathrm{C}$ was essential to realize densification. However, with respect to $\mathrm{WC}-\mathrm{SiC}$ composites, high relative density above $98 \%$ was achieved as a result of $2-10 \mathrm{~mol} \% \mathrm{SiC}$ addition.

As shown in Fig. 5 b, WC-SiC $\mathrm{w}_{\mathrm{w}}$ composites containing $3-5 \mathrm{vol} \% \mathrm{SiC}_{\mathrm{w}}$ were fully dense at $1650{ }^{\circ} \mathrm{C}$, while pure WC could not be sintered densely at $1650{ }^{\circ} \mathrm{C}$, suggesting that $\mathrm{SiC}_{\mathrm{w}}$ was efficacious in lowering the sintering temperature of WC [88]. However, the relative density gradually decreased with the $\mathrm{SiC}_{\mathrm{w}}$ addition regarding $10 \mathrm{vol} \% \mathrm{SiC}_{\mathrm{w}}$. $1750{ }^{\circ} \mathrm{C}$ was necessary for $30 \mathrm{vol} \% \mathrm{SiC}_{\mathrm{w}}$ composites to realize a fully dense level.

However, while initially appealing, caution should be exercised as the mechanism of the WC sinterability improvement by $\mathrm{SiC}$ addition, to data, is still unclear and $\mathrm{WC}-\mathrm{SiC}$ composites, possessing only a small market share, were employed only to a limited extent for specialized applications. Moreover, it is noted that $\mathrm{SiC}$ addition tended to result in the abnormal growth of WC grains; thus, some grain growth inhibitors such as $\mathrm{ZrC}$ [71], $\mathrm{NbC}$ [72], $\mathrm{Mo}_{2} \mathrm{C}$ [89], $\mathrm{VC}$ [56], and $\mathrm{Cr}_{3} \mathrm{C}_{2}$ [86, 90] are required to obtain the excellent microstructure as well as mechanical properties.

\subsubsection{Alumina $\left(\mathrm{Al}_{2} \mathrm{O}_{3}\right)$}

Alumina $\left(\mathrm{Al}_{2} \mathrm{O}_{3}\right)$, as a refractory oxide, has been widely used in industry applications owing to its excellent properties, such as low density, good thermal and chemical stability, high hardness, and high temperature [91]. Besides, the price of $\mathrm{Al}_{2} \mathrm{O}_{3}$ is lower than that of $\mathrm{Co}$ and many other metal oxides as $\mathrm{ZrO}_{2}$ and $\mathrm{MgO}$. Moreover, $\mathrm{Al}_{2} \mathrm{O}_{3}$ has a 

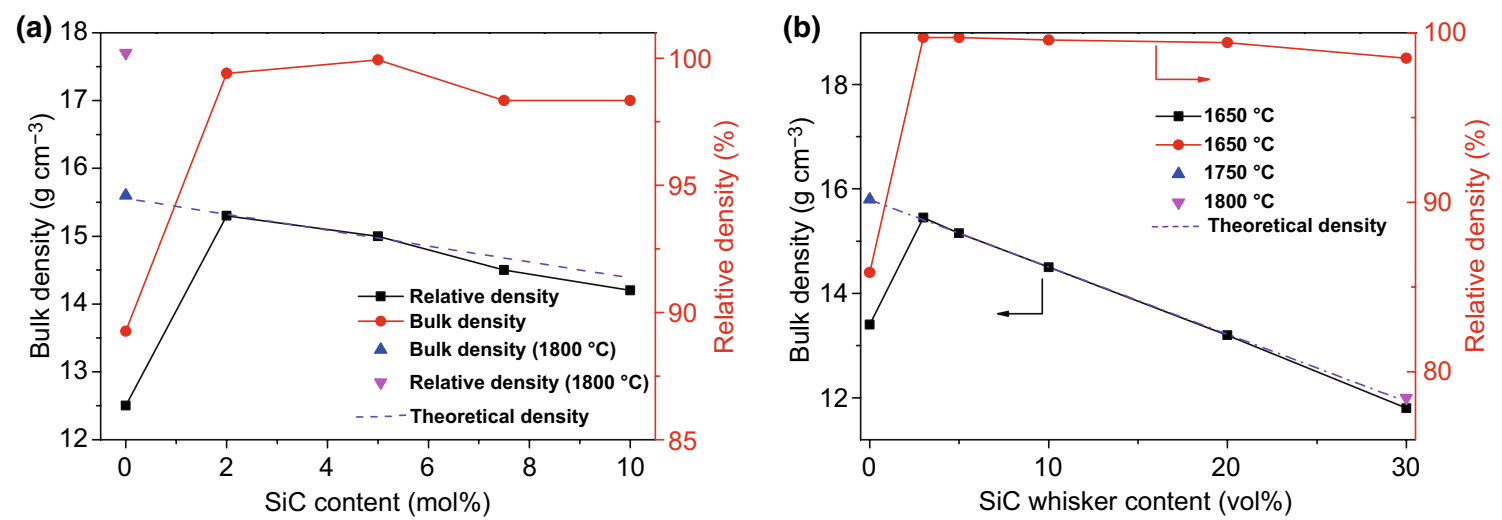

Fig. 5 a Bulk density and relative density of WC-SiC composites [87]. b Bulk density and relative density of $\mathrm{WC}^{-S i C} \mathrm{w}_{\mathrm{w}}$ composites [88]. Figure panels reproduced from Ref. [87] with permission from Japan Institute of Metals (JIM) copyright 2011, Ref. [88] with permission from Japan Institute of Metals (JIM) copyright 2008

lower melting point in comparison with that of $\mathrm{ZrO}_{2}$ and $\mathrm{MgO}$, which is more helpful in lowering the temperature of reinforced materials by generating liquid phase. Therefore, $\mathrm{Al}_{2} \mathrm{O}_{3}$ can be an economical and suitable candidate to replace Co in WC matrix [92-99].

Zheng et al. [99] investigated the effect of $\mathrm{Al}_{2} \mathrm{O}_{3}$ addition on the sintering behavior of $\mathrm{WC}-\mathrm{Al}_{2} \mathrm{O}_{3}$ composite as shown in Fig. 6a, b. For pure WC, the densification process took place at around $1140{ }^{\circ} \mathrm{C}$ and ended at about $1880{ }^{\circ} \mathrm{C}$. As far as WC-3 wt $\% \mathrm{Al}_{2} \mathrm{O}_{3}$ was concerned, the densification starting point was $\sim 930{ }^{\circ} \mathrm{C}$ and the ending temperature was $\sim 1770{ }^{\circ} \mathrm{C}$. Obviously, $\mathrm{Al}_{2} \mathrm{O}_{3}$ addition significantly facilitated the sintering process by accomplishing the densification process at a lower temperature range owing to $\mathrm{Al}_{2} \mathrm{O}_{3}$ 's lower melting point of around $2050{ }^{\circ} \mathrm{C}$ than WC (about $2785^{\circ} \mathrm{C}$ ), which is well in line with the findings of Oh et al. [100] as depicted in Fig. 6c.

$\mathrm{Qu}$ et al. [101] prepared highly dense WC-(10, 20, 30, $40,50)$ vol $\% \mathrm{Al}_{2} \mathrm{O}_{3}$ composites by a hot-pressing sintering method, suggesting that the relative density increased with the increasing content of $\mathrm{Al}_{2} \mathrm{O}_{3}$. Furthermore, the author demonstrated that $\mathrm{Al}_{2} \mathrm{O}_{3}$ addition was effective to suppress the WC grain growth. A work conducted by Seung-Jin Oh et al. [102] reported the same conclusion through HFIHS methods as demonstrated in Table 3 .

\subsubsection{Zirconia $\left(\mathrm{ZrO}_{2}\right)$}

Zirconia $\left(\mathrm{ZrO}_{2}\right)$ has received attention as a substitute for Co because of its excellent properties: (1) high chemical stability up to quite high temperature about $1400{ }^{\circ} \mathrm{C} ;(2)$ not softening at elevated temperatures; (3) high electrochemical corrosion resistance; (4) increasing toughness by transformation toughening [103-107]. Besides, $\mathrm{ZrO}_{2}$ was found to facilitate the sintering of BTC by many researches [108-110].

Basu et al. [111] proposed that it was inappropriate to use $\mathrm{ZrO}_{2}$ itself as the sintering additive, but $\mathrm{Y}_{2} \mathrm{O}_{3}$-stabilized tetragonal $\mathrm{ZrO}_{2}$ was effective to improve the sinterability of BTC. Figure 7a illustrates the effect of $\mathrm{Y}_{2} \mathrm{O}_{3}$ content in $\mathrm{ZrO}_{2}$ on the densification of $\mathrm{WC}$ employing pressureless sintering. Though sintered at $1700{ }^{\circ} \mathrm{C}$ for $1 \mathrm{~h}$, the composites can only achieve a relative density of $93.9 \%$ with $\mathrm{Y}_{2} \mathrm{O}_{3}$-free $\mathrm{ZrO}_{2}$ addition, conforming that $\mathrm{Y}_{2} \mathrm{O}_{3}$-free $\mathrm{ZrO}_{2}$ was ineffective to enhance the densification process of WC.

Figure $7 \mathrm{~b}, \mathrm{c}$ demonstrates the densification curves for the pure $\mathrm{WC}$ sintered at $1800{ }^{\circ} \mathrm{C}$ for holding $5 \mathrm{~min}$ and the WC3Z (WC-3 wt $\% \mathrm{ZrO}_{2}$ ) and $\mathrm{WC} 10 \mathrm{Z}$ (WC-10 wt\% $\mathrm{ZrO}_{2}$ ) samples sintered at $1600{ }^{\circ} \mathrm{C}$ for holding 5 min. Caution should be noted that the $\mathrm{ZrO}_{2}$ used in this research was $3 \mathrm{~mol} \% \mathrm{Y}_{2} \mathrm{O}_{3}$-stabilized tetragonal $\mathrm{ZrO}_{2}$. Ignoring several shrinkage rate fluctuations below $\sim 650{ }^{\circ} \mathrm{C}$, it is considered that the densification process took place when the shrinkage rate turned to be positive and ended when the shrinkage rate was down to zero again. As shown in Fig. 7b, the densification of pure WC started at around $1050{ }^{\circ} \mathrm{C}$ and ended at around $1790{ }^{\circ} \mathrm{C}$. Concerning WC sample, the densification began at a lower temperature $\sim 850{ }^{\circ} \mathrm{C}$ and ended at a lower temperature $\sim 1600{ }^{\circ} \mathrm{C}$ in comparison with pure WC. Further increasing $\mathrm{ZrO}_{2}$ content, the densification process can be 

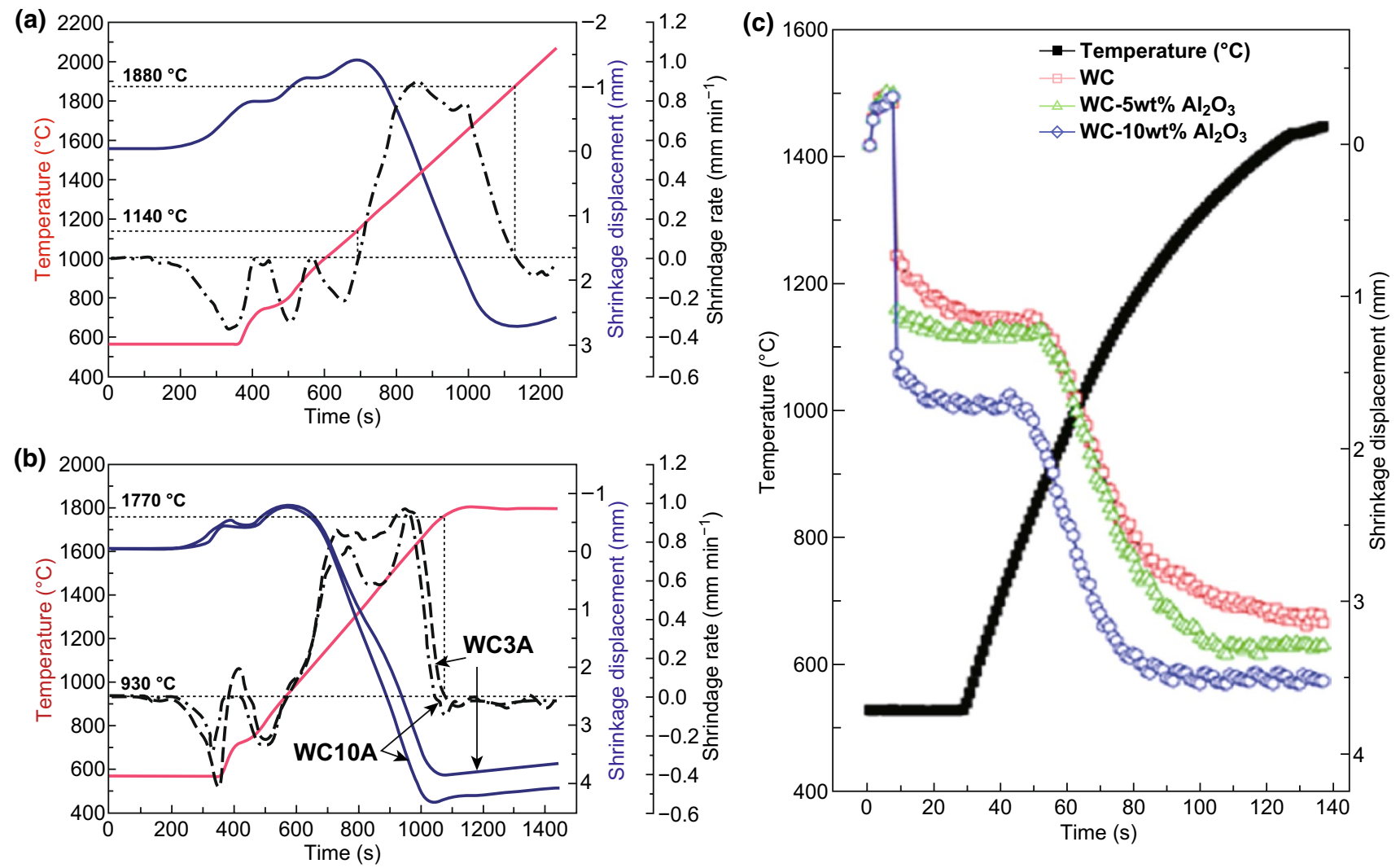

Fig. 6 Densification behavior of a WC, SPSed at $2060{ }^{\circ} \mathrm{C}$ for 0 min, and b WC3A (WC-3 wt $\left.\% \mathrm{Al}_{2} \mathrm{O}_{3}\right)$ and $\mathrm{WC} 10 \mathrm{~A}\left(\mathrm{WC}-10 \mathrm{wt} \% \mathrm{Al} \mathrm{O}_{3}\right)$, SPSed at $1800{ }^{\circ} \mathrm{C}$ for $5 \mathrm{~min}$ [99]. c Variations of temperature and shrinkage with heating time during the pulsed current activated sintering of WC- $\mathrm{Al}_{2} \mathrm{O}_{3}$ powder [100]. Figure panels reproduced from Ref. [99] with permission from Elsevier copyright 2012, Ref. [100] with permission from Elsevier copyright 2016

Table 3 Average grain size and relative density of pure WC and WC- $\mathrm{Al}_{2} \mathrm{O}_{3}$ composite after the same HFIHS sintering conditions with same staring WC powders [102]

\begin{tabular}{lll}
\hline Composition & $\begin{array}{l}\text { Relative density } \\
(\%)\end{array}$ & Grain size (nm) \\
\hline $\mathrm{WC}$ & 97 & 265 \\
$\mathrm{WC}-5$ vol\% $\mathrm{Al}_{2} \mathrm{O}_{3}$ & 98 & 185 \\
$\mathrm{WC}-10 \mathrm{vol} \% \mathrm{Al}_{2} \mathrm{O}_{3}$ & 99 & 138 \\
$\mathrm{WC}-15 \mathrm{vol} \% \mathrm{Al}_{2} \mathrm{O}_{3}$ & 99.8 & 101 \\
\hline
\end{tabular}

accomplished at even lower temperature range. With respect to WC10Z specimen, the densification beginning temperature yielded at $\sim 740{ }^{\circ} \mathrm{C}$, and the ending point of densification was $\sim 1530{ }^{\circ} \mathrm{C}$. Obviously, $\mathrm{ZrO}_{2}$ addition significantly improved the densification process of WC. Additionally, the cures exhibited a bimodal shape regarding $\mathrm{WC}-\mathrm{ZrO}_{2}$ specimens, an extra shrinkage rate maximum appearing at about $1050-1100{ }^{\circ} \mathrm{C}$, which was considered as a result of transformation of retained $\mathrm{m}-\mathrm{ZrO}_{2}$ in original $\mathrm{ZrO}_{2}$ powders involving a volume decrease (3-5\%) and assisting particle rearrangement during the densification process. Since the densification process is mainly diffusion controlled, it is denoted that $\mathrm{ZrO}_{2}$ addition elevated the diffusivity of $\mathrm{WC}-\mathrm{ZrO}_{2}$ system. Densification starting temperature was decreased due to $\mathrm{ZrO}_{2}$ addition, so the densification improving mechanism can be concluded that $\mathrm{ZrO}_{2}$ addition lowers the activation energy for atoms diffusion, resulting in a higher diffusivity and then an enhanced densification [104].

\subsection{Advanced Sintering Techniques}

The properties of BTC fabricated by powder metallurgy can be significantly enhanced through improving the density coupled with decreasing the grain size of the sintered bodies. However, since WC possesses a high melting point $\left(2785{ }^{\circ} \mathrm{C}\right)$ and no metallic binder addition, it is rather 

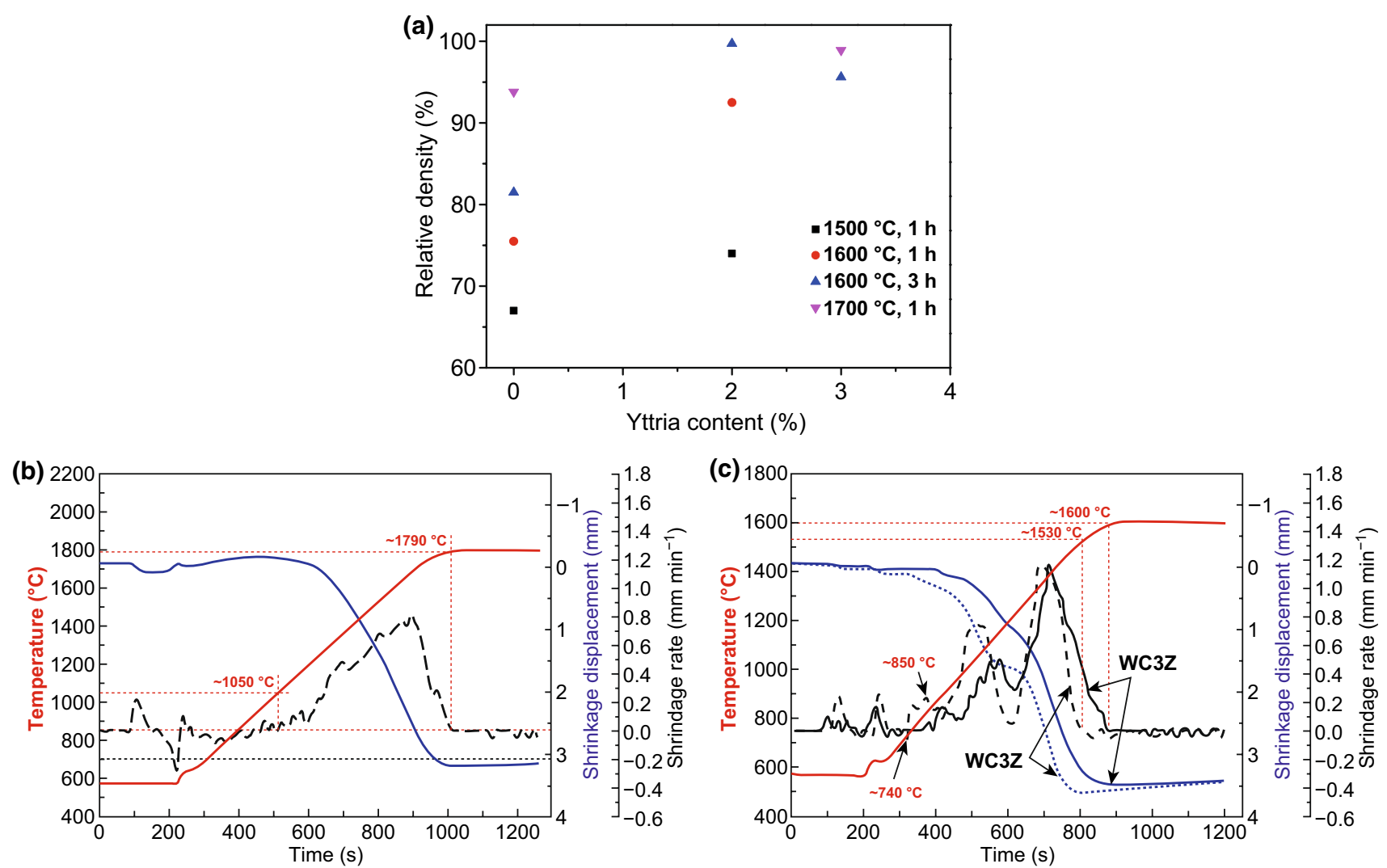

Fig. 7 a Relative density obtained at different sintering temperatures with $\mathrm{WC}$ composites with $6 \mathrm{wt} \% \mathrm{ZrO}_{2}$ (stabilized with varying amount of $\mathrm{Y}_{2} \mathrm{O}_{3}$ ) sinter-additive [111]. Densification curves for $\mathbf{b}$ pure WC sintered at $1800{ }^{\circ} \mathrm{C}$ for holding 5 min, $\mathbf{c}$ WC $3 Z$ and WC10Z specimens sintered at $1600{ }^{\circ} \mathrm{C}$ for holding 5 min [104]. Figure panels reproduced from Ref. [111] with permission from Elsevier copyright 2005, Ref. [104] with permission from Elsevier copyright 2013

difficult to consolidate WC to a high density with a fine grain employing the conventional sintering process. Generally speaking, excessively high sintering temperature and/or long holding time is easy to incur porosities in the sintered material and results in coarsening of the microstructure. Thus, it is crucial to carefully control the sintering parameters, particularly sintering temperature and time, for preparing materials with excellent properties. Compared with conventional sintering techniques, some advanced sintering techniques such as fast sintering techniques are known for their higher heating and cooling rates, as well as shorter densification time at lower sintering temperature, as a function of external field together with high-pressure application such as SPS, RSPS, PCAS, and HFIHS. SPS, for example, applying pulsed electrical fields coupled with resistance heating and pressure as shown in Fig. 8a, can consolidate materials rapidly, uniformly, and thoroughly because of the large pulsed direct current during heat treatment of powders in the graphite die. The external field is prone to enhancing the mass transport during the sintering, and the effect can be determined through the electromigration theory (Eq. 9) [113]:

$J_{i}=-\frac{D_{i} C_{i}}{R T}\left[\frac{R T \partial \ln C_{i}}{\partial x}+F Z^{*} E\right]$

where $J_{i}$ is the flux of the diffusing ith species, $D_{i}$ is the diffusivity of ith species, $C_{i}$ is the concentration of ith species, $F$ is Faraday's constant, $z^{*}$ is the effective charge on the diffusing species, $E$ is the field, $R$ is the universal gas, and $T$ is absolute temperature. Furthermore, high pressure is helpful in accelerating the particle rearrangement, sliding, or even distortion as well as breaking (Fig. 8b). These merits of fast sintering techniques highly open up the possibilities for successful production of highly dense BTC with fine grains.

Table 4 summarizes the densification as well as grain sizes of materials obtained through various sintering techniques. Obviously, even without any sintering additive or 
(a)
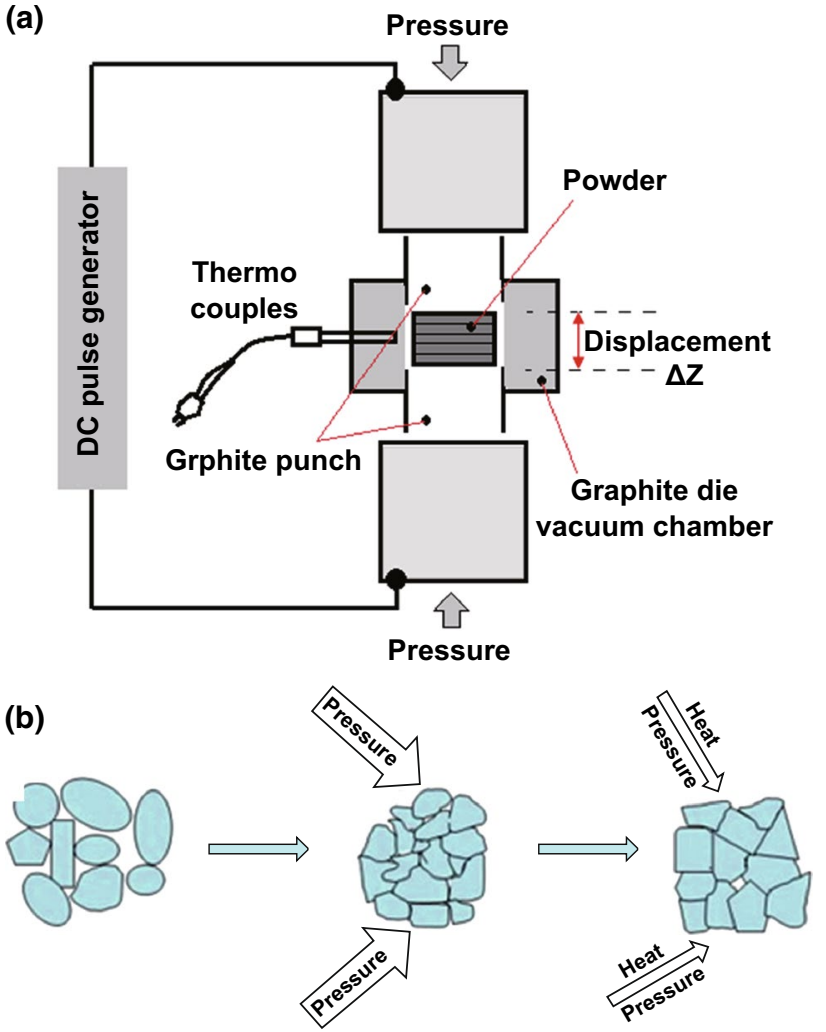

Fig. 8 a Schematic representation of SPS equipment [112]. b The formation mechanism of WC sintered under high pressure [18]. Figure panels reproduced from Ref. [112] with permission from Taylor \& Francis copyright 2007, Ref. [18] with permission from Elsevier copyright 2016

grain growth inhibitor addition, fine-grained WC with nearly full densification was prepared. SPS, the most employed sintering technique during the fabrication of BTC, attracted most attention among materials researchers as well as production engineers. SPS was proposed according to the idea employing the plasma on electric discharge machine for sintering ceramics and metal in the early 1960s by Inoue et al. [114] expecting that the plasma-assisted sintering could contribute to the realization of advanced materials [115]. Thereafter, the concept obtained further development during the mid-1980s to the early 1990s. In 1998, it was first experimentally verified that SPS enhanced the densification of materials [116]. SPS is also named as pulsed electric current sintering (PECS) or electric pulse-assisted consolidation (EPAC) $[117,118]$. Conventional rapid heating can easily result in temperature gradients and then differential densification (non-uniform microstructures), low density, or sample cracking. SPS densifies the materials at a homogeneous temperature or heat distribution by applying pulsed direct current through the sample and graphite die. Furthermore, it is found by Huang et al. [119] that the grain growth of WC hardly occurred during SPS process, which is greatly different from WC-Co cemented carbides showing obvious WC grain coarsening during SPS process [120].

\section{Toughening of Binderless Tungsten Carbide}

Brittle fracture limits the use of BTC in many applications. The fracture toughness of BTC strongly depends on the interaction of the crack tip stress field with the microstructure. Therefore, microstructural design to reduce stresses near crack tips has been a key issue during the development of highly tough BTC.

In order to reduce the brittleness and to enhance the strength and the toughness of BTC, varieties of traditional toughening methods, including particle dispersion toughening, transformation toughening, whisker toughening, and synergistic toughening, have been proposed in the past decades. Recently, with our deep understanding of brittle fracture, some new-concept toughening methods, such as laminated structure toughening, carbon nanotube toughening as well as graphene toughening, are proved to be also operative in BTC, offering great promise of a revolutionary advance in the production of high-toughness BTC. The purpose of this section is to demonstrate how the knowledge gained is currently being applied to the development of highly tough BTC or BTC composites.

\subsection{Particle Dispersion Toughening}

Particle dispersion toughening, as the simplest toughening method, is the foundation of the other toughening methods of ceramics [131]. It can be subdivided into non-transformation secondary-phase particle dispersion toughening, ductile particle dispersion toughening as well as nanoparticle dispersion toughening. The major toughening mechanisms existing particle-toughened ceramics were ascribed to (i) crack deflection by the particulates ahead of a propagating crack (crack deflection model); (ii) crack bridging by particulates (particulate bridging model); (iii) interaction between the crack front and particulates (crack front bowing model); 
Table 4 Results of various sintering techniques regarding densification as well as grain size

\begin{tabular}{|c|c|c|c|c|c|c|}
\hline Sintering process & $\begin{array}{l}\text { Temperature and } \\
\text { holding time }\end{array}$ & $\begin{array}{l}\text { Heating rate } \\
\left({ }^{\circ} \mathrm{C} \min ^{-1}\right)\end{array}$ & Pressure $(\mathrm{MPa})$ & Starting powder and grain size & $\begin{array}{l}\text { Relative } \\
\text { density } \\
(\%)\end{array}$ & $\begin{array}{l}\text { Sintered } \\
\text { grain size } \\
(\mathrm{nm})\end{array}$ \\
\hline $\mathrm{HP}^{\mathrm{a}}[33]$ & $2150^{\circ} \mathrm{C} / 1 \mathrm{~min}$ & N/A & 25 & WC, $0.5-0.7 \mu \mathrm{m}$ & 97.5 & \\
\hline HP [121] & $2000^{\circ} \mathrm{C} / 30 \mathrm{~min}$ & $3-10$ & 28 & WC-0.33 wt $\%$ VC- -0.54 wt $\% \mathrm{Cr}_{3} \mathrm{C}_{2}, 0.53 \mu \mathrm{m}$ & 97.9 & 730 \\
\hline $\operatorname{HIP}^{\mathrm{b}}[121]$ & $1750^{\circ} \mathrm{C} / 120 \mathrm{~min}$ & N/A & 150 & WC-0.33 wt $\%$ VC- $-0.54 \mathrm{wt} \% \mathrm{Cr}_{3} \mathrm{C}_{2}, 0.53 \mu \mathrm{m}$ & 99.4 & 750 \\
\hline HP [90] & $1600^{\circ} \mathrm{C} / 10 \mathrm{~min}$ & 50 & 50 & $\mathrm{WC}-20 \mathrm{~mol} \% \mathrm{SiC}, 0.73 \mu \mathrm{m}$ & 98 & 530 \\
\hline HP [90] & $1600^{\circ} \mathrm{C} / 10 \mathrm{~min}$ & 50 & 50 & $\mathrm{WC}-20 \mathrm{~mol} \% \mathrm{SiC}-0.9 \mathrm{~mol} \% \mathrm{Cr}_{3} \mathrm{C}_{2}, 0.73 \mu \mathrm{m}$ & 98 & 340 \\
\hline HP [101] & $1540^{\circ} \mathrm{C} / 90 \mathrm{~min}$ & 10 & 39.6 & $\mathrm{WC}-40$ vol\% $\mathrm{Al}_{2} \mathrm{O}_{3}$ & 97.98 & 2750 \\
\hline $\mathrm{HPHT}^{\mathrm{c}}[18]$ & $1500^{\circ} \mathrm{C} / 20 \mathrm{~min}$ & 100 & $5 \mathrm{GPa}$ & $\mathrm{WC}, 150-250 \mathrm{~nm}$ & 99.2 & $150-250$ \\
\hline $\operatorname{GPS}^{\mathrm{d}}[122]$ & $1860{ }^{\circ} \mathrm{C} / 60 \mathrm{~min}$ & $3-6$ & 0 & $\mathrm{WC}, 1.03 \mu \mathrm{m}$ & 95.1 & \\
\hline $\mathrm{SPS}^{\mathrm{e}}[119]$ & $1500^{\circ} \mathrm{C} / 4 \mathrm{~min}$ & 180 & 60 & $\mathrm{WC}, 200 \mathrm{~nm}$ & 99.6 & 200 \\
\hline SPS [123] & $1460^{\circ} \mathrm{C} / 3 \mathrm{~min}$ & 150 & 30 & $\mathrm{WC}-0.1 \mathrm{wt} \% \mathrm{C}, 200 \mathrm{~nm}$ & 99.5 & 350 \\
\hline $\operatorname{RSPS}^{\mathrm{f}}[124]$ & $1350^{\circ} \mathrm{C} / 1.5 \mathrm{~min}$ & 100 & 60 & $\mathrm{~W}_{2} \mathrm{~N}-\mathrm{C}, 40 \mathrm{~nm}$ & & 270 \\
\hline SPS [125] & $1800^{\circ} \mathrm{C} / 1 \mathrm{~min}$ & 150 & 80 & $\mathrm{WC}, 55 \mathrm{~nm}$ & 100 & 160 \\
\hline SPS [126] & $1750^{\circ} \mathrm{C} / 10 \mathrm{~min}$ & 50 & 50 & $\mathrm{WC}, 1.8 \mu \mathrm{m}$ & 99.6 & \\
\hline SPS [42] & $1750^{\circ} \mathrm{C} / 0 \mathrm{~min}$ & 1500 & 126 & $\mathrm{WC}, 40-70 \mathrm{~nm}$ & 100 & 305 \\
\hline SPS [127] & $1400^{\circ} \mathrm{C} / 2 \mathrm{~min}$ & 180 & 50 & $\mathrm{WC}-0.3 \mathrm{wt} \% \mathrm{VC}-0.5 \mathrm{wt} \% \mathrm{Cr}_{3} \mathrm{C}_{2}, 200 \mathrm{~nm}$ & 97.5 & 240 \\
\hline SPS [63] & $1600^{\circ} \mathrm{C} / 5 \mathrm{~min}$ & 105 & 50 & $\mathrm{WC}-3 \mathrm{wt} \% \mathrm{ZrC}, 700 \mathrm{~nm}$ & 100 & \\
\hline SPS [64] & $1300^{\circ} \mathrm{C} / 5 \mathrm{~min}$ & 600 & 30 & $\mathrm{WC}-6 \mathrm{wt} \% \mathrm{ZrO}_{2}, 200 \mathrm{~nm}$ & 99.9 & \\
\hline $\operatorname{PECS}^{\mathrm{g}}[83]$ & $1900^{\circ} \mathrm{C} / 1.5 \mathrm{~min}$ & 200 & 60 & $\mathrm{WC}, 200 \mathrm{~nm}$ & 100 & 280 \\
\hline PECS [109] & $1700^{\circ} \mathrm{C} / 1.5 \mathrm{~min}$ & 200 & 60 & $\mathrm{WC}-5 \mathrm{vol} \% \mathrm{ZrO}_{2}, 200 \mathrm{~nm}$ & 100 & \\
\hline $\operatorname{PCAS}^{\mathrm{h}}[100]$ & $1450^{\circ} \mathrm{C} / 0 \mathrm{~min}$ & 900 & 80 & WC-10 vol $\% \mathrm{Al}_{2} \mathrm{O}_{3},<0.5 \mu \mathrm{m}$ & 98 & 112 \\
\hline SPS [128] & $1450^{\circ} \mathrm{C} / 0 \mathrm{~min}$ & 100 & 30 & WC-2.8 wt $\% \mathrm{Al}_{2} \mathrm{O}_{3}-6.8 \mathrm{wt} \% \mathrm{ZrO}_{2}, 0.8 \mu \mathrm{m}$ & 99 & \\
\hline HFIHS $^{\mathrm{i}}[129]$ & $1500{ }^{\circ} \mathrm{C} / 100 \mathrm{~s}$ & 1400 & 60 & $\mathrm{WC}, 400 \mathrm{~nm}$ & 98.5 & 380 \\
\hline HFIHS [130] & $1250^{\circ} \mathrm{C} / 0 \mathrm{~min}$ & N/A & 80 & $\mathrm{WC}, 40 \mathrm{~nm}$ & 99 & 87 \\
\hline
\end{tabular}

${ }^{\mathrm{a}} \mathrm{Hot}$ pressing; ${ }^{\mathrm{b}} \mathrm{Hot}$ isostatic pressing; ${ }^{\mathrm{H}} \mathrm{HIgh}$ pressure and high temperature; ${ }^{\mathrm{d}} \mathrm{Gas}$ protection sintering; ${ }^{\mathrm{e}}$ Spark plasma sintering; ${ }^{\mathrm{f}} \mathrm{Reactive} \mathrm{spark}$ plasma sintering; ${ }^{\mathrm{g}} \mathrm{Pulsed}$ electric current sintering; ${ }^{\mathrm{h}} \mathrm{Pulsed}$ current activated sintering; ${ }^{\mathrm{i}} \mathrm{High}$ frequency induction-heated sintering

and (iv) thermal residual stress field resulting from mismatch in coefficients of thermal expansion of ceramic matrix and particulates as well as (v) the grain size $[132,133]$.

With respect to BTC, the most used dispersed phases are $\mathrm{Al}_{2} \mathrm{O}_{3}$ [95, 99], $\mathrm{MgO}$ [134-137], TiC [79], $\mathrm{SiC}$ [71, 87, 90], $\mathrm{Mo}_{2} \mathrm{C}$ [85], and $\mathrm{ZrC}$ [63]. Qu et al. [101] successfully prepared $\mathrm{WC}-\mathrm{Al}_{2} \mathrm{O}_{3}$ composite by employing conventional hot-pressing sintering. $\mathrm{Al}_{2} \mathrm{O}_{3}$ grains were homogenously distributed in WC matrix as demonstrated in Fig. 9. Excellent fracture toughness of $10.43 \mathrm{MPa} \mathrm{m}^{1 / 2}$ was obtained for WC $-40 \mathrm{vol} \% \mathrm{Al}_{2} \mathrm{O}_{3}$ composite. It is noted from Table 5 that significant toughening effect was achieved due to the dispersed $\mathrm{Al}_{2} \mathrm{O}_{3}$ particle. Figure 9e-h illustrates the Vickers indentation crack extension path of $\mathrm{WC}-\mathrm{Al}_{2} \mathrm{O}_{3}$ composites. With the increasing $\mathrm{Al}_{2} \mathrm{O}_{3}$ content, the crack propagation path became more tortuous, and more crack bridgings and crack deflections were observed. Additionally, WC -40 vol\% $\mathrm{Al}_{2} \mathrm{O}_{3}$ composites exhibited secondary crack pattern as depicted in Fig. 9h. The generation and existence of secondary crack consumed the energy of main crack and increased the length of crack propagation path, resulting in improved fracture toughness.

Recently, we prepared nano-laminated $\mathrm{WC}-\mathrm{Al}_{2} \mathrm{O}_{3}-\mathrm{TiC}$ ceramics with a high fracture toughness of $11.49 \mathrm{MPa} \mathrm{m}^{1 / 2}$ $[138,139] . \mathrm{Al}_{2} \mathrm{O}_{3}$ crack deflection, transgranular $\mathrm{Al}_{2} \mathrm{O}_{3}$, microcracking, WC crack bridging, and plate-like WC crack deflection were the major toughening mechanisms (Fig. 10). Resulting from the thermal expansion mismatch between the secondary phase and the matrix, the residual stresses acting on $\mathrm{WC} / \mathrm{Al}_{2} \mathrm{O}_{3}$ interfaces played a crucial role in the enhancement of grain boundary strength and then significantly improved the toughness of the matrix. As shown in Fig. 11, nanosized $\mathrm{Al}_{2} \mathrm{O}_{3}$ grains were located at the interface of WC grains and formed inter-granular structure, which hindered the WC grain growth and changed the grain shape. Nano-grained TiC grains were found to be embedded either 

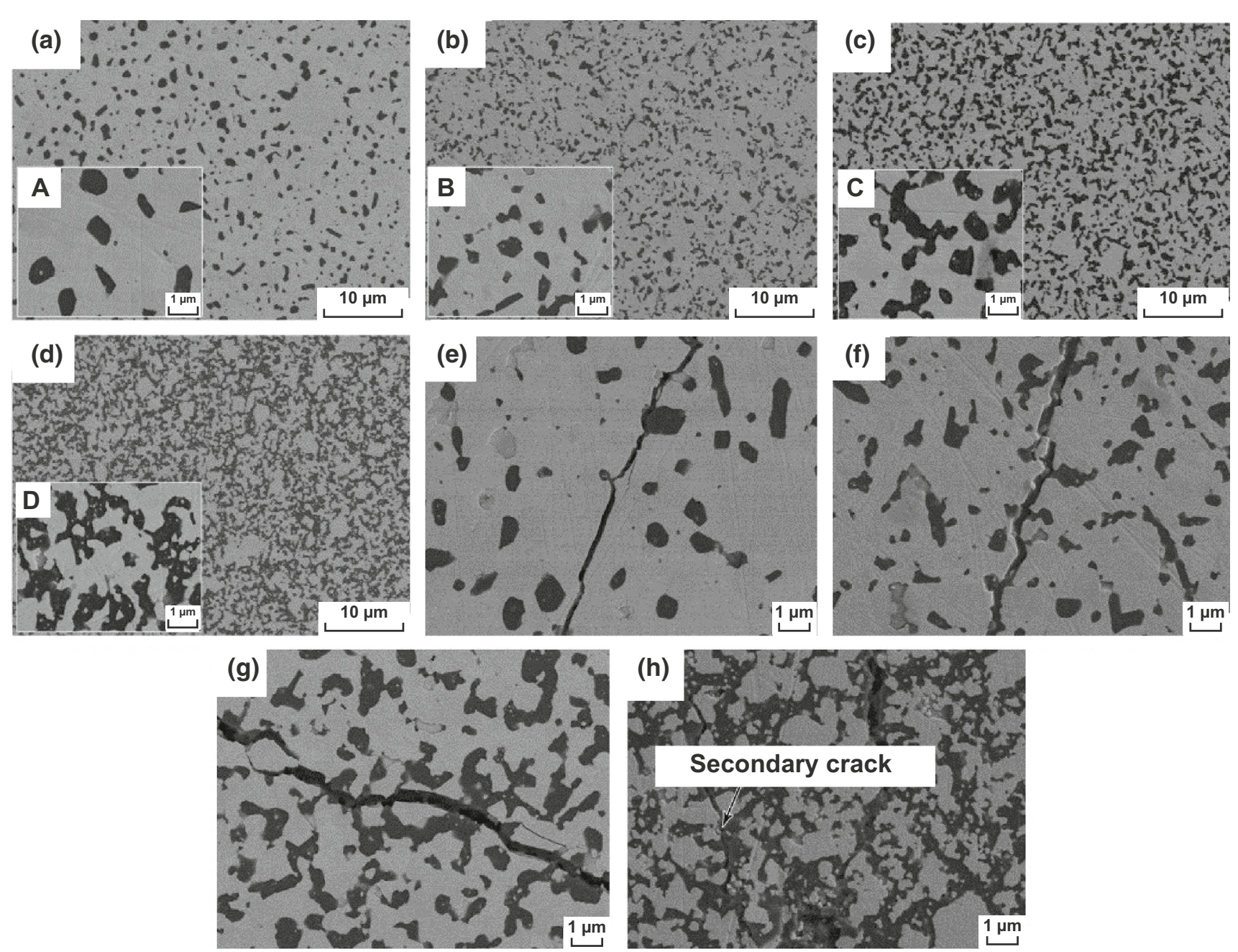

Fig. 9 FE-SEM images of the polished samples showing the different dispersion states and morphologies of the toughening particulates: (a, A) WC-10 vol\% $\mathrm{Al}_{2} \mathrm{O}_{3},(\mathbf{b}, \mathbf{B}) \mathrm{WC}-20 \mathrm{vol} \% \mathrm{Al}_{2} \mathrm{O}_{3},(\mathbf{c}, \mathbf{C}) \mathrm{WC}-30 \mathrm{vol} \% \mathrm{Al}_{2} \mathrm{O}_{3}$, and (d, D) WC $-40 \mathrm{vol} \% \mathrm{Al}_{2} \mathrm{O}_{3}$, composites sintered at $1540{ }^{\circ} \mathrm{C}$ for 90 min. FE-SEM images of Vickers indentation crack extension path of e WC-10 vol\% $\mathrm{Al}_{2} \mathrm{O}_{3}, \mathbf{f} \mathrm{WC}-20 \mathrm{vol} \% \mathrm{Al}_{2} \mathrm{O}_{3}, \mathbf{g ~ W C}-30 \mathrm{vol} \% \mathrm{Al}_{2} \mathrm{O}_{3}$, and h WC -40 vol\% $\mathrm{Al}_{2} \mathrm{O}_{3}$ composites sintered at $1540{ }^{\circ} \mathrm{C}$ for 90 min [101]. Figure panels reproduced from Ref. [101] with permission from Elsevier copyright 2012

Table 5 Composition proportion, relative density and fracture toughness of $\mathrm{WC}-\mathrm{Al}_{2} \mathrm{O}_{3}$ composites [101]

\begin{tabular}{|c|c|c|c|c|}
\hline WC (vol\%) & $\mathrm{Al}_{2} \mathrm{O}_{3}(\mathrm{vol} \%)$ & Sintering process & Relative density (\%) & $\begin{array}{l}\text { Fracture } \\
\text { toughness } \mathrm{K}_{\mathrm{IC}} \\
\left(\mathrm{MPa} \mathrm{m}^{1 / 2}\right)\end{array}$ \\
\hline 90 & 10 & \multirow{4}{*}{$\begin{array}{l}1540{ }^{\circ} \mathrm{C} \\
90 \mathrm{~min} \\
39.6 \mathrm{MPa}\end{array}$} & 95.73 & 7.86 \\
\hline 80 & 20 & & 96.52 & 8.10 \\
\hline 70 & 30 & & 96.53 & 9.43 \\
\hline 60 & 40 & & 97.98 & 10.43 \\
\hline
\end{tabular}

in the WC matrix or at the WC grain boundaries, forming either intra-granular or inter-granular structure. Microcracks were found to be segregated inside alumina crystals
(Fig. 11a). This might be a pinning effect caused by alumina grains and would substantially increase the number of potential sources of crack branching. Furthermore, dislocation 
morphologies were found to exist both at the $\mathrm{WC} / \mathrm{Al}_{2} \mathrm{O}_{3}$ interfaces (Fig. 11b) and inside alumina crystals (Fig. 11c, d), which could increase the flaw tolerance of the material and enhance the toughness of the material.

\subsection{Transformation Toughening}

Transformation toughening has been proved to be a significant approach to improve the toughness of ceramics [140-142]. Transformation toughening takes place, resulting from a stress-induced phase transformation of particulate inclusions in a ceramic matrix during fracture process, in which the most used particle is $\mathrm{ZrO}_{2}$ partially stabilized with $\mathrm{Y}_{2} \mathrm{O}_{3}$ or $\mathrm{MgO}$. It depends on the transformation of metastable retained tetragonal zirconia to the stable monoclinic zirconia phase in the tensile stress field around a crack tip. Compressive stresses are introduced in the matrix due to shear deformation (1-7\%) coupled with volume expansion (4-5\%) resulting from monoclinic phase occupying more volume in comparison with tetragonal phase. The compresses, acting as closure stresses, reduce the local crack tip stress intensity, thereby enhancing the toughness of the matrix [143].

Significant toughness improvement was obtained for $\mathrm{WC}-\mathrm{ZrO}_{2}$ composite by incorporating $\mathrm{ZrO}_{2}$ particles into WC matrix [109-111]. Mukhopadhyay et al. [144] reported that $\mathrm{WC}-6 \mathrm{wt} \% \mathrm{ZrO}_{2}$ exhibited a toughness of $10.9 \mathrm{MPa} \mathrm{m}{ }^{1 / 2}$, which is only modestly lower by $16 \%$ in comparison with that of reference WC- $6 \mathrm{wt} \%$ Co cemented carbide, while the flexure strength enhanced by $18 \%$. By comparing the XRD patterns of polished and fractured surface of same specimen, the author [104] found the presence of a strong $\mathrm{m}-\mathrm{ZrO}_{2}$ peak with an intensity-reduced $\mathrm{t}-\mathrm{ZrO}_{2}$ peak in the fractured surface, identifying the transformation of $t \rightarrow m-\mathrm{ZrO}_{2}$ during the fracture process, which was the principle source of toughening. Furthermore, the author proposed that the toughness of $\mathrm{WC}-\mathrm{ZrO}_{2}$ composite can be no more elevated with more than $\sim 6 \mathrm{wt} \% \mathrm{ZrO}_{2}$ addition. The presence of $\mathrm{ZrO}_{2}$ grains in the $\mathrm{WC}$ matrix as a discrete second phase enables the former to behave in an intrinsic manner, that is, to undergo the $t-m$ transformation or to be retained as the metastable tetragonal form
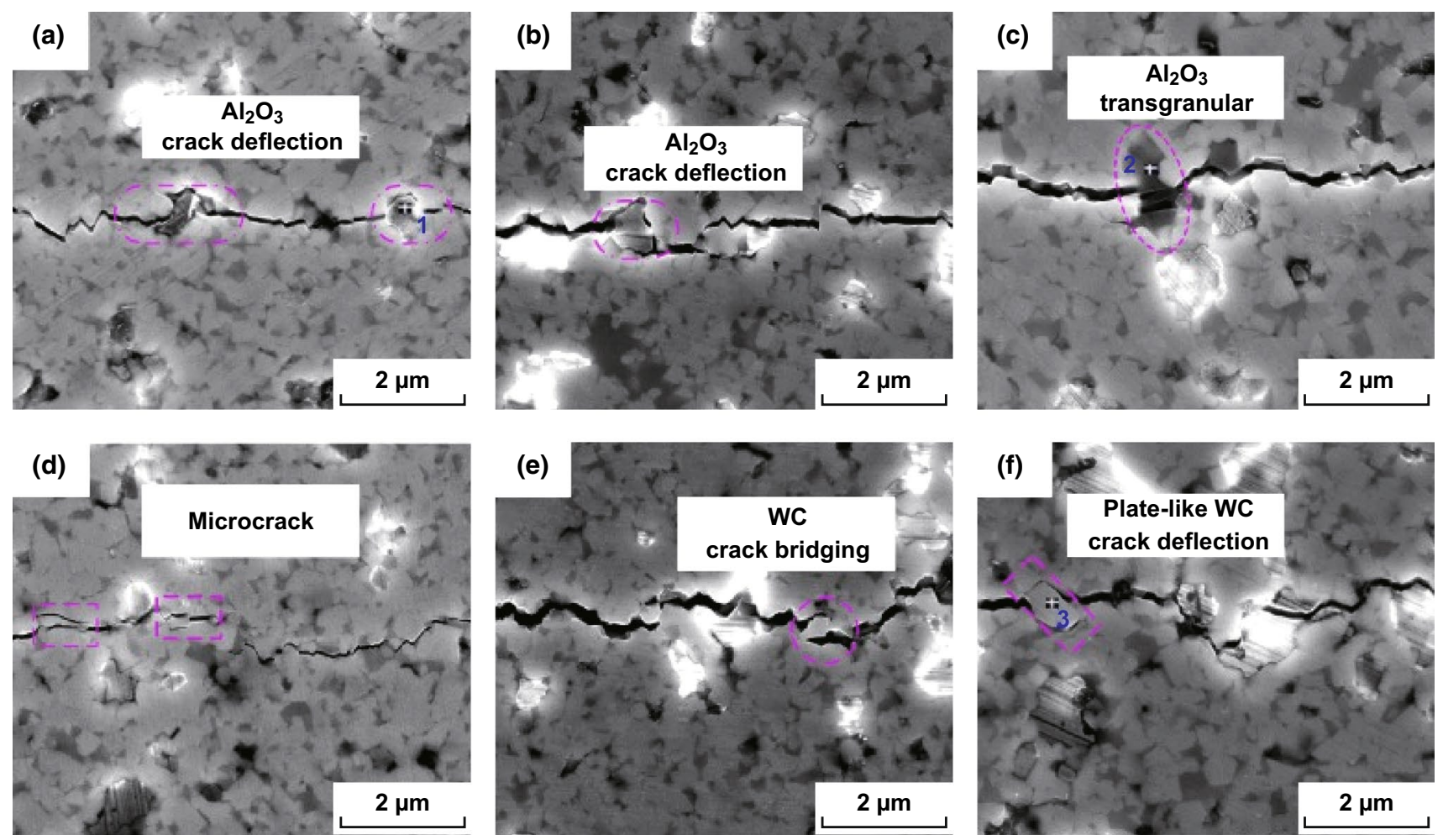

Fig. 10 Toughening mechanisms in $\mathrm{WC}-\mathrm{Al}_{2} \mathrm{O}_{3}-\mathrm{TiC}$ ceramics: a, b $\mathrm{Al}_{2} \mathrm{O}_{3}$ crack deflection, $\mathbf{c} \mathrm{Al}_{2} \mathrm{O}_{3}$ transgranular, $\mathbf{d}$ microcracking, e WC crack bridging and $\mathbf{f}$ plate-like WC crack deflection [138]. Figure panels reproduced from Ref. [138] Elsevier copyright 2018 

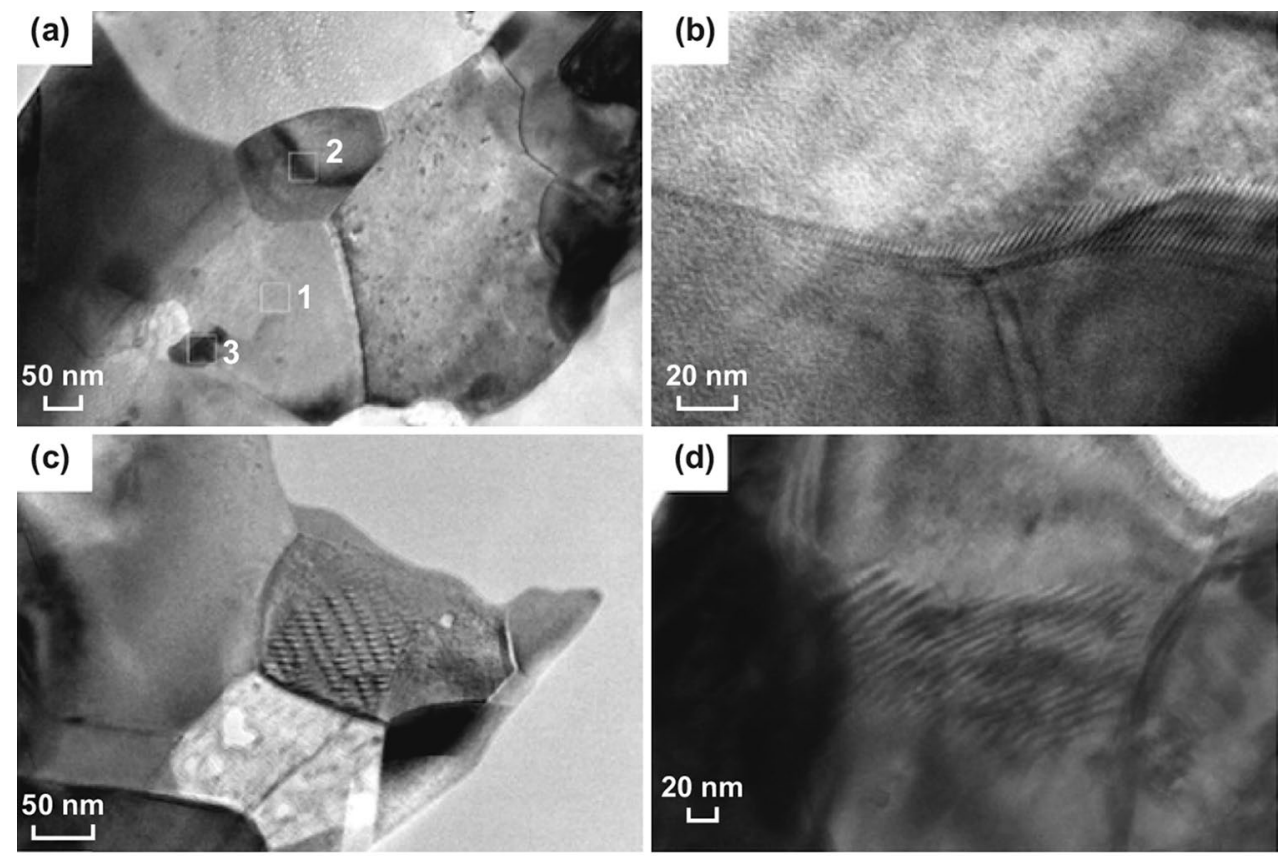

(d)
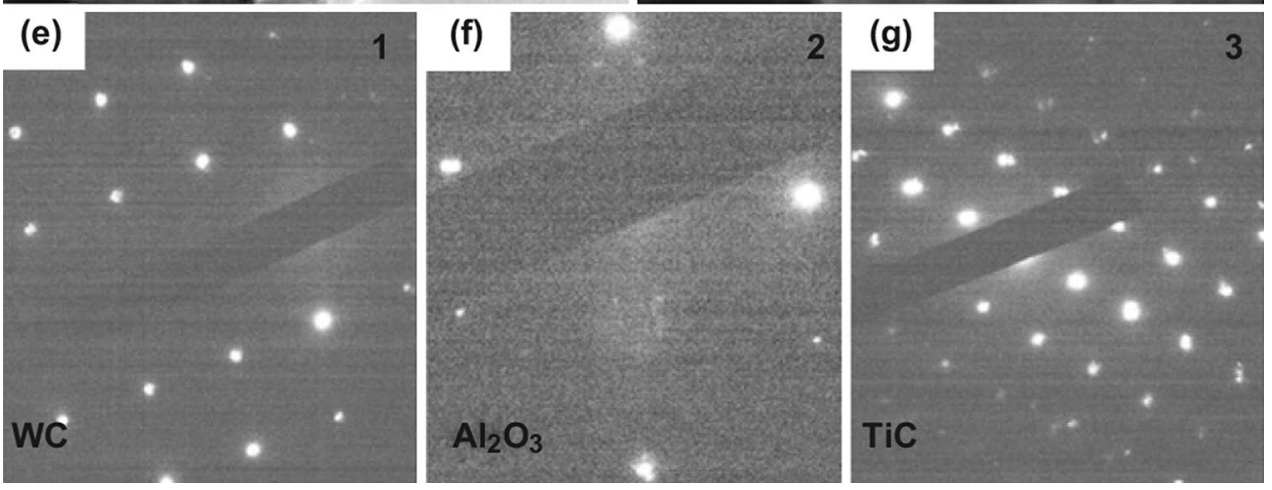

Fig. 11 a TEM micrographs of WC-TiC- $\mathrm{Al}_{2} \mathrm{O}_{3}$ ceramics, b-d dislocation morphology, and electron diffraction spots of $\mathbf{e}$ point 1 , $\mathbf{f}$ point 2 , and g point 3 [138]. Figure panels reproduced from Ref. [138] with permission from Elsevier copyright 2018

during cooling from the sintering temperatures. Thermally induced monoclinic transformation during the cooling process would result in the formation of microcracks around the transformed monoclinic $\mathrm{ZrO}_{2}$ particles. The microcracks are effective to toughen the materials by absorbing fracture energy, but the linkup or coalescence of the microcracks, as a result of added $\mathrm{ZrO}_{2}$ increasing, can reduce the toughness significantly. Therefore, it can be concluded that the highest toughness for $\mathrm{WC}-\mathrm{ZrO}_{2}$ composite can be achieved by adding about $\sim 6 \mathrm{wt} \% \mathrm{ZrO}_{2}$ containing both tetragonal and monoclinic particles.

Wang [145] demonstrated that there existed a critical grain size for tetragonal $\mathrm{ZrO}_{2}$ retention during cooling from the sintering temperature to a given temperature, above which the tetragonal $\mathrm{ZrO}_{2}$ would transform to the monoclinic phase during the cooling process. In other words, the fraction of retained $t-\mathrm{ZrO}_{2}$ decreases with the increasing $\mathrm{ZrO}_{2}$ particle size. Therefore, a grain growth inhibitor addition is beneficial for the transformation toughening. Zheng et al. [146] reported that the toughness of $\mathrm{WC}-8 \mathrm{wt} \% \mathrm{ZrO}_{2}$ was insensitive to the coarseness of microstructure and enhanced to $11 \mathrm{MPa} \mathrm{m}^{1 / 2}$ as a function of $\mathrm{VC}$ together with $\mathrm{Cr}_{3} \mathrm{C}_{2}$ addition.

\subsection{Whiskers Toughening}

Profound toughening has been achieved in numbers of ceramics by incorporating whiskers. Compared with other toughening methods such as $\mathrm{ZrO}_{2}$ transformation toughening, whisker toughening enjoys a potential advantage that 
is the retention of high-toughness values at temperatures exceeding $1000^{\circ} \mathrm{C}$. Though sharing the similar toughness level with continuous-fiber-reinforced ceramics, whiskerreinforced composites possess advantages of easier fabrication as well as a higher degree of isotropy in mechanical properties because of the smaller aspect ratios involved. It is reported that five toughening mechanisms may be operative in whisker-toughened ceramics, that is, crack deflection, crack bowing, microcracking, whisker pullout, and crack bridging [147-149].

Though the number of researches and publications in whisker-toughened ceramics increased significantly, there are only a few reports with respect to BTC toughened by whiskers. Silicon carbide whiskers $\left(\mathrm{SiC}_{\mathrm{w}}\right)$, as a reinforcing agent, exhibited a prominent effect on improving the toughness of ceramics [150]. Chao et al. [151] suggested that it was feasible to toughen WC ceramics by using $\mathrm{SiC}_{\mathrm{w}}$ instead of metallic binder phase. The toughness of $\mathrm{WC}-\mathrm{SiC}_{\mathrm{w}}$ was increased by $30-40 \%$ in comparison with pure WC, due to $\mathrm{SiC}_{\mathrm{w}}$ addition. Sugiyama et al. $[88,152]$ reported that a highly tough $\mathrm{WC}-3 \mathrm{vol} \% \mathrm{SiC}_{\mathrm{w}}$ composites with an initial powder size of $0.71 \mu \mathrm{m}$, which were fabricated by SPS, had an improved fracture toughness about 7.8 $\mathrm{MPa} \mathrm{m}^{1 / 2}$ in comparison with pure WC (about 5.9 $\mathrm{MPa} \mathrm{m}^{1 / 2}$ ). The best toughening effect was achieved at 3-5 vol\% $\mathrm{SiC}_{\mathrm{w}}$ addition. Above $10 \mathrm{vol} \%$, the toughness decreased from the maximums; however, it still maintained high levels above $7 \mathrm{MPa} \mathrm{m}{ }^{1 / 2}$. Additionally, the author demonstrated that proper sintering parameter was of great importance to achieve the best toughening effect for the reason that an excessively high sintering temperature would made $\mathrm{SiC}_{\mathrm{w}}$ thick, coarsen, and balloon and thus lowered the aspect ratio of the whiskers. Furthermore, Bengisu et al. [147] proposed that the amount of toughening would decrease significantly if the surface oxygen content of $\mathrm{SiC}_{\mathrm{w}}$ was high. A possible solution to this problem is to eliminate the oxide formation on $\mathrm{SiC}_{\mathrm{w}}$ surface by acid leaching cleaning the whiskers or coating the whiskers with an oxidationresistant material.

Besides $\mathrm{SiC}$ whisker, $\mathrm{Si}_{3} \mathrm{~N}_{4}$ whisker is another most common ceramic whisker used as a toughening agent for ceramics. Zheng et al. [153-155] investigated the effect of in situ growing $\beta-\mathrm{Si}_{3} \mathrm{~N}_{4}$ whiskers on toughening WC ceramics prepared by SPS. The formation of $\beta-\mathrm{Si}_{3} \mathrm{~N}_{4}$ whiskers significantly improved the toughness to $10.94 \mathrm{MPa} \mathrm{m}^{1 / 2}$ for
WC- $\mathrm{Si}_{3} \mathrm{~N}_{4}$ sample from $6.69 \mathrm{MPa} \mathrm{m}^{1 / 2}$ for pure WC. The major toughening mechanisms were found to be $\mathrm{Si}_{3} \mathrm{~N}_{4 \mathrm{w}}$ pullout and crack bridging by $\mathrm{Si}_{3} \mathrm{~N}_{4}$ whiskers as shown in Fig. 12. Furthermore, the author found that at temperature above $1700{ }^{\circ} \mathrm{C}, \beta-\mathrm{Si}_{3} \mathrm{~N}_{4}$ grains ripened rapidly and grew into $\beta-\mathrm{Si}_{3} \mathrm{~N}_{4}$ whiskers speedily; at $1450-1600{ }^{\circ} \mathrm{C}$, $\mathrm{WC}$ grains grew slowly, while the growth of $\beta-\mathrm{Si}_{3} \mathrm{~N}_{4}$ grain and the formation of $\beta-\mathrm{Si}_{3} \mathrm{~N}_{4}$ whiskers were slow. Exploiting the kinetics difference between $\beta-\mathrm{Si}_{3} \mathrm{~N}_{4}$ grain growth and $\mathrm{WC}$ grain growth, the author proposed a two-step sintering method. For sample heated to $1700{ }^{\circ} \mathrm{C}$ and then immediately cooled to $1600{ }^{\circ} \mathrm{C}$ with a holding time of $30 \mathrm{~min}$, a plenty of $\mathrm{Si}_{3} \mathrm{~N}_{4}$ whiskers formed and WC grains did not grow rapidly.

From an oxidation resistance point of view, $\mathrm{Al}_{2} \mathrm{O}_{3}$ whisker seems to be a more reasonable choice. Dong et al. [94] successfully fabricated $\mathrm{WC}-\mathrm{Al}_{2} \mathrm{O}_{3}$ whiskers composites employing hot-pressing sintering as the assistance of $\mathrm{VC}$ as grain growth inhibitor. Maximum toughness (13.8 $\mathrm{MPa} \mathrm{m}^{1 / 2}$ ) was obtained for $\mathrm{WC}-10 \mathrm{wt} \% \mathrm{Al}_{2} \mathrm{O}_{3 \mathrm{w}}$ composites. The toughening mechanisms were crack bridging, crack deflection as well as ligamentary bridging between crack surfaces. When the whisker content was above $10 \mathrm{wt} \%$, the toughness decreased with the increasing whiskers content. Generally speaking, whisker addition deteriorates the densification process, due to whiskers resisting particle rearrangement, resulting from extensive sliding distances along whisker boundaries during sintering as well as at high whisker aspect ratios, or ratios above a critical volume fraction [147]. Therefore, there are two opposing factors operating in whisker-reinforced composites, and those are toughening effect and densification deteriorating influence. Densification becomes more difficult with the increasing whisker content, resulting from the formation of a rigid network as a result of whiskers coming into contact with each other. As the whiskers further increased beyond a critical value, for example $10 \mathrm{wt} \%$ in Dong's research [94], the densification deteriorating influence started dominating and then the toughness was decreased.

\subsection{Laminated Structures and Functional Gradient Materials (FGM)}

Besides optimizing the chemical composition, another strategy to enhance the fracture toughness of ceramics is through the design of ceramic laminates. Residual 

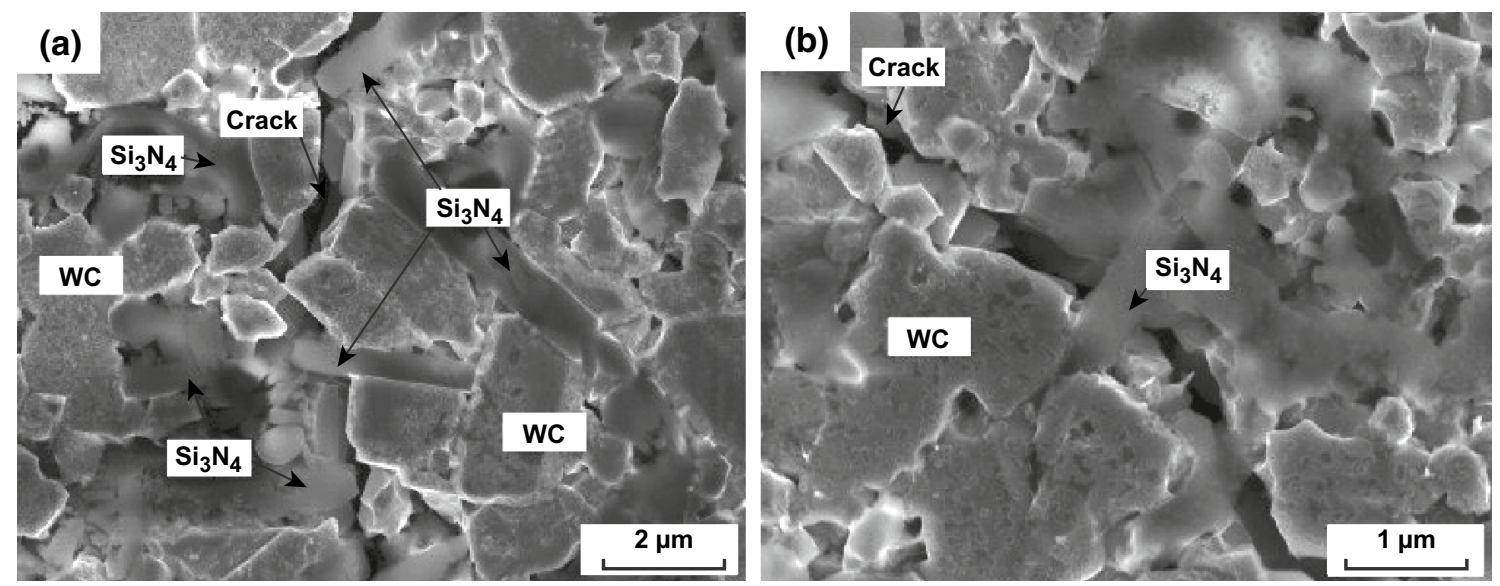

Fig. 12 SEM images of indentation cracks observed in the sintered WC-Si $i_{3} \mathrm{~N}_{4}$ composites: $\mathrm{Si}_{3} \mathrm{~N}_{4}$ whiskers pullout, b crack-bridging by $\mathrm{Si}_{3} \mathrm{~N}_{4}$ whiskers [153]. Figure panels reproduced from Ref. [153] with permission from Elsevier copyright 2013

stresses are inevitably set up during the cooling of layered ceramics, due to the mismatch in thermal expansion coefficients as well as elastic moduli. Lakshminarayanan et al. [156] demonstrated that a residual compression stress of about $400 \mathrm{MPa}$ developed in the surface layer of a threelayered $\mathrm{Al}_{2} \mathrm{O}_{3}-\mathrm{ZrO}_{2}$ ceramics significantly enhanced the fracture toughness to $30 \mathrm{MPa} \mathrm{m}{ }^{1 / 2}$ where the intrinsic fracture toughness was only 5-7 MPa ${ }^{1 / 2}$. Blugan et al. $[157,158]$ reported that apparent fracture toughness of $18 \mathrm{MPa} \mathrm{m}^{1 / 2}$ was obtained for micro-laminated $\mathrm{Si}_{3} \mathrm{~N}_{4}-\mathrm{TiN}$ composites, as a result of the formation of surface compressive stresses. It can be concluded that the residual stresses can be tailored to obtain high surface compressive stress, resulting in the great enhancement of fracture toughness.

Recently, we successfully prepared nano-laminated $\mathrm{WC}-\mathrm{Al}_{2} \mathrm{O}_{3}-\mathrm{TiC}$ composites with the assistance of $\mathrm{Cr}_{3} \mathrm{C}_{2}$ and $\mathrm{VC}$ as grain growth inhibitor (Fig. 13) [139]. Because the coefficient of thermal expansion of TiC $\left(7.74 \times 10^{-6} /{ }^{\circ} \mathrm{C}\right)$ and $\mathrm{Al}_{2} \mathrm{O}_{3}\left(8.8 \times 10^{-6} /{ }^{\circ} \mathrm{C}\right)$ is higher than that of WC $\left(3.84 \times 10^{-6} /{ }^{\circ} \mathrm{C}\right)$, an increase content of $\mathrm{TiC}$ and $\mathrm{Al}_{2} \mathrm{O}_{3}$ from surface layer to core layer and a decrease content of WC from surface layer to core layer contributed to the generation of significant residual compressive stress on the surface of material, leading to the significant toughness enhancement.

\subsection{New-Concept Toughening (Carbon Nanotube and Graphene Toughening)}

Carbon nanotube (CNT), a one-dimensional (1D) nanomaterial discovered by Iijima [159] in 1991, has captured tremendous interests among scientific community and industry, owing to its high aspect ratio together with extraordinary mechanical, electronic, thermal, magnetic, and optical characteristics [160]. Many of these exceptional properties can be effectively exploited through incorporating carbon nanotube into BTC matrix, aiming to significantly improve the mechanical properties, fracture behavior, and functional features.

Shon et al. [161] reported the production of highly dense WC-CNT composites employing HFIHS under a pressure of $80 \mathrm{MPa}$ within $3 \mathrm{~min}$. The fracture toughness of obtained WC, WC-5 vol\% CNT, and WC-10 vol\% CNT was 7, 10.5, and $11 \mathrm{MPa} \mathrm{m}{ }^{1 / 2}$, suggesting that $\mathrm{CNT}$ addition significantly enhanced the toughness of BTC. The primary toughening mechanism was crack deflection by CNT as shown in Fig. 14a, b. Furthermore, the author demonstrated that the CNT addition was beneficial for the densification of WC. Bai et al. [162-164] demonstrated that adding CNT into WCbased matrix significantly enhanced the toughness, resulting from crack bridging, CNTs debonding, crack deflection, and CNT pullout. Jang et al. [165] reported that $46.8 \%$ increment 

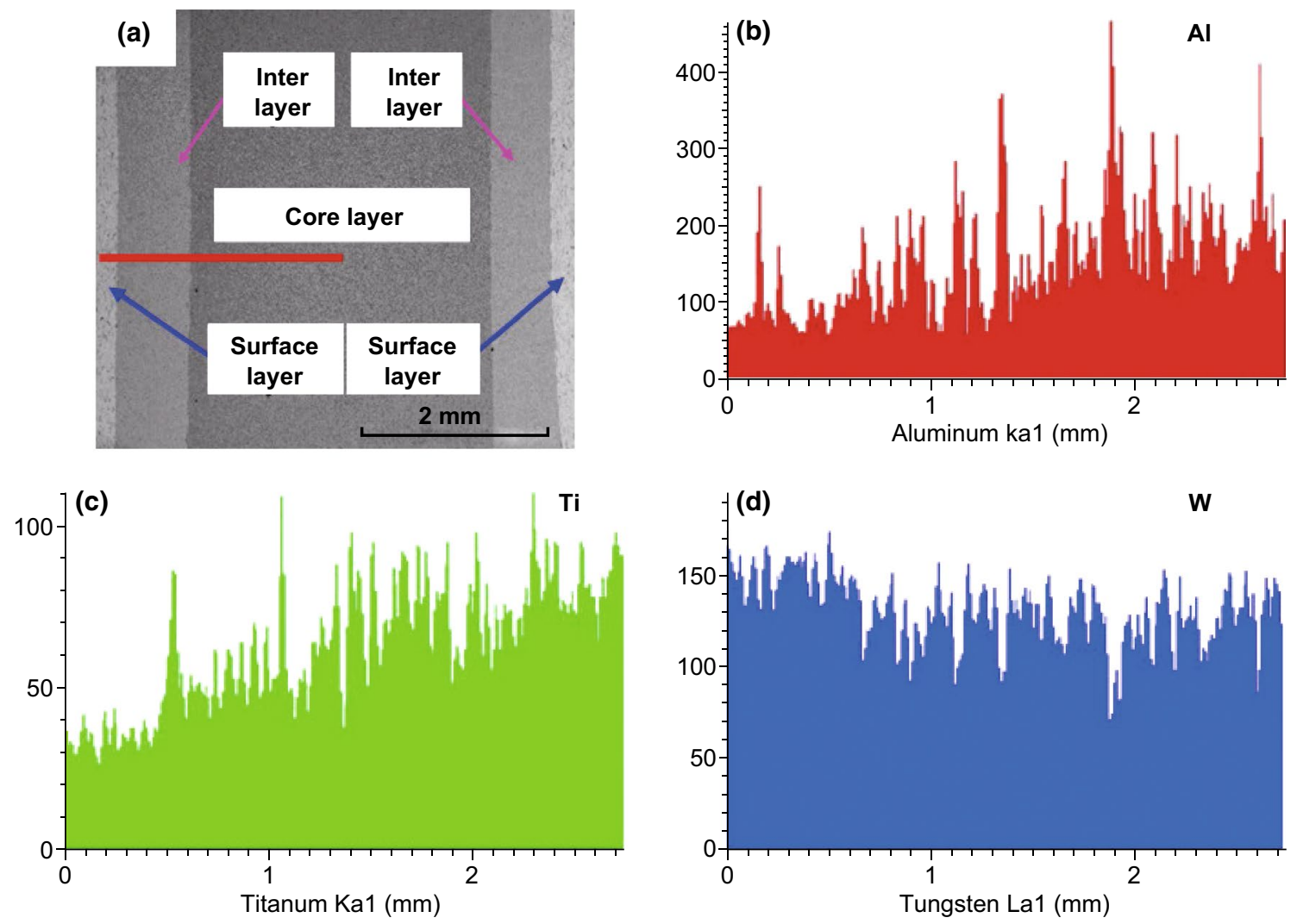

Fig. 13 a SEM micrographs and EDS maps of the distribution of $\mathbf{b} \mathrm{Al} \mathbf{c} \mathrm{Ti}$, and $\mathbf{d} \mathrm{W}$ elements on the red line of nano-laminated $\mathrm{WC}-\mathrm{Al}_{2} \mathrm{O}_{3}-$ TiC ceramics [139]. Figure panels reproduced from Ref. [139] with permission from Elsevier copyright 2017. (Color figure online)

in fracture toughness was obtained for $\mathrm{WC}$ as a function of 15 vol\% CNT addition, demonstrating that CNT prevented crack propagation by shielding a stress field in front of the crack tip or by bridging the crack forming ligaments behind the crack tip. Cao et al. [166] prepared ultra-fine-grained WC-1.0 wt\% CNT composites with a high toughness of $9.11 \mathrm{MPa} \mathrm{m}^{1 / 2}$ using SPS and investigated the effect of sintering temperature on the structure of CNT. In addition to crack deflection by CNT, CNT pullout was identified as another toughening mechanism as illustrated in Fig. 14c, d. Moreover, the author found that the structure of CNT was destroyed and CNT transformed to graphite phase in $1900{ }^{\circ} \mathrm{C}$, indicating that WC-CNT composites should be sintered at moderate temperatures.

Besides CNT, graphene is another nanocarbon material, but possesses a unique two-dimensional (2D) $s p^{2}$ structure with considerable theoretical specific surface area $\left(\sim 2630 \mathrm{~m}^{2} \mathrm{~g}^{-1}\right)$ and distinctive mechanical properties (e.g., breaking strength $42 \mathrm{~N} \mathrm{~m}^{-1}$, tensile strength $130 \mathrm{GPa}$, stiffness $300-400 \mathrm{~N} \mathrm{~m}^{-1}$, thermal conductivity
3000-5000 $\mathrm{W} \mathrm{m}^{-1} \mathrm{~K}^{-1}$, spring constant $1-5 \mathrm{~N} \mathrm{~m}^{-1}$, and Young's modulus $0.5-1 \mathrm{TPa})[167,168]$. The 2D structure endows graphene with inherent advantages over other carbon allotropes as CNT. Furthermore, graphene possesses better dispersion properties than CNT and can be homogeneously dispersed into a ceramic matrix, which is another rather advantageous factor in improving the microstructure and mechanical properties of the ceramic composites [169, 170]. Additionally, graphene is endowed with energy dissipating mechanism by generating graphene bending and kinking. The coordination deformation of graphene consumes strain energy and then reduces the crack extension energy, significantly contributing to the improvement of fracture toughness [171]. All these properties are very attractive for the application of graphene as reinforcement for ceramic composites [172].

It is reported that graphene showed remarkable effectiveness in enhancing the fracture toughness of $\mathrm{Al}_{2} \mathrm{O}_{3}$-based ceramics [173], $\mathrm{Si}_{3} \mathrm{~N}_{4}$-based ceramics [174], $\mathrm{ZrB}_{2}$-based ceramics [175], $\mathrm{ZrO}_{2}$-based ceramics [176], and TaC-based 

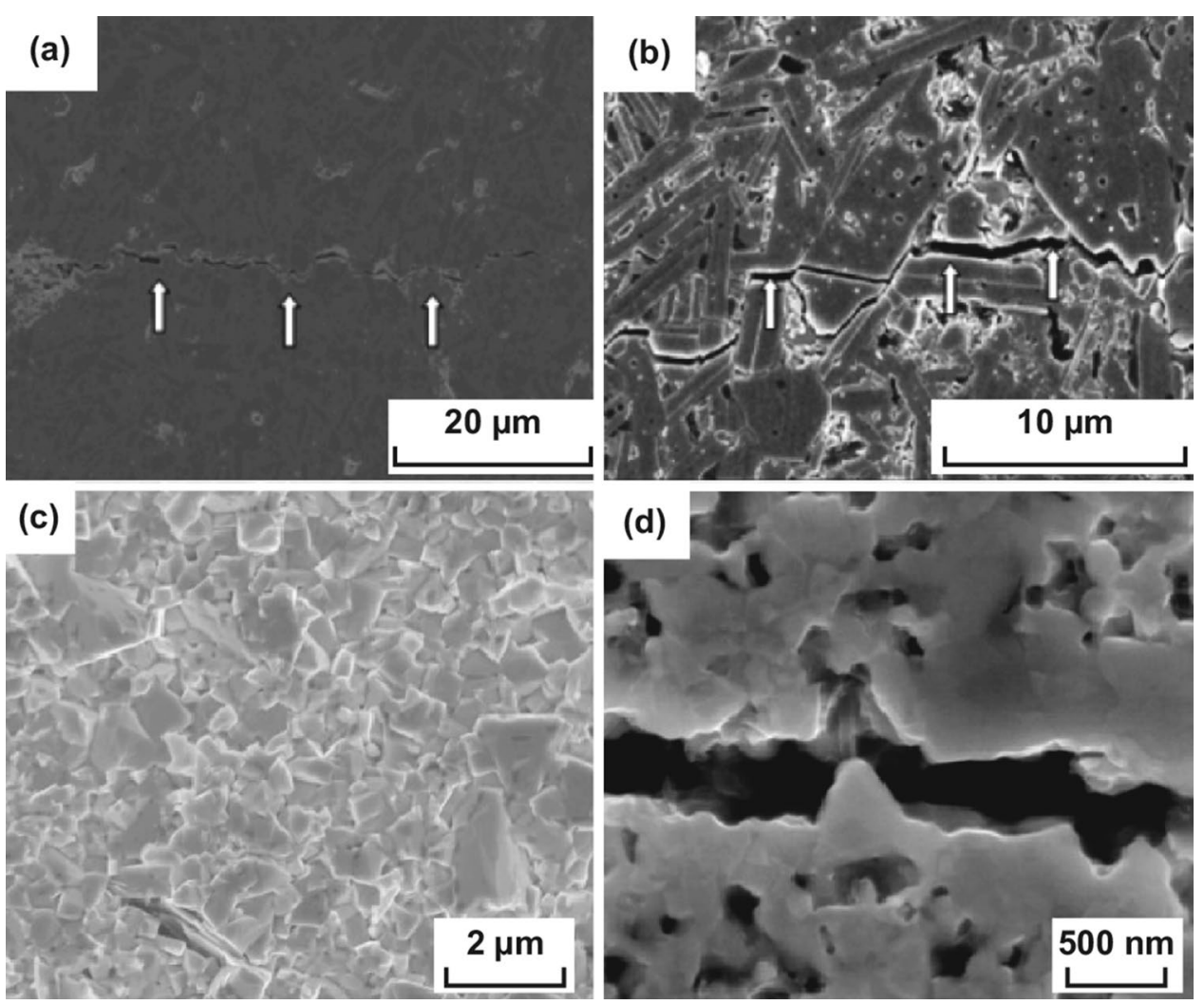

Fig. 14 FE-SEM micrographs of crack propagation in a WC-5 vol\% CNT and $\mathbf{b}$ WC-10 vol\% CNT [161]. Typical SEM images of $\mathbf{c}$ the fracture surfaces and $\mathbf{d}$ crack details of WC-CNT composites [166]. Figure panels reproduced from Ref. [161] with permission from INST Problems Mechanical Engineering-Russian Card Sciences copyright 2011, Ref. [166] with permission from Elsevier copyright 2018

ceramics [177]. To the best of our knowledge, few studies have been reported on the effects of graphene addition on the densification and properties of BTC materials hitherto.

Recently, we investigated the toughening effect of multilayer graphene (MLG) on BTC through hot-pressing method [178]. It is worthwhile mentioning that the achievement of good graphene/WC composites depends extremely on three critical factors, and those are homogeneous dispersion within the WC matrix, minimization of the mechanical damage of graphene, and optimum bonding between WC matrix and graphene. MLG was homogeneously dispersed in the WC-based ceramic matrix as shown in Fig. 15a. Figure 15b depicts Raman spectroscopy of MLG and sintered ceramics, implying the survival of MLG after the so-designed two-step sintering. Both the spectra presented the characteristic D, G, and 2D bands corresponding to MLG at $\sim 1350, \sim 1580$, and $\sim 2700 \mathrm{~cm}^{-1}$, confirming that the graphene-based structure has not been damaged during the milling and sintering processes. WC-based ceramics with $0.1 \mathrm{wt} \%$ MLG addition exhibited a fracture toughness of $14.1 \mathrm{MPa} \mathrm{m}^{1 / 2}$, undergoing $53.3 \%$ enhancement in comparison with monolithic ceramics. MLG bending, wrapping, interface debonding, MLG wall and network, MLG-induced weak interface, grains bridging by MLG, MLG pullout, crack deflection, crack bridging, and crack stopping were the major toughening mechanisms (Fig. 16). Also, the preferential orientation of MLG in WC matrix and MLG intrinsic energy dissipating mechanisms as sheet kinking, bending, and sliding played very significant roles in contributing to the toughness enhancement of BTC reinforced by MLG. The detailed discussion about the toughening mechanism in WC/MLG composites can be found in our previous article [178].

\subsection{Synergistic Toughening}

An area of remarkable potential is the synergistic toughening, taking advantage of the possibilities of multiple toughening mechanisms operative within a single composite. It is 

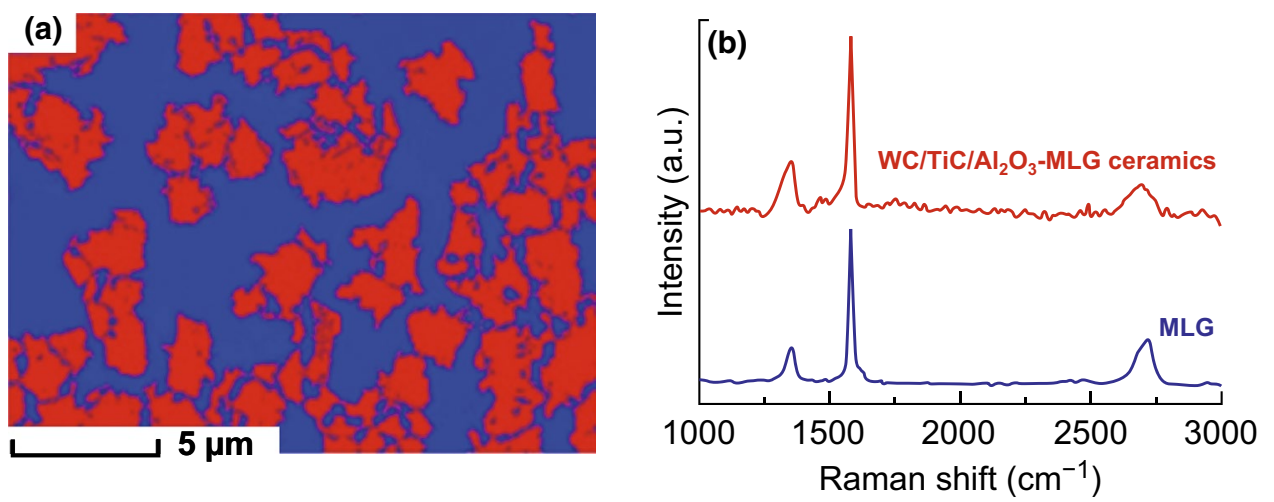

Fig. 15 a The distribution of MLG (color in red) in WC-based composites reinforced by 0.1 wt\% MLG (by EBSD). b Raman spectroscopy of MLG and sintered ceramics [178]. Figure panels reproduced from Ref. [178] with permission from Elsevier copyright 2017. (Color figure online)

suggested from both theoretical analysis and experimental observations that the overall effect of combined toughening mechanisms may be greater than the sum of the increments from individual components.

Combining secondary-phase reinforcements, such as platelets as well as whiskers, with microstructural tailoring of the matrix may be of great potential. Also, transformation toughening could be combined with other toughening methods. Furthermore, toughening by designing laminated structure combined with toughening by the design of chemical composition would be of significant promise to improve the fracture toughness of ceramics. By combining particle dispersion toughening (with $\mathrm{Al}_{2} \mathrm{O}_{3}$ ) with transformation toughening (with $\mathrm{ZrO}_{2}$ ), Xia et al. [128] prepared $\mathrm{WC}-\mathrm{Al}_{2} \mathrm{O}_{3}-\mathrm{ZrO}_{2}$ composites with high fracture toughness. Bai et al. [163] reported a highly tough $\mathrm{WC}-\mathrm{Al}_{2} \mathrm{O}_{3}-\mathrm{CNT}$ composite coupling carbon nanotube toughening with $\mathrm{Al}_{2} \mathrm{O}_{3}$ particle dispersion toughening. Combining particle dispersion toughening, graphene toughening, and laminated structure toughening, we prepared highly tough laminated WC- $\mathrm{Al}_{2} \mathrm{O}_{3}-\mathrm{TiC}-\mathrm{MLG}$ composite [178].

\section{Mechanical Properties of Binderless Tungsten Carbide}

Mechanical properties of BTC are strongly dependent on their densification degree, grain size, chemical compositions as well as microstructure. Hardness and fracture toughness, the critical properties in many applications of engineering structural materials, are the most important intrinsic mechanical properties for BTC. Despite its high hardness as well as excellent wear/corrosion/oxidation resistance, a major limitation of BTC's further applications, structural application as an example, is its poor fracture toughness. Enhancing the fracture toughness without sacrificing hardness is invariably one of the goals of BTC development. Wear resistance of BTC is also one of the most significant mechanical properties; however, it is mostly determined by the hardness coupled with fracture toughness.

\subsection{Hardness Versus Fracture Toughness}

Hardness is always a stress standing for the resistance to non-recoverable deformation of a material, while fracture toughness characterizes a material's resistance to crack propagation and, as such, is measured as the fracture energy. They are the two basic mechanical properties of BTC and the foundation of other mechanical properties, such as wear resistance, flexural strength as well as impact resistance.

The mechanical properties of pure WC were reported in several researches. Date demonstrates that the fracture toughness of pure WC decreased with the increasing hardness (Fig. 17a), which is similar to the general tendency of conventional WC-Co cemented carbide. It should be noted that for WC-Co cemented carbides, Co binder phase acts for impeding the crack propagation through shielding a stress in front of crack tip. However, in pure WC, crack propagates along the WC/WC interface or penetrates into large WC grains, implying that the large WC grains together with the remaining small pores prevent crack growth and absorb 

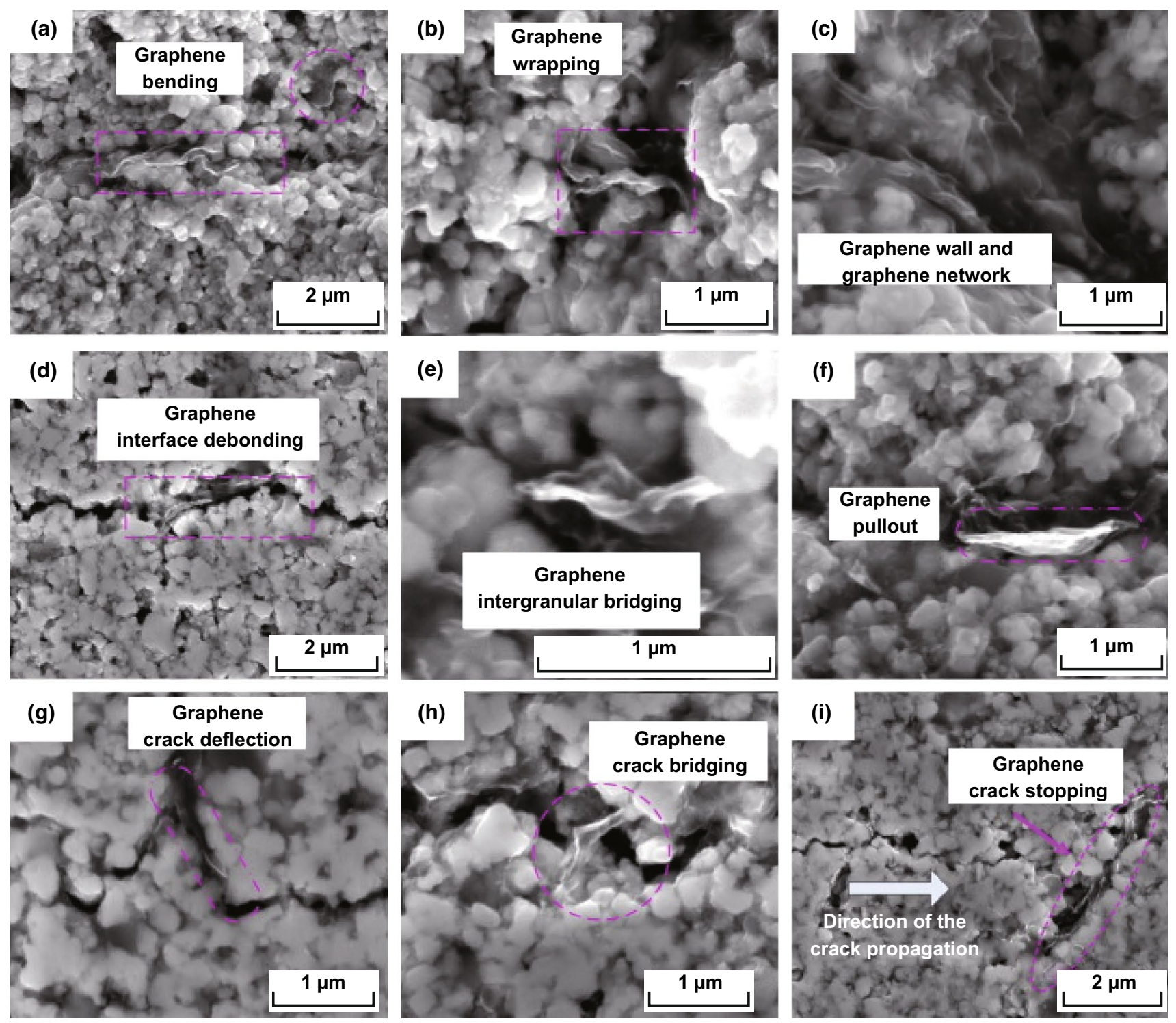

Fig. 16 Toughening mechanisms in WC-based ceramics reinforced by MLG: a graphene bending, $\mathbf{b}$ graphene wrapping, $\mathbf{c}$ graphene wall and network, $\mathbf{d}$ graphene interface debonding, $\mathbf{e}$ graphene intergranular bridging, $\mathbf{f}$ graphene pullout, $\mathbf{g}$ graphene deflection, $\mathbf{h}$ crack bridging, and $\mathbf{i}$ crack stopping [178]. Figure panels reproduced from Ref. [178] with permission from Elsevier copyright 2017

fracture energy. Furthermore, the mechanical properties of BTC can be remarkably enhanced by improving the densification. As shown in Fig. 17b, c, both hardness and fracture toughness were improved with the increase in the relative density, and high mechanical properties (hardness and fracture toughness) corresponded to high density. Also, it is revealed that Hall-Petch-like relationship is applied to BTC as shown in Fig. 17d, implying that hardness enhancement of BTC is associated primarily with obtaining fine grain in the sintered material at a given relative density.
It has been recognized that the reduction in microstructural scale to nanometer resulted in substantial enhancement in mechanical properties of BTC. The trade-off relationship between hardness and fracture toughness may be reduced when the grain sizes approach nanoscale as $100 \mathrm{~nm}$. With respect to conventional BTC, the fracture toughness reduces with increasing hardness; however, the hardness increase in nanosized BTC does not lower or even increase the fracture toughness. Though possessing higher relative density (99.1\%), micro-sized WC (400 nm) exhibited both lower 

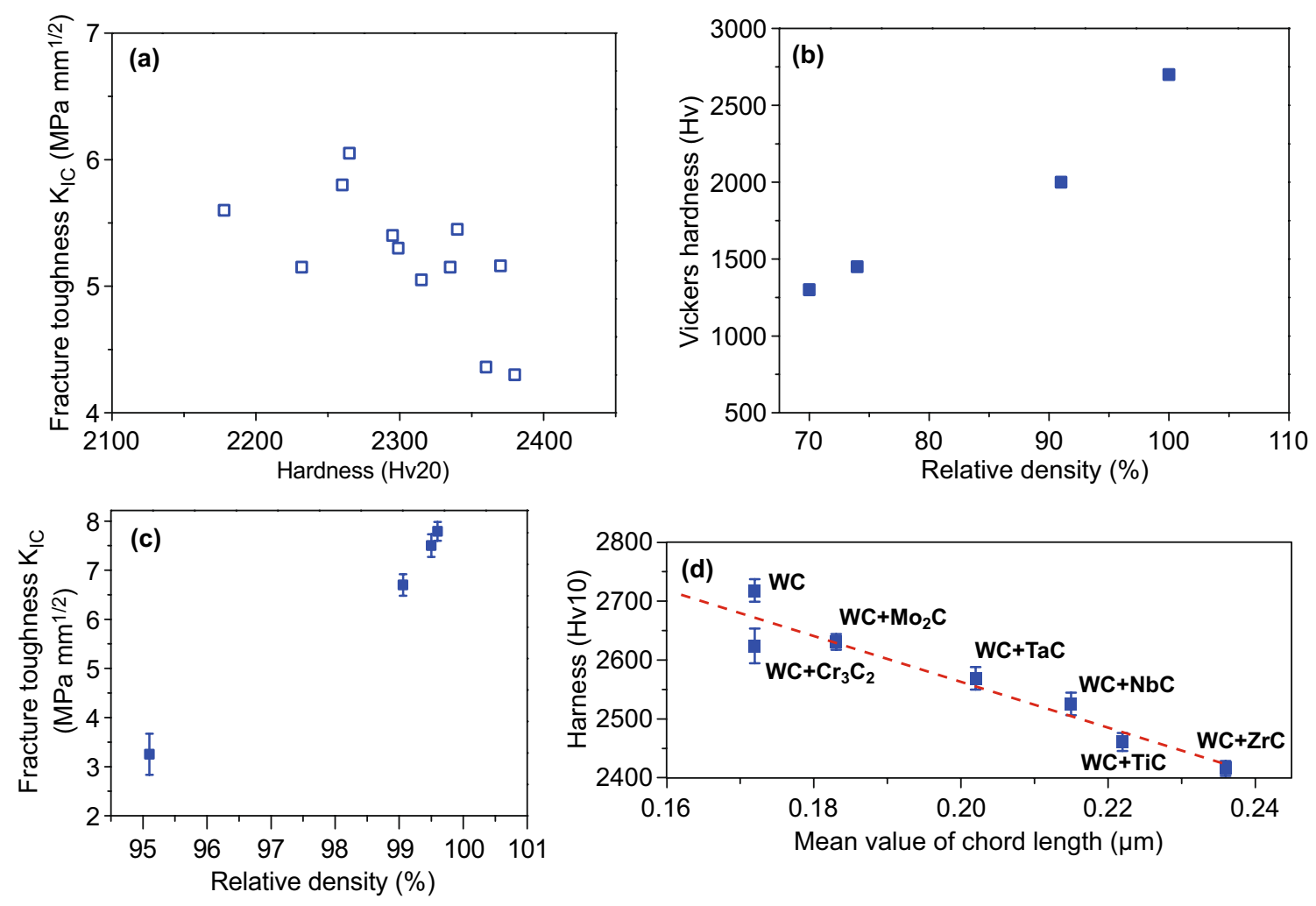

Fig. 17 a Plot of fracture toughness versus hardness of BTC [126]. b Plot of hardness and $\mathbf{c}$ fracture toughness versus relative density [119, 179]. d Plot of hardness versus chord length of dense samples [180]. Figure panels reproduced from Ref. [126] with permission from IEEE copyright 2005, Ref. [119] with permission from Elsevier copyright 2006, Ref. [179] with permission from Elsevier copyright 2017, Ref. [180] with permission from EPMA copyright 2014

hardness $(27.5 \mathrm{GPa})$ and toughness $\left(4.5 \mathrm{MPa} \mathrm{m}{ }^{1 / 2}\right)$ in comparison with nanosized WC $(87 \mathrm{~nm})$ having a hardness of 29.6 GPa and toughness of 7.1 MPa $\mathrm{m}^{1 / 2}[130,181]$.

Table 6 illustrates hardness and fracture toughness of some reported BTC with various chemical compositions, relative densities, and grain sizes. As discussed before, some carbide addition can improve the sinterability of BTC; however, the carbide-added BTC, such as WC-TiC, WC-VC, and $\mathrm{WC}-\mathrm{TaC}$, exhibited a deteriorated hardness and similar or slightly lower fracture toughness in comparison with pure WC. Metal-oxide-added WC-based composites, such as $\mathrm{WC}-\mathrm{Al}_{2} \mathrm{O}_{3}$, WC- $\mathrm{MgO}$, and $\mathrm{WC}-\mathrm{ZrO}_{2}$, showed a good combined property similar to or even better than conventional WC-Co cemented carbide. Grain growth inhibitor is essential for WC-based composites to further improve mechanical properties, regardless of carbide addition or oxide addition. Graphene-reinforced WC-based composites exhibited the best combined property.

\subsection{Wear Resistance}

Liu et al. [187] studied the wear resistance of pure WC. The experiments were ball-on-disk type, in which ball is the $\mathrm{SiC}$ counterpart ball with a diameter of $6.25 \mathrm{~mm}$ and a hardness of $28 \mathrm{GPa}$, and disk is WC. The test temperature increased from 25 to $800{ }^{\circ} \mathrm{C}$ under air and vacuum conditions. The results showed that pure WC can maintain phase stability at the temperature till $800{ }^{\circ} \mathrm{C}$ in vacuum. In air, the wear mechanism of pure WC was mainly oxidation wear, and the critical temperatures causing degradation on the wear properties were 500 and $550{ }^{\circ} \mathrm{C}$.

Engqvist et al. [188] compared the sliding wear resistance of WC-TiC-TaC with conventional WC-Co cemented carbides and ceramics as $\mathrm{Al}_{2} \mathrm{O}_{3}$ and $\mathrm{SiC}$ (Table 7). Three kinds of abrasive particles, including diamond, silicon carbide, and silica, were used. During the test, the normal load was $0.2 \mathrm{~N}$ and the total sliding distance was $50 \mathrm{~m}$. The results showed 
Table 6 Hardness and fracture toughness of some reported BTCs

\begin{tabular}{|c|c|c|c|c|}
\hline Material & $\begin{array}{l}\text { Relative den- } \\
\text { sity (\%) }\end{array}$ & $\begin{array}{l}\text { Sintered grain } \\
\text { size }(\mathrm{nm})\end{array}$ & $\operatorname{Hardness}^{\mathrm{a}}(\mathrm{Hv})$ & $\begin{array}{l}\text { Fracture } \\
\text { toughness } \\
\left(\mathrm{MPa} \mathrm{m}^{1 / 2}\right)\end{array}$ \\
\hline WC [18] & 99.2 & 200 & 2925 & 8.9 \\
\hline WC [181] & 100 & 130 & 3061 & 7.3 \\
\hline WC [182] & 98.5 & 380 & 2854 & 7.1 \\
\hline WC [130] & 99 & 87 & 3020 & 7.1 \\
\hline WC [125] & 99.8 & 220 & 2959 & 7.2 \\
\hline WC [58] & 97.6 & 360 & 2480 & 6.6 \\
\hline WC-20 at.\% TiC [81] & 98.5 & 200 & 2032 & 6.3 \\
\hline WC-20 at.\% TiC [183] & 99 & 200 & 2240 & 7.5 \\
\hline WC-3 wt $\%$ TiC-2 wt $\%$ TaC- -0.2 wt $\% \mathrm{Cr}_{3} \mathrm{C}_{2}-0.2 \mathrm{wt} \% \mathrm{VC}$ [184] & & 600 & 2300 & 7.9 \\
\hline $\mathrm{WC}-6 \mathrm{wt} \% \mathrm{Mo}_{2} \mathrm{C}[184]$ & & 250 & 2400 & 8.4 \\
\hline WC $[84]$ & 99.9 & 280 & 2795 & 4.38 \\
\hline WC-1 wt \% VC [84] & 96.5 & 280 & 2795 & 4.2 \\
\hline WC-1 wt $\%$ VC [185] & 99.8 & 272 & 2585 & 6.9 \\
\hline $\mathrm{WC}-1 \mathrm{wt} \% \mathrm{Cr}_{3} \mathrm{C}_{2}[185]$ & 100 & 277 & 2605 & 7.2 \\
\hline $\mathrm{WC}-0.3 \mathrm{wt} \% \mathrm{VC}-0.5 \mathrm{wt} \% \mathrm{Cr}_{3} \mathrm{C}_{2}[119]$ & 97.5 & 240 & $2875^{\mathrm{d}}$ & 6.05 \\
\hline $\mathrm{WC}-0.33 \mathrm{wt} \% \mathrm{VC}-0.54 \mathrm{wt} \% \mathrm{Cr}_{3} \mathrm{C}_{2}[121]$ & 97.9 & 730 & 2464 & 4.4 \\
\hline WC $[180]$ & 100.6 & 171 & 2720 & 7.0 \\
\hline $\mathrm{WC}-1 \mathrm{wt} \% \mathrm{Mo}_{2} \mathrm{C}[180]$ & 100.8 & 183 & 2630 & 6.6 \\
\hline $\mathrm{WC}-1 \mathrm{wt} \% \mathrm{Mo}_{2} \mathrm{C}[85]$ & 99 & 450 & 2461 & 4.8 \\
\hline WC-1 wt\% TaC [180] & 99.7 & 202 & 2570 & 6.9 \\
\hline WC-1 wt\% ZrC [180] & 98.8 & 236 & 2420 & 6.5 \\
\hline WC-1 wt\% NbC [180] & 99.6 & 214 & 2540 & 6.6 \\
\hline WC-6 mol\% SiC-2 mol\% ZrC [71] & 99 & 720 & $2193^{\mathrm{e}}$ & 6.7 \\
\hline $\mathrm{WC}-20 \mathrm{~mol} \% \mathrm{SiC}-0.3 \mathrm{~mol} \% \mathrm{Cr}_{3} \mathrm{C}_{2}[90]$ & 99 & 420 & 2193 & 6.4 \\
\hline$\left(\mathrm{WC}-0.8 \mathrm{~mol}^{2} \mathrm{Cr}_{3} \mathrm{C}_{2}\right)-5$ vol\% $\mathrm{SiC}_{\mathrm{w}}[152]$ & 100.4 & 1500 & 2041 & 7 \\
\hline $\mathrm{WC}-14.3 \mathrm{wt} \% \mathrm{Al}_{2} \mathrm{O}_{3}-0.5 \mathrm{wt} \% \mathrm{VC}[93]$ & 98 & 2000 & 2103 & 11.54 \\
\hline $\mathrm{WC}-10 \mathrm{wt} \% \mathrm{Al}_{2} \mathrm{O}_{3 \mathrm{w}}-0.5 \mathrm{wt} \% \mathrm{VC}[94]$ & 98 & 2000 & 2103 & 13.8 \\
\hline WC-10 vol\% $\mathrm{Al}_{2} \mathrm{O}_{3}[102]$ & 99.8 & 101 & 2540 & 9.4 \\
\hline $\mathrm{WC}-4.3 \mathrm{wt} \% \mathrm{MgO}[135]$ & 99 & 2590 & $1878^{\mathrm{f}}$ & 12.95 \\
\hline WC-6 wt $\% \mathrm{ZrO}_{2}[104]$ & 100 & 660 & 1876 & 10.8 \\
\hline WC-3 wt\% AlN [186] & 99.6 & 700 & 2400 & 7.5 \\
\hline $\mathrm{WC}-10 \mathrm{wt} \% \mathrm{Si}_{3} \mathrm{~N}_{4 \mathrm{w}}[153]$ & 100 & 1260 & 1801 & 10.94 \\
\hline WC-1.0 wt\% CNT [166] & 101 & 200 & 2328 & 8.95 \\
\hline $\mathrm{WC}-3 \mathrm{wt} \% \mathrm{Al}_{2} \mathrm{O}_{3}-2 \mathrm{wt} \% \mathrm{TiC}-0.15 \mathrm{wt} \% \mathrm{MLG}^{\mathrm{c}}[178]$ & 98.9 & 400 & 2255 & 14.5 \\
\hline
\end{tabular}

${ }^{a}$ For convenience of comparison, the original hardness values from papers were converted to Vickers hardness values

${ }^{\mathrm{b}}$ Fracture toughness value was calculated from indentation method

${ }^{\mathrm{c}}$ This is the surface layer of a functionally graded $\mathrm{WC}-\mathrm{AL}_{2} \mathrm{O}_{3}-\mathrm{TiC}-\mathrm{MLG}$ composites

${ }^{\mathrm{d}}$ This is a value of HV0.5

${ }^{\mathrm{e}}$ This is a value of HV1.0

${ }^{\mathrm{f}}$ This is a value of HV30

that the $\mathrm{WC}-\mathrm{TiC}-\mathrm{TaC}$ had a slightly lower wear resistance than WC-Co cemented carbides, but much higher than that of common engineering ceramics $\mathrm{Al}_{2} \mathrm{O}_{3}$ and $\mathrm{SiC}$ as demonstrated in Fig. 18a. The BTC was worn by a preferential removal of $\mathrm{TiC}$ grains, leaving the $\mathrm{TaC} / \mathrm{NbC}$ and $\mathrm{WC}$ grains unsupported, which contributed to an increased wear rate in comparison with WC-Co cemented carbides, implying that TiC was a weak constituent of the binderless carbide. 
Therefore, it is denoted that BTC composites free of TiC may have a superior wear resistance to conventional WC-Co cemented carbides. Based on this idea, Botton et al. [184] investigated the wear resistance of $\mathrm{WC}-6 \mathrm{wt} \% \mathrm{Mo}_{2} \mathrm{C}$ and WC-6 wt\% Co (Table 8) as shown in Fig. 18b. The results demonstrated that $\mathrm{WC}-\mathrm{Mo}_{2} \mathrm{C}$ exhibited better wear resistance than WC-Co cemented carbides. The wear mechanism of $\mathrm{WC}-\mathrm{Mo}_{2} \mathrm{C}$ was found to be ductile, which was different from that of WC-TiC-TaC suffering from grain pullout of TiC. It seems that the wear resistance of BTC strongly depends on the bonding between the carbide grains, and $\mathrm{WC}-\mathrm{Mo}_{2} \mathrm{C}$ provided a better bonding than $\mathrm{WC}-\mathrm{TiC}-\mathrm{TaC}$.

Venkateswaran et al. [106, 107] investigated the wear resistance of $\mathrm{WC}-\mathrm{ZrO}_{2}$ composites using a fretting wear tester employing bearing steel as a counter body on $\mathrm{WC}-\mathrm{ZrO}_{2}$ under the ambient condition of temperature and humidity, demonstrating that the abrasion and tribochemical wear resulting in $\mathrm{WO}_{3}$ formation were the predominant wear mechanisms for $\mathrm{WC}-\mathrm{ZrO}_{2}$ composites.
Recently, we investigated the sliding wear resistance of MLG-reinforced BTC [178]. The results showed that the ab plane of MLG exhibited a preferential orientation perpendicular to the direction of applied pressing as shown in Fig. 19a, b, playing a rather significant role in enhancing the tribological performance of MLG-reinforced materials. MLG-reinforced WC exhibited $73.8 \%$ decrement in friction coefficient and $~ 82.65 \%$ improvement in wear resistance in surface perpendicular to the direction of applied pressing in comparison with monolithic ceramics as illustrated in Fig. 19c, d. It is noted from Fig. 19e-h that both the depth and the width of the wear track of WC ceramics containing $0.1 \mathrm{wt} \%$ MLG are smaller than those of monolithic ceramics. The dramatic improvement in tribological performance is attributed to the self-lubrication of MLG and easily formed friction layer in the contact interface as shown in Fig. 20. Furthermore, the unrivaled thermal conductivity of MLG and its rather significant effect in inhibiting the grain growth

Table 7 Composition, grain size, hardness, and fracture toughness of the tested materials [188]

\begin{tabular}{|c|c|c|c|c|}
\hline Specimen & Composition (wt\%) & Grain size $(\mu \mathrm{m})$ & Hardness (HV0.5) & $\begin{array}{l}\text { Fracture } \\
\text { toughness } \mathrm{K}_{\mathrm{IC}} \\
\left(\mathrm{MPa} \mathrm{m}^{1 / 2}\right)\end{array}$ \\
\hline B1 & $94.5 \mathrm{WC}, 2 \mathrm{Ta} / \mathrm{NbC}, 3 \mathrm{TiC},<0.5 \mathrm{Co}$ & 1.3 & 1900 & 7.9 \\
\hline F6 & $94 \mathrm{WC}, 5.4 \mathrm{Co}, 0.6(\mathrm{Ta}, \mathrm{Nb}) \mathrm{C}$ & 1.0 & 1720 & 10.8 \\
\hline C6 & $94 \mathrm{WC}, 6 \mathrm{Co}$ & 7.0 & 1220 & 15 \\
\hline $\mathrm{SiC}$ & $\mathrm{SiC}$ + some free $\mathrm{C}$ & 3.0 & 2300 & 4.5 \\
\hline $\mathrm{Al}_{2} \mathrm{O}_{3}$ & $96.95 \mathrm{Al}_{2} \mathrm{O}_{3}, 0.25 \mathrm{MgO}, 2.8 \mathrm{ZrO}_{2}$ & 1.9 & 1820 & 5.4 \\
\hline
\end{tabular}
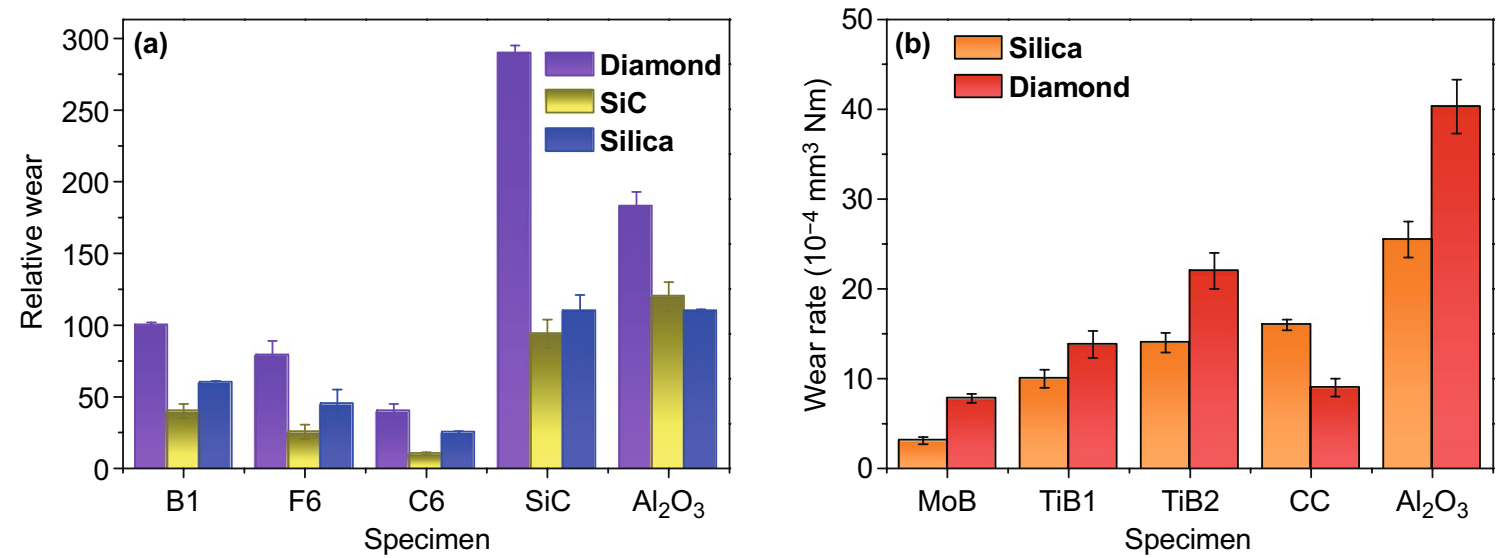

Fig. 18 a Relative wear rates for the tested materials as shown in Table 7 abraded with diamond, SiC, and silica. 100 corresponds to B1 worn with diamond [188]. b Wear rates for the different tested materials as shown in Table 8 abraded with silica and diamond [184]. Figure panels reproduced from Ref. [188] with permission from Springer Nature 1998, Ref. [184] with permission from Wiley copyright 2000 
Table 8 Composition, grain size, hardness and fracture toughness of the tested materials

\begin{tabular}{|c|c|c|c|c|}
\hline Specimen & Composition (wt $\%$ ) & Grain size $(\mu \mathrm{m})$ & Hardness (HV0.5) & $\begin{array}{l}\text { Fracture } \\
\text { toughness } \mathrm{K}_{\mathrm{IC}} \\
\left(\mathrm{MPa} \mathrm{m}^{1 / 2}\right)\end{array}$ \\
\hline MoB [184] & $94 \mathrm{WC}, 6 \mathrm{Mo}_{2} \mathrm{O}$ & 0.25 & 2400 & 8.4 \\
\hline TiB1 [184] & 94.6WC, 3TiC, $2 \mathrm{TaC}, 0.2 \mathrm{Cr}_{3} \mathrm{C}_{2}, 0.2 \mathrm{VC}$ & 0.6 & 2300 & 7.9 \\
\hline TiB2 [188] & 95WC, 3TiC, $2 \mathrm{TaC}$ & 2.0 & 1900 & 7.9 \\
\hline CC [188] & 94WC, 6Co & 7 & 1200 & 15 \\
\hline $\mathrm{Al}_{2} \mathrm{O}_{3}[188]$ & $96.95 \mathrm{Al}_{2} \mathrm{O}_{3}, 0.25 \mathrm{MgO}, 2.8 \mathrm{ZrO}_{2}$ & 1.9 & 1820 & 5.4 \\
\hline
\end{tabular}

are an important contribution to the improved tribological performance.

\section{Concluding Remarks and Outlook}

In this review, recent extensive investigations on the processing, microstructure, and mechanical properties of BTC and BTC composites are summarized. Such insights should be very helpful in tailoring the properties by judiciously selecting the chemical composition coupled with processing techniques and parameters.

Critical issue associated with the densification of BTC has been reviewed. It is believed that the densification of BTC is rather challenging due to the absence of metallic binder. The review highlights the crucial roles of mixed carbon content, carbide grain size, ceramic additive as well as advanced sintering techniques in the densification process. Carbon control is rather essential for BTC achieving maximum densification and performance levels. Strict design of additives including carbon, $\mathrm{WO}_{3}$, and $\mathrm{W}$ together with carefully control of thermal processing process is of great importance to the carbon content in final product. Sintering temperature strongly depends on the grain size; thus, finer initial powder grain size is helpful in lowering the sintering temperature as well as shortening the sintering process, especially for nanopowders. Nanocrystalline WC powders possess better sinterability in comparison with micro-sized ones, due to their high surface energy increasing the sintering driving forces. Besides reducing the particle size of WC matrix, it is also effective to facilitate the sintering of WC by dispersing some nanosized second-phase additive within micro-sized WC matrix grains or at the grain boundaries of WC matrix. The low melting point of the metal and possibility of carbonation and oxidation make the selection of the transition-metal carbides ( $\mathrm{TiC}, \mathrm{TaC}$, and $\mathrm{SiC}$ ) and metal oxides $\left(\mathrm{Al}_{2} \mathrm{O}_{3}, \mathrm{ZrO}_{2}, \mathrm{Y}_{2} \mathrm{O}_{3}\right.$, and $\left.\mathrm{La}_{2} \mathrm{O}_{3}\right)$ binders more favorable for consolidating WC powders. The advanced sintering techniques, such as SPS, RSPS, HFIHS as well as PCAS, are successfully employed in laboratory scale preparing dense BTC. Particularly, SPS is currently the most commonly used sintering method to consolidate BTC or BTC composites.

Another critical issue associated with the toughening of BTC has also been reviewed. Varieties of traditional toughening methods including particle dispersion toughening $\left(\mathrm{Al}_{2} \mathrm{O}_{3}, \mathrm{MgO}\right.$, etc.), transformation toughening $\left(\mathrm{ZrO}_{2}\right)$, whisker toughening $\left(\mathrm{SiC}_{\mathrm{w}}, \mathrm{Si}_{3} \mathrm{~N}_{4 \mathrm{w}}, \mathrm{Al}_{2} \mathrm{O}_{3 \mathrm{w}}\right)$, and synergistic toughening together with some new-concept toughening methods, such as laminated structure toughening, carbon nanotube toughening, and graphene toughening, have been proposed to toughening BTC. Particularly, new-concept toughening methods offered great promise of a revolutionary advance in the production of highly tough BTC. Furthermore, toughening by designing laminated structure combined with toughening by the design of chemical composition would be of significant promise to enhance the fracture toughness of BTC.

Mechanical properties of BTC are strongly dependent on their densification degree, grain size, chemical compositions as well as microstructure. The fracture toughness of pure WC decreases with the increasing hardness, which is similar to the general tendency of conventional WC-Co. Both hardness and fracture toughness can be improved with the increase in the relative density, and high mechanical properties (hardness and fracture toughness) correspond to high densification. The trade-off relationship between hardness and fracture toughness may be reduced when the grain sizes approach nanoscale as $100 \mathrm{~nm}$. Compared with other materials reinforced BTC, graphene-reinforced BTC exhibited the best combined property. BTC has comparable or higher wear resistance than conventional WC-Co cemented carbides, but 


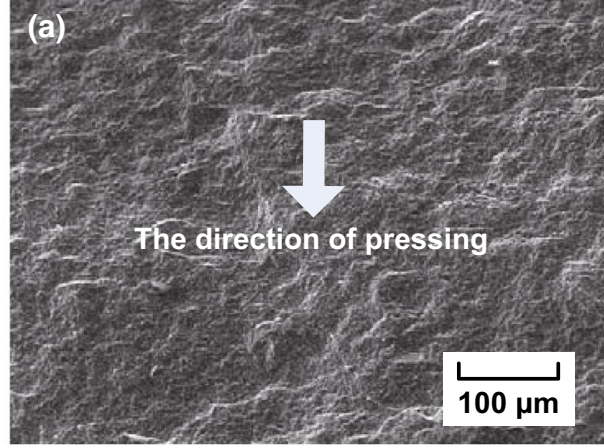

(c) 0

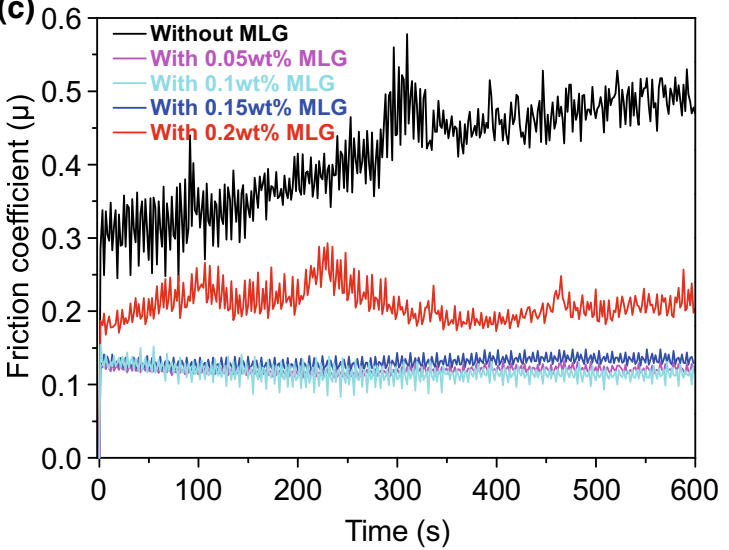

(e)

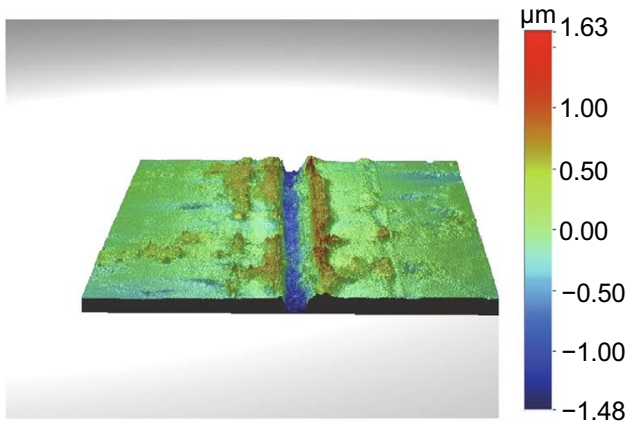

(g)

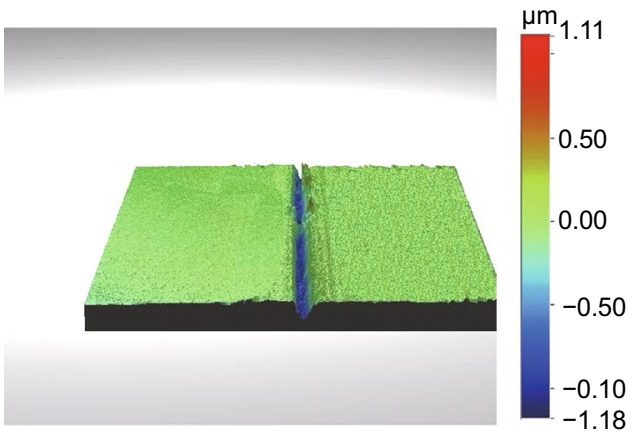

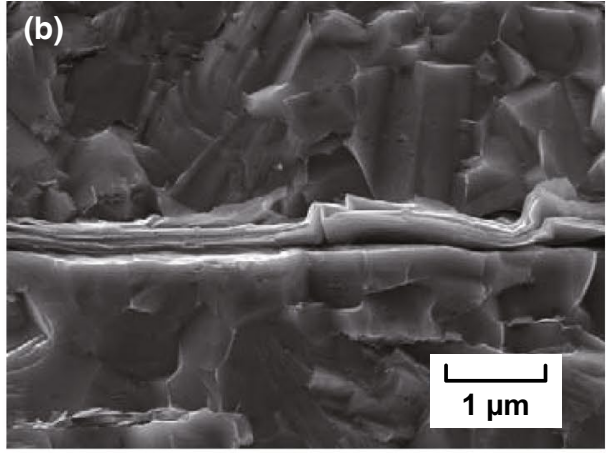

(d)

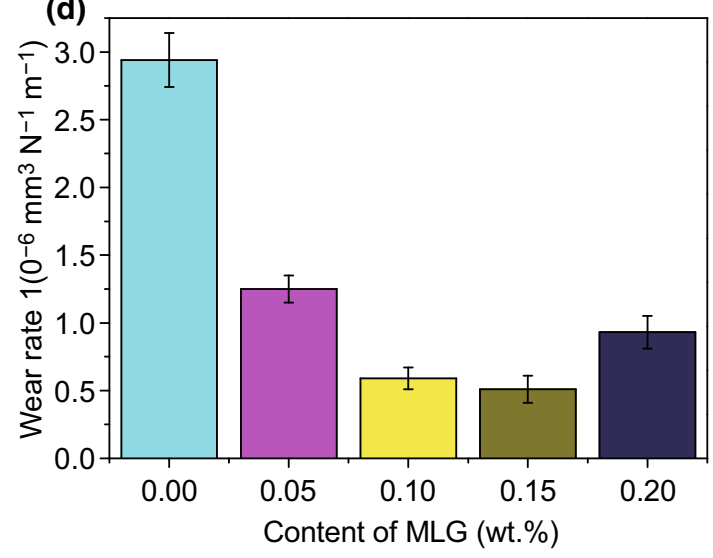

(f)

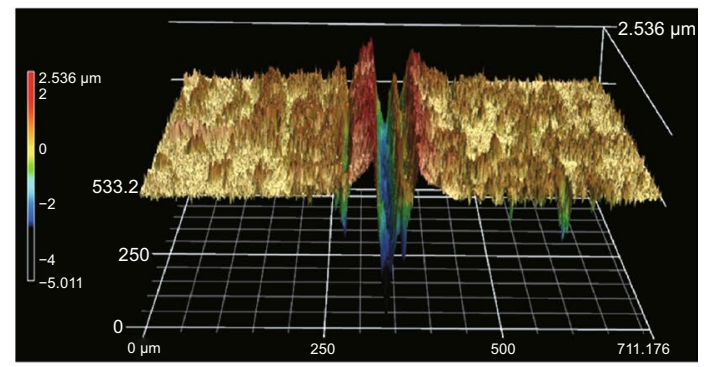

(h)

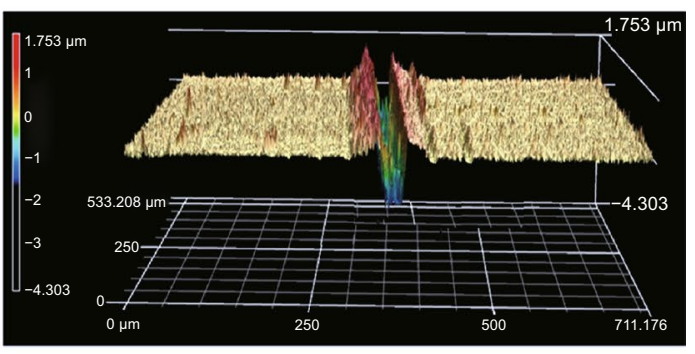

Fig. 19 Preferential orientation of MLG in WC ceramics after hot-pressing $\mathbf{a}$ in low magnification and $\mathbf{b}$ in high magnification, influence of MLG contents on $\mathbf{c}$ friction coefficient and $\mathbf{d}$ wear rates, surface topographies of wear tracks on $\mathbf{e}, \mathbf{f}$ monolithic WC ceramics and $\mathbf{g}, \mathbf{h}$ ceramics containing 0.1 wt\% MLG [178]. Figure panels reproduced from Ref. [178] with permission from Elsevier copyright 2017 
(a)
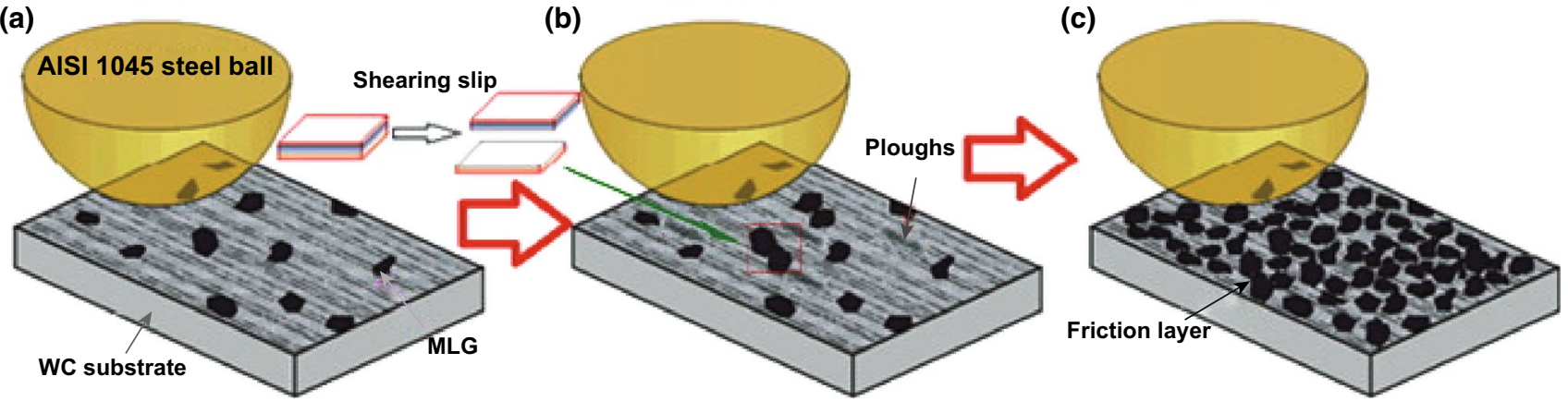

Fig. 20 Schematic of effect mechanism of MLG reinforced WC-based materials against AISI 1045 steel [178]. Figure panels reproduced from Ref. [178] with permission from Elsevier copyright 2017

much higher than that of common engineering ceramics such as $\mathrm{Al}_{2} \mathrm{O}_{3}$ and $\mathrm{SiC}$.

Finally, it should be noted that, in spite of the progress made in the processing as well as properties of BTC, this remains a field of prospect, and further research is required to optimize chemical composition, further enhance mechanical properties as well as reduce manufacturing costs, develop sintering techniques for large scale production, develop new techniques as selective laser sintering for fabricating complex-shaped functional BTC composite powder parts, and advance them more widely and novel applications, so as to produce BTC or BTC composites on an industrial or commercial scale.

Acknowledgements This work is supported by the China Postdoctoral Science Foundation (No. 2019M663685).

Open Access This article is licensed under a Creative Commons Attribution 4.0 International License, which permits use, sharing, adaptation, distribution and reproduction in any medium or format, as long as you give appropriate credit to the original author(s) and the source, provide a link to the Creative Commons licence, and indicate if changes were made. The images or other third party material in this article are included in the article's Creative Commons licence, unless indicated otherwise in a credit line to the material. If material is not included in the article's Creative Commons licence and your intended use is not permitted by statutory regulation or exceeds the permitted use, you will need to obtain permission directly from the copyright holder. To view a copy of this licence, visit http://creativecommons.org/licenses/by/4.0/.

\section{References}

1. Z.Z. Fang, M.C. Koopman, H.T. Wang, Cemented tungsten carbide hardmetal-an introduction, in Comprehensive Hard Materials, ed. by D. Mari, L. Llanes, V.K. Sarin (Elsevier,
Oxford, 2014), pp. 123-138. https://doi.org/10.1016/B9780-08-096527-7.00004-0

2. L. Prakash, Introduction to hardmetals-fundamentals and general applications of hardmetals, in Comprehensive Hard Materials, ed. by D. Mari, L. Llanes, V.K. Sarin (Elsevier, Oxford, 2014), pp. 29-90. https://doi.org/10.1016/B978-008-096527-7.00002-7

3. R. Viswanadham, Science of Hard Materials (Springer, Berlin, 1983). https://doi.org/10.1007/978-1-4684-4319-6

4. A.V. Shatov, S.S. Ponomarev, S.A. Firstov, Hardness and deformation of hardmetals at room temperature, in Comprehensive Hard Materials, ed. by D. Mari, L. Llanes, V.K. Sarin (Elsevier, Oxford, 2014), pp. 647-699. https://doi. org/10.1016/B978-0-08-096527-7.00009-X

5. A.V. Shatov, S.S. Ponomarev, S.A. Firstov, Fracture and strength of hardmetals at room temperature, in Comprehensive Hard Materials, ed. by D. Mari, L. Llanes, V.K. Sarin (Elsevier, Oxford, 2014), pp. 301-343. https://doi. org/10.1016/B978-0-08-096527-7.00010-6

6. J.L. Sun, J. Zhao, F. Gong, X.Y. Ni, Z.L. Li, Development and application of WC-based alloys bonded with alternative binder phase. Crit. Rev. Solid. State. 44(3), 211-238 (2019). https://doi.org/10.1080/10408436.2018.1483320

7. A. Mukhopadhyay, B. Basu, Recent developments on WCbased bulk composites. J. Mater. Sci. 46(3), 571-589 (2011). https://doi.org/10.1007/s10853-010-5046-7

8. A. Krawitz, E. Drake, Residual stresses in cemented carbides-an overview. Int. J. Refract. Met. Hard Mater. 49, 27-35 (2015). https://doi.org/10.1016/j.ijrmhm.2014.07.018

9. A.D. Krawitz, E.F. Drake, Residual stresses, in Comprehensive Hard Materials, ed. by D. Mari, L. Llanes, V.K. Sarin (Elsevier, Oxford, 2014), pp. 385-404. https://doi. org/10.1016/B978-0-08-096527-7.00013-1

10. D. Mari, A.D. Krawitz, J.W. Richardson, W. Benoit, Residual stress in WC-Co measured by neutron diffraction. Mater. Sci. Eng., A 209(1-2), 197-205 (1996). https://doi. org/10.1016/0921-5093(95)10147-0

11. H.U. Sverdrup, K.V. Ragnarsdottir, D. Koca, Integrated modelling of the global cobalt extraction, supply, price and 
depletion of extractable resources using the world6 model. BioPhys. Econ. Resour. Qual. 2(1), 4 (2017). https://doi. org/10.1007/s41247-017-0017-0

12. S. Bastian, W. Busch, D. Kühnel, A. Springer, T. Meißner et al., Toxicity of tungsten carbide and cobalt-doped tungsten carbide nanoparticles in mammalian cells in vitro. Environ. Health Perspect. 117(4), 530 (2009). https://doi.org/10.1289/ ehp.0800121

13. IARC Working Group on the Evaluation of Carcinogenic Risks to Humans, Cobalt in hard metals and cobalt sulfate, gallium arsenide, indium phosphide and vanadium pentoxide. IARC monographs on the evaluation of carcinogenic risks to humans 86, 1 (2006)

14. Y. Kanemitsu, T. Nishimura, H. Yoshino, K. Takao, Y. Masumoto, Effect of hot isostatic pressing on binderless cemented carbide. Int. J. Refract. Met. Hard Mater. 1(2), 66-68 (1982)

15. M.F. Ashby, The CES EduPack Resource Booklet 2: Material and Process Selection Charts (Granta Design Limited, Cambridge, 2009)

16. K.M. Tsai, C.Y. Hsieh, H.H. Lu, Sintering of binderless tungsten carbide. Ceram. Int. 36(2), 689-692 (2010). https://doi. org/10.1016/j.ceramint.2009.10.017

17. J. Poetschke, V. Richter, T. Gestrich, Sintering behaviour of binderless tungsten carbide, in Euro PM2012 Congress and Exhibition, Basel, pp. 7-12, September 2012

18. D.J. Ma, Z.L. Kou, Y.J. Liu, Y.K. Wang, S.P. Gao et al., Submicron binderless tungsten carbide sintering behavior under high pressure and high temperature. Int. J. Refract. Met. Hard Mater. 54, 427-432 (2016). https://doi.org/10.1016/j.ijrmh m.2015.10.001

19. D. Demirskyi, A. Ragulya, D. Agrawal, Initial stage sintering of binderless tungsten carbide powder under microwave radiation. Ceram. Int. 37(2), 505-512 (2011). https://doi. org/10.1016/j.ceramint.2010.09.036

20. R.L. Coble, Sintering crystalline solids. I. Intermediate and final state diffusion models. J. Appl. Phys. 32(5), 787-792 (1961). https://doi.org/10.1063/1.1736107

21. R.L. Coble, Sintering crystalline solids. II. Experimental test of diffusion models in powder compacts. J. Appl. Phys. 32(5), 793-799 (1961). https://doi.org/10.1063/1.1736108

22. P. Boch, A. Leriche, Sintering and Microstructure of Ceramics, in Ceramic Materials: Processes, Properties, and Applicatons, ed. by P. Boch, J.C. Niepce (ISTE Ltd, New Porth Beach, 2007), pp. 55-94. https://doi.org/10.1002/97804 70612415.ch3

23. C. Agte, R. Kohlermann, Hilfsmetallarme Hartmetallegierungen. Die Tech. 10, 686-689 (1957)

24. T. Ungár, A. Borbély, G.R. Goren-Muginstein, S. Berger, A.R. Rosen, Particle-size, size distribution and dislocations in nanocrystalline tungsten-carbide. Nanostruct. Mater. 11(1), 103-113 (1911). https://doi.org/10.1016/S0965 -9773(99)00023-9

25. V. Richter, G. Boden, M. Nebelung, M. Ruthendorf, Manufacturing and properties of superhard materials with ceramic sintering aids. Presentation of the COST503-3rd Round Annual Meeting, Subgroup Hard Materials, Hannover (1994)

26. V. Richter, Hard sintered materials made of nano-sized powders. Annual Report of Fraunhofer IKTS, pp. 44-45 (1995)

27. V. Richter, Manufacturing and properties of super-ultrafine hardmetals. Annual Report of Fraunhofer IKTS, pp. 46-47 (1997)

28. Editors of JOM, European powder metallurgy association awards innovation. J. Miner. Met. Mater. Soc. 53-3, 4-9 (2001)

29. V. Richter, M. Ruthendorf, Wasserstrahlschneidhochdruckdüse. DE Patent No. 10052021 (2000)

30. J. Gurland, A study of the effect of carbon content on the structure and properties of sintered WC-Co alloys. Trans. AIME 200(3), 285-290 (1954)

31. C.M. Fernandes, A.M.R. Senos, Cemented carbide phase diagrams: a review. Int. J. Refract. Met. Hard Mater. 29(4), 405418 (2011). https://doi.org/10.1016/j.ijrmhm.2011.02.004

32. S.K. Li, J.Q. Li, Y. Li, F.S. Liu, W.Q. Ao, Dense pure binderless WC bulk material prepared by spark plasma sintering. Mater. Sci. Technol. 31(14), 1749-1756 (2015). https://doi. org/10.1179/1743284714Y.0000000753

33. A. Gubernat, P. Rutkowski, G. Grabowski, D. Zientara, Hot pressing of tungsten carbide with and without sintering additives. Int. J. Refract. Met. Hard Mater. 43, 193-199 (2014). https://doi.org/10.1016/j.ijrmhm.2013.12.002

34. A. Gubernat, L. Stobierski, Fractography of dense metallike carbides sintered with carbon. Key Eng. Mater. 409, 287-290 (2009). https://doi.org/10.4028/www.scientific.net/ KEM.409.287

35. J. Poetschke, V. Richter, T. Gestrich, A. Michaelis, Grain growth during sintering of tungsten carbide ceramics. Int. J. Refract. Met. Hard Mater. 43, 309-316 (2014). https://doi. org/10.1016/j.ijrmhm.2014.01.001

36. R.T. Fox, R. Nilsson, Binderless tungsten carbide carbon control with pressureless sintering. Int. J. Refract. Met. Hard Mater. 76, 82-89 (2018). https://doi.org/10.1016/j.ijrmh m.2018.05.020

37. A. Nino, K. Morimura, S. Sugiyama, H. Taimatsu, Effects of $\mathrm{C}$ and $\mathrm{NbC}$ additions on the microstructure and mechanical properties of binderless WC ceramics. Key Eng. Mater. 749, 205-210 (2017). https://doi.org/10.4028/www.scientific.net/ KEM.749.205

38. A. Nino, K. Takahashi, S. Sugiyama, H. Taimatsu, Effects of carbon addition on microstructures and mechanical properties of binderless tungsten carbide. Mater. Trans. 53(8), 14751480 (2012). https://doi.org/10.2320/matertrans.M2012148

39. G.Z. Zhang, C. Wang, J.X. Zhang, M.L. Zhou, T.X. Zhou, Effects of mixed carbon content on spark plasma sintering of binder-free nanostructured WC cemented carbides. Rare Metals Cemented Carbides 33(2), 12-15 (2005)

40. L. Girardini, M. Zadra, F. Casari, A. Molinariet, SPS, binderless WC powders, and the problem of sub carbide. Metal Powder Rep. 63(4), 18-22 (2008). https://doi.org/10.1016/ S0026-0657(09)70039-6 
41. S.I. Cha, S.H. Hong, Microstructures of binderless tungsten carbides sintered by spark plasma sintering process. Mater. Sci. Eng., A 356(1-2), 381-389 (2003). https://doi. org/10.1016/S0921-5093(03)00151-5

42. J.F. Zhao, T. Holland, C. Unuvar, Z.A. Munir, Sparking plasma sintering of nanometric tungsten carbide. Int. J. Refract. Met. Hard Mater. 27(1), 130-139 (2009). https:// doi.org/10.1016/j.ijrmhm.2008.06.004

43. K. Kornaus, M. Rączka, A. Gubernat, D. Zientara, Pressureless sintering of binderless tungsten carbide. J. Eur. Ceram. Soc. 37(15), 4567-4576 (2017). https://doi.org/10.1016/j. jeurceramsoc.2017.06.008

44. Z.Z. Fang, H. Wang, Densification and grain growth during sintering of nanosized particles. Int. Mater. Rev. 53(6), 326-352 (2008). https://doi.org/10.1179/174328008X35353 8

45. J. Poetschke, V. Richter, A. Michaelis, Fundamentals of sintering nanoscaled binderless hardmetals. Int. J. Refract. Met. Hard Mater. 49, 124-132 (2015). https://doi.org/10.1016/j. ijrmhm.2014.04.022

46. M.J. Mayo, Processing of nanocrystalline ceramics from ultrafine particles. Int. Mater. Rev. 41(3), 85-115 (1996). https://doi.org/10.1179/imr.1996.41.3.85

47. C.C. Koch, Nanostructured Materials: Processing, Properties and Applications (Noyes Publications, New York, 2002), pp. 173-217

48. A.N. Kumar, M. Watabe, K. Kurokawa, The sintering kinetics of ultrafine tungsten carbide powders. Ceram. Int. 37(7), 2643-2654 (2011). https://doi.org/10.1016/j.ceram int.2011.04.011

49. S. Berger, R. Porat, R. Rosen, Nanocrystalline materials: a study of WC-based hard metals. Prog. Mater Sci. 42(1-4), 311-320 (1997). https://doi.org/10.1016/S0079 $-6425(97) 00021-2$

50. Z.Z. Fang, X. Wang, T. Ryu, K.S. Hwang, H.Y. Sohn, Synthesis, sintering, and mechanical properties of nanocrystalline cemented tungsten carbide-a review. Int. J. Refract. Met. Hard Mater. 27(2), 288-299 (2009). https://doi.org/10.1016/j. ijrmhm.2008.07.011

51. K. Brookes, Nano carbides make for low temperature sintering. Metal Powder Rep. 64(9), 26-32 (2009). https://doi. org/10.1016/S0026-0657(09)70217-6

52. M. Leiderman, O. Botstein, A. Rosen, Sintering microstructure and properties of sub-micron cemented carbide. Powder Metall. 40, 219 (1997). https://doi.org/10.1179/ pom.1997.40.3.219

53. R. Porat, S. Berger, A. Rosen, Dilatometric study of the sintering mechanism of nanocrystalline cemented carbides. Nanostruct. Mater. 7(4), 429-436 (1996). https://doi. org/10.1016/0965-9773(96)00014-1

54. H. Ogawa, Y. Kataoka, Observation of sintering of several cemented carbides by a new high-temperature sintering dilatometer. High Temp.-High Press. 13(5), 481-494 (1981)

55. G.R. Goren-Muginstein, S. Berger, A. Rosen, Sintering studies of nanocrystalline WC powder, in Proceedings of the 14th
International Plansee Seminar, Metallwerk Plansee, Reutte, February 1997

56. H.C. Kim, I.J. Shon, J.E. Garay, Z.A. Munir, Consolidation and properties of binderless sub-micron tungsten carbide by field-activated sintering. Int. J. Refract. Met. Hard Mater. 22(6), 257-264 (2004). https://doi.org/10.1016/j.ijrmh m.2004.08.003

57. V.N. Chuvil'deev, Y.V. Blagoveshchenskiy, A.V. Nokhrin, M.S. Boldin, N.V. Sakharov et al., Spark plasma sintering of tungsten carbide nanopowders obtained through DC arc plasma synthesis. J. Alloy. Compd. 708, 547-561 (2017). https://doi.org/10.1016/j.jallcom.2017.03.035

58. V.N. Chuvil'deev, Y.V. Blagoveshchenskiy, A.V. Nokhrin, N.V. Sakharov, M.S. Boldin et al., Sparking plasma sintering of tungsten carbide nanopowders. Nanotechnol. Russ. 10(5-6), 434-448 (2015). https://doi.org/10.1134/S1995 078015030040

59. B.W. Kwak, J.K. Yoon, I.J. Shon, Pulsed current activated rapid sintering of binderless nanostructured TiC and $\mathrm{WC}$ and their properties. J. Nanosci. Nanotechnol. 17(6), 4214-4217 (2017). https://doi.org/10.1166/jnn.2017.13388

60. I.J. Shon, Mechanical properties and rapid sintering of binderless nanostructured TiC and WC by high frequency induction heated sintering. J. Ceram. Process. Res. 17(7), 707-711 (2016)

61. I.J. Shon, B.R. Kim, J.M. Doh, J.K. Yoon, K.D. Woo, Properties of nanostructured tungsten carbide and their rapid consolidation by pulsed current activated sintering. Phys. Scripta T139, 014043 (2010). https://doi.org/10.1088/00318949/2010/T139/014043

62. G.R. Goren-Muginstein, S. Berger, A. Rosen, Sintering study of nanocrystalline tungsten carbide powders. Nanostruct. Mater. 10(5), 795-804 (1998). https://doi.org/10.1016/S0965 -9773(98)00116-0

63. X.Y. Ren, Z.J. Peng, C.B. Wang, Z.Q. Fu, L.H. Qi et al., Effect of $\mathrm{ZrC}$ nano-powder addition on the microstructure and mechanical properties of binderless tungsten carbide fabricated by spark plasma sintering. Int. J. Refract. Met. Hard Mater. 48, 398-407 (2015). https://doi.org/10.1016/j.ijrmh m.2014.10.013

64. K. Biswas, A. Mukhopadhyay, B. Basu, K. Chattopadhyay, Densification and microstructure development in spark plasma sintered WC-6 wt $\% \mathrm{ZrO}_{2}$ nanocomposites. J. Mater. Res. 22(6), 1491-1501 (2007). https://doi.org/10.1557/ JMR.2007.0189

65. B. Basu, J.H. Lee, D.Y. Kim, Development of WC$\mathrm{ZrO}_{2}$ nanocomposites by spark plasma sintering. J. Am. Ceram. Soc. 87(2), 317-319 (2004). https://doi.org/10.111 $1 / \mathrm{j} .1551-2916.2004 .00317 . \mathrm{x}$

66. R. Holm, Electric Contacts: Theory and Application (Springer, New York, 1967), p. 22. https://doi. org/10.1007/978-3-662-06688-1

67. G. Petzow, W.A. Kaysser, Sintering with additives, in Sintering Key Papers, ed. by S. Somiya, Y. Moriyoshi (Elsevier, London, 1990), pp. 615-638. https://doi. org/10.1007/978-94-009-0741-6_39 
68. J.L. Sun, J. Zhao, M.J. Chen, X.C. Wang, X. Zhong et al., Determination of microstructure and mechanical properties of functionally graded $\mathrm{WC}-\mathrm{TiC}-\mathrm{Al}_{2} \mathrm{O}_{3}-\mathrm{GNPs}$ micro-nano composite tool materials via two-step sintering. Ceram. Int. 43(12), 9276-9284 (2017). https://doi.org/10.1016/j.ceram int.2017.04.086

69. Z. Qiao, J. Räthel, L.M. Berger, M. Herrmann, Investigation of binderless $\mathrm{WC}-\mathrm{TiC}-\mathrm{Cr}_{3} \mathrm{C}_{2}$ hard materials prepared by spark plasma sintering (SPS). Int. J. Refract. Met. Hard Mater. 38, 7-14 (2013). https://doi.org/10.1016/j.ijrmh m.2012.12.002

70. Z. Li, S. Cheng, C. Shu, N. Qing, C. Xin et al., Hot pressing densification and grain growth behavior of WC-TiC-TaC binderless carbide. Mater. Sci. Eng. Powder Metall. 16(5), 781-786 (2011)

71. A. Nino, Y. Izu, T. Sekine, S. Sugiyama, H. Taimatsu, Effects of $\mathrm{ZrC}$ and $\mathrm{SiC}$ addition on the microstructures and mechanical properties of binderless WC. Int. J. Refract. Met. Hard Mater. 69, 259-265 (2017). https://doi.org/10.1016/j.ijrmh m.2017.09.002

72. A. Nino, N. Takahashi, S. Sugiyama, H. Taimatsu, Effects of carbide grain growth inhibitors on the microstructures and mechanical properties of $\mathrm{WC}-\mathrm{SiC}-\mathrm{Mo}_{2} \mathrm{C}$ hard ceramics. Int. J. Refract. Met. Hard Mater. 43, 150-156 (2014). https://doi. org/10.1016/j.ijrmhm.2013.11.016

73. A. Fazili, L. Nikzad, M.R. RahimiPour, M. Razavi, E. Salahi, Effect of $\mathrm{Al}_{2} \mathrm{O}_{3}$ ceramic binder on mechanical and microstructure properties of spark plasma sintered WC-Co cermets. Int. J. Refract. Met. Hard Mater. 69, 189-195 (2017). https://doi.org/10.1016/j.ijrmhm.2017.08.010

74. A. Vornberger, J. Pötschke, C. Berger, Manufacturing and properties of tungsten carbide-oxide composites. Key Eng. Mater. 742, 223-230 (2017). https://doi.org/10.4028/www. scientific.net/KEM.742.223

75. J. Wang, D. Zuo, L. Zhu, W.W. Li, Z.B. Tu et al., Effects and influence of $\mathrm{Y}_{2} \mathrm{O}_{3}$ addition on the microstructure and mechanical properties of binderless tungsten carbide fabricated by spark plasma sintering. Int. J. Refract. Met. Hard Mater. 71, 167-174 (2018). https://doi.org/10.1016/j.ijrmh m.2017.11.016

76. O.A. El-Kady, Effect of nano-yttria addition on the properties of WC/Co composites. Mater. Des. 52, 481-486 (2013). https ://doi.org/10.1016/j.matdes.2013.05.034

77. X.Y. Ren, Z.J. Peng, C. Wang, H.Z. Miao, Influence of nano-sized $\mathrm{La}_{2} \mathrm{O}_{3}$ addition on the sintering behavior and mechanical properties of $\mathrm{WC}-\mathrm{La}_{2} \mathrm{O}_{3}$ composites. Ceram. Int. 41(10), 14811-14818 (2015). https://doi.org/10.1016/j.ceram int.2015.08.002

78. A. Rajabi, M.J. Ghazali, A.R. Daud, Chemical composition, microstructure and sintering temperature modifications on mechanical properties of TiC-based cerme-a review. Mater. Des. 67, 95-106 (2017). https://doi.org/10.1016/j.matde s.2014.10.081

79. H. Kim, D. Kim, I. Ko et al., Sintering behavior and mechanical properties of binderless $\mathrm{WC}-\mathrm{TiC}$ produced by pulsed current activated sintering. J. Ceram. Process Res. 8(2), 91 (2007)

80. S. Imasato, K. Tokumoto, T. Kitada, S. Sakaguchi, Properties of ultra-fine grain binderless cemented carbide 'RCCFN'. Int. J. Refract. Met. Hard Mater. 13(5), 305-312 (1995). https:// doi.org/10.1016/0263-4368(95)92676-B

81. H.C. Kim, D.K. Kim, K.D. Woo, I.Y. Ko, I.J. Shon, Consolidation of binderless WC-TiC by high frequency induction heating sintering. Int. J. Refract. Met. Hard Mater. 26(1), 48-54 (2008). https://doi.org/10.1016/j.ijrmhm.2007.01.006

82. J.J. Gao, L.K. Jiang, J.P. Song, G.X. Liang, J. Ang et al., Effects of TiC content on microstructure and mechanical property of WC-TiC-TaC cemented carbides. J. Inorg. Mater. 32(8), 891-896 (2017). https://doi.org/10.15541/jim20 160633

83. H. Engqvist, G.A. Botton, N. Axe, S. Hogmark, A study of grain boundaries in a binderless cemented carbide. Int. J. Refract. Met. Hard Mater. 16(4-6), 309-313 (1998). https:// doi.org/10.1016/S0263-4368(98)00034-1

84. S.G. Huang, K. Vanmeensel, B. Vander, J. Vleugels, Binderless WC and WC-VC materials obtained by pulsed electric current sintering. Int. J. Refract. Met. Hard Mater. 26(1), 41-47 (2008). https://doi.org/10.1016/j.ijrmhm.2007.01.002

85. H.C. Kim, H.K. Park, I.K. Jeong, I.Y. Ko, I.J. Shon, Sintering of binderless $\mathrm{WC}-\mathrm{Mo}_{2} \mathrm{C}$ hard materials by rapid sintering process. Ceram. Int. 34(6), 1419-1423 (2008). https://doi. org/10.1016/j.ceramint.2007.03.029

86. H. Taimatsu, S. Sugiyama, M. Komatsu, Effects of $\mathrm{Cr}_{3} \mathrm{C}_{2}$ and $\mathrm{V}_{8} \mathrm{C}_{7}$ on the microstructure and mechanical properties of WC-SiC whisker ceramics. Mater. Trans. 50(10), 2435-2440 (2009). https://doi.org/10.2320/matertrans.M2009169

87. A. Nino, Y. Nakaibayashi, S. Sugiyama, H. Taimatsu, Microstructure and mechanical properties of WC-SiC composites. Mater. Trans. 52(8), 1641-1645 (2011). https://doi. org/10.2320/matertrans.M2011045

88. S. Sugiyama, D. Kudo, H. Taimatsu, Preparation of WC$\mathrm{SiC}$ whisker composites by hot pressing and their mechanical properties. Mater. Trans. 49(7), 1644-1649 (2008). https:// doi.org/10.2320/matertrans.MRA2008019

89. A. Nino, Y. Nakaibayashi, S. Sugiyama, H. Taimatsu, Effect of $\mathrm{Mo}_{2} \mathrm{C}$ addition on the microstructures and mechanical properties of WC-SiC ceramics. Int. J. Refract. Met. Hard Mater. 64, 35-39 (2017). https://doi.org/10.1016/j.ijrmh m.2016.12.018

90. A. Nino, T. Sekine, K. Sugawara, S. Sugiyama, H. Taimatsu, Effect of added $\mathrm{Cr}_{3} \mathrm{C}_{2}$ on the microstructure and mechanical properties of WC-SiC ceramics. Key Eng. Mater. 656, 33 (2015). https://doi.org/10.4028/www.scientific.net/ KEM.656-657.33

91. O.L. Ighodaro, O.I. Okoli, Fracture toughness enhancement for alumina systems, a review. Int. J. Appl. Ceram. Technol. 5(3), 313-323 (2008). https://doi.org/10.111 $1 / \mathrm{j} .1744-7402.2008 .02224 . x$

92. W.H. Chen, H.T. Lin, P.K. Nayak, J.L. Huang, Material properties of tungsten carbide-alumina composites fabricated by 
spark plasma sintering. Ceram. Int. 40(9), 15007-15012 (2014). https://doi.org/10.1016/j.ceramint.2014.06.102

93. W. Dong, S. Zhu, Y. Wang, T. Bai, Influence of VC and $\mathrm{Cr}_{3} \mathrm{C}_{2}$ as grain growth inhibitors on $\mathrm{WC}-\mathrm{Al}_{2} \mathrm{O}_{3}$ composites prepared by hot press sintering. Int. J. Refract. Met. Hard Mater. 45, 223-229 (2014). https://doi.org/10.1016/j.ijrmh m.2014.04.011

94. W. Dong, S. Zhu, T. Bai, Y. Luo, Influence of $\mathrm{Al}_{2} \mathrm{O}_{3}$ whisker concentration on mechanical properties of $\mathrm{WC}-\mathrm{Al}_{2} \mathrm{O}_{3}$ whisker composite. Ceram. Int. 41(10), 13685-13691 (2015). https://doi.org/10.1016/j.ceramint.2015.07.167

95. H. Qu, S. Zhu, Two step hot pressing sintering of dense fine grained $\mathrm{WC}-\mathrm{Al}_{2} \mathrm{O}_{3}$ composites. Ceram. Int. 39(5), 54155425 (2013). https://doi.org/10.1016/j.ceramint.2012.12.049

96. W.H. Chen, H.T. Lin, P.K. Nayak, M.P. Chang, J.L. Huang et al., Sintering behavior and mechanical properties of WC$\mathrm{Al}_{2} \mathrm{O}_{3}$ composites prepared by spark plasma sintering (SPS). Int. J. Refract. Met. Hard Mater. 48, 414-417 (2015). https:// doi.org/10.1016/j.ijrmhm.2014.10.016

97. W.W. Dong, S.G. Zhu, C.X. Ouyang, The effect of VC on the sintering ability and microstructure of $\mathrm{WC}-\mathrm{Al}_{2} \mathrm{O}_{3}$ composites. Appl. Mech. Mater. 490, 43-48 (2014). https://doi. org/10.4028/www.scientific.net/AMM.490-491.43

98. S.G. Zhu, H.X. Qu, C.X. Ouyang, Hot pressing of tungsten carbide ceramic matrix composites, in Advances in Ceramic Matrix Composites, ed. by I.M. Low (Woodhead Publishing, Cambridge, 2014), pp. 203-229. https://doi.org/10.1016/ B978-0-08-102166-8.00009-8

99. D. Zheng, X. Li, X. Ai, C. Yang, Y. Li, Bulk WC- $-\mathrm{Al}_{2} \mathrm{O}_{3}$ composites prepared by spark plasma sintering. Int. J. Refract. Met. Hard Mater. 30(1), 51-56 (2012). https://doi. org/10.1016/j.ijrmhm.2011.07.003

100. S.J. Oh, B.S. Kim, J.K. Yoon, K.T. Hong, I.J. Shon, Enhanced mechanical properties and consolidation of the ultra-fine WC- $\mathrm{Al}_{2} \mathrm{O}_{3}$ composites using pulsed current activated heating. Ceram. Int. 42(7), 9304-9310 (2016). https://doi. org/10.1016/j.ceramint.2016.02.113

101. H. Qu, S. Zhu, Q. Li, C. Quyang, Microstructure and mechanical properties of hot-pressing sintered $\mathrm{WC}-\mathrm{x}$ vol.\% $\mathrm{Al}_{2} \mathrm{O}_{3}$ composites. Mater. Sci. Eng., A 543, 96-103 (2012). https:// doi.org/10.1016/j.msea.2012.02.053

102. S.J. Oh, B.S. Kim, I.J. Shon, Mechanical properties and rapid consolidation of nanostructured $\mathrm{WC}$ and $\mathrm{WC}-\mathrm{Al}_{2} \mathrm{O}_{3}$ composites by high-frequency induction-heated sintering. Int. J. Refract. Met. Hard Mater. 58, 189-195 (2016). https://doi. org/10.1016/j.ijrmhm.2016.04.016

103. W.H. Tuan, R.Z. Chen, T.C. Wang, C.H. Cheng, P.S. Kuo, Mechanical properties of $\mathrm{Al}_{2} \mathrm{O}_{3} / \mathrm{ZrO}_{2}$ composites. J. Eur. Ceram. Soc. 22(16), 2827-2833 (2002). https://doi. org/10.1016/S0955-2219(02)00043-2

104. D. Zheng, X. Li, Y. Li, S. Qu, C. Yang, $\mathrm{ZrO}_{2}$ (3Y) toughened WC composites prepared by spark plasma sintering. J. Alloy. Compd. 572, 62-67 (2013). https://doi.org/10.1016/j. jallcom.2013.03.259
105. F.Z. Yang, J. Zhao, X. Ai, Effect of initial particulate and sintering temperature on mechanical properties and microstructure of $\mathrm{WC}-\mathrm{ZrO}_{2}-\mathrm{VC}$ ceramic composites. J. Mater. Process. Technol. 209(9), 4531-4536 (2009). https://doi. org/10.1016/j.jmatprotec.2008.10.027

106. T. Venkateswaran, D. Sarkar, B. Basu, WC- $\mathrm{ZrO}_{2}$ composites, processing and unlubricated tribological properties. Wear 260(1-2), 1-9 (2006). https://doi.org/10.1016/j. wear.2004.11.005

107. T. Venkateswaran, D. Sarkar, B. Basu, Tribological properties of $\mathrm{WC}-\mathrm{ZrO}_{2}$ nanocomposites. J. Am. Ceram. Soc. 88(3), 691-697 (2005). https://doi.org/10.111 1/j.1551-2916.2005.00129.x

108. B. Basu, J.H. Lee, D.Y. Kim, Development of WC$\mathrm{ZrO}_{2}$ nanocomposites by spark plasma sintering. J. Am. Ceram. Soc. 87(2), 317-319 (2004). https://doi.org/10.111 $1 / \mathrm{j} .1551-2916.2004 .00317 . x$

109. O. Malek, B. Lauwers, Y. Perez, P.D. Baets, J. Vleugels, Processing of ultrafine $\mathrm{ZrO}_{2}$ toughened WC composites. J. Eur. Ceram. Soc. 29(16), 3371-3378 (2009). https://doi. org/10.1016/j.jeurceramsoc.2009.07.013

110. A. Nasser, M.A. Kassem, A. Elsayed, M.A. Gepreel, A.A. Moniem, Influence of grain refinement on microstructure and mechanical properties of tungsten carbide/zirconia nanocomposites. J. Mater. Eng. Perform. 25(11), 5065-5075 (2016). https://doi.org/10.1007/s11665-016-2341-8

111. B. Basu, T. Venkateswaran, D. Sarkar, Pressureless sintering and tribological properties of $\mathrm{WC}-\mathrm{ZrO}_{2}$ composites. J. Eur. Ceram. Soc. 25(9), 1603-1610 (2005). https://doi. org/10.1016/j.jeurceramsoc.2004.05.021

112. A. Mukhopadhyay, B. Basu, Consolidation-microstructureproperty relationships in bulk nanoceramics and ceramic nanocomposites, a review. Int. Mater. Rev. 52(5), 257-288 (2007). https://doi.org/10.1179/174328007X160281

113. Z.A. Munir, U. Anselmi-Tamburini, M. Ohyanagi, The effect of electric field and pressure on the synthesis and consolidation of materials, a review of the spark plasma sintering method. J. Mater. Sci. 41(3), 763-777 (2006). https://doi. org/10.1007/s10853-006-6555-2

114. K. Inoue, US Patent, No 3241956 (1966)

115. M. Omori, Sintering, consolidation, reaction and crystal growth by the spark plasma system (SPS). Mater. Sci. Eng., A 287(2), 183-188 (2000). https://doi.org/10.1016/S0921 $-5093(00) 00773-5$

116. R.S. Mishra, S.H. Risbud, A.K. Mukherjee, Influence of initial crystal structure and electrical pulsing on densification of nanocrystalline alumina powder. J. Mater. Res. 13(1), 86-89 (1998). https://doi.org/10.1557/JMR.1998.0013

117. K.A. Khalil, Advanced sintering of nano-ceramic materials, in Ceramic Materials-Progress in Modern Ceramics, ed. by S. Feng (InTech, Shanghai, 2012), pp. 65-82

118. M. Suárez, J.L. Fernández, R. Menéndez, R. Torrecillas, H.U. Kessel et al., Challenges and opportunities for spark plasma sintering, a key technology for a new generation of materials, 
in Sintering Applications, ed. by B. Ertuğ (InTech, Turkey, 2013), pp. 319-342. https://doi.org/10.5772/53706

119. B. Huang, L.D. Chen, S.Q. Bai, Bulk ultrafine binderless WC prepared by spark plasma sintering. Scr. Mater. 54(3), 441445 (2006). https://doi.org/10.1016/j.scriptamat.2005.10.014

120. S.I. Cha, S.H. Hong, B.K. Kim, Spark plasma sintering behavior of nanocrystalline WC-10Co cemented carbide powders. Mater. Sci. Eng., A 351(1-2), 31-38 (2003). https ://doi.org/10.1016/S0921-5093(02)00605-6

121. Y. Wang, D. Zhu, X. Jiang, P. Sun, Binderless sub-micron WC consolidated by hot pressing and treated by hot isostatic pressing. J. Ceram. Soc. Jpn. 122(1425), 329-335 (2014). https://doi.org/10.2109/jcersj2.122.329

122. K.M. Tsai, The effect of consolidation parameters on the mechanical properties of binderless tungsten carbide. Int. J. Refract. Met. Hard Mater. 29(2), 188-201 (2011). https://doi. org/10.1016/j.ijrmhm.2010.10.006

123. J. Zhang, G. Zhang, S. Zhao, X. Song, Binder-free WC bulk synthesized by spark plasma sintering. J. Alloy. Compd. 479(1-2), 427-431 (2009). https://doi.org/10.1016/j.jallc om.2008.12.151

124. S.K. Sun, Y.M. Kan, G.J. Zhang, Fabrication of nanosized tungsten carbide ceramics by reactive spark plasma sintering. J. Am. Ceram. Soc. 94(10), 3230-3233 (2011). https://doi. org/10.1111/j.1551-2916.2011.04813.x

125. M. Dopita, A. Salomon, D. Chmelik, B. Reichel, Field assisted sintering technique compaction of ultrafine-grained binderless WC hard metals. Acta Phys. Pol., A 122(3), 639 (2012). https://doi.org/10.12693/APhysPolA.122.639

126. H.T. Kim, J.S. Kim, Y.S. Kwon, Mechanical properties of binderless tungsten carbide by spark plasma sintering, in Proceedings of the 9th Russian-Korean International Symposium on Science and Technology, KORUS (2005)

127. X. Liu, L. Tao, H. Shao, Z. Guo, J. Luo et al., Consolidation and properties of ultrafine binderless cemented carbide by spark plasma sintering. Rare Met. 27(3), 320-323 (2008). https://doi.org/10.1016/S1001-0521(08)60137-0

128. X. Xia, X. Li, J. Li, D. Zheng, Microstructure and characterization of $\mathrm{WC}-2.8 \mathrm{wt} \% \mathrm{Al}_{2} \mathrm{O}_{3}-6.8 \mathrm{wt} \% \mathrm{ZrO}_{2}$ composites produced by spark plasma sintering. Ceram. Int. 42(12), 1418214188 (2016). https://doi.org/10.1016/j.ceramint.2016.06.044

129. H.C. Kim, I.J. Shon, I.K. Jeong, I.Y. Ko, J.K. Yoon et al., Rapid sintering of ultrafine WC and WC-Co hard materials by high-frequency induction heated sintering and their mechanical properties. Met. Mater. Int. 13(1), 39-45 (2007). https://doi.org/10.1007/BF03027821

130. I.J. Shon, B.R. Kim, J.M. Doh, J.K. Yoon, K.D. Woo, Properties and rapid consolidation of ultra-hard tungsten carbide. J. Alloy. Compd. 489(1), L4-L8 (2010). https://doi. org/10.1016/j.jallcom.2009.09.040

131. H. Awaji, S.M. Choi, E. Yagi, Mechanisms of toughening and strengthening in ceramic-based nanocomposites. Mech. Mater. 34(7), 411-422 (2002). https://doi.org/10.1016/S0167 $-6636(02) 00129-1$
132. M. Taya, S. Hayashi, A.S. Kobayashi, H.S. Yoon, Toughening of a particulate-reinforced ceramic-matrix composite by thermal residual stress. J. Am. Ceram. Soc. 73(5), 1382-1391 (1990). https://doi.org/10.1111/j.1151-2916.1990.tb05209.x

133. B. Budiansky, J.C. Amazigo, A.G. Evans, Small-scale crack bridging and the fracture toughness of particulate-reinforced ceramics. J. Mech. Phys. Solids 36, 167-187 (1988). https:// doi.org/10.1016/S0022-5096(98)90003-5

134. M.S. El-Eskandarany, Fabrication of nanocrystalline WC and nanocomposite $\mathrm{WC}-\mathrm{MgO}$ refractory materials at room temperature. J. Alloy. Compd. 296(1-2), 175-182 (2000). https ://doi.org/10.1016/S0925-8388(99)00508-3

135. J. Ma, S. Zhu, C. Ouyang, Two-step hot-pressing sintering of nanocomposite WC-MgO compacts. J. Eur. Ceram. Soc. 31(10), 1927-1935 (2011). https://doi.org/10.1016/j.jeurc eramsoc.2011.04.001

136. C. Ouyang, S. Zhu, H. Qu, VC and $\mathrm{Cr}_{3} \mathrm{C}_{2}$ doped WC$\mathrm{MgO}$ compacts prepared by hot-pressing sintering. Mater. Des. 40, 550-555 (2012). https://doi.org/10.1016/j.matde s.2012.04.030

137. M. Radajewski, C. Schimpf, L. Krüger, Study of processing routes for $\mathrm{WC}-\mathrm{MgO}$ composites with varying $\mathrm{MgO}$ contents consolidated by FAST/SPS. J. Eur. Ceram. Soc. 37(5), 2031-2037 (2017). https://doi.org/10.1016/j.jeurcerams oc. 2017.01 .005

138. J.L. Sun, J. Zhao, X.Y. Ni, F. Gong et al., Fabrication of dense nano-laminated tungsten carbide materials doped with $\mathrm{Cr}_{3} \mathrm{C}_{2} /$ VC through two-step sintering. J. Eur. Ceram. Soc. 38(9), 3096-3103 (2018). https://doi.org/10.1016/j.jeurcerams oc. 2018.02 .037

139. J.L. Sun, J. Zhao, M.J. Chen, X.Y. Ni, Z.L. Li et al., Determination of microstructure and mechanical properties of $\mathrm{VC} / \mathrm{Cr}_{3} \mathrm{C}_{2}$ reinforced functionally graded $\mathrm{WC}-\mathrm{TiC}-\mathrm{Al}_{2} \mathrm{O}_{3}$ micro-nano composite tool materials via two-step sintering. J. Alloys Compd. 709, 197-205 (2017). https://doi. org/10.1016/j.jallcom.2017.03.137

140. P.M. Kelly, L.F. Rose, The martensitic transformation in ceramics-its role in transformation toughening. Prog. Mater Sci. 47(5), 463-557 (2002). https://doi.org/10.1016/S0079 $-6425(00) 00005-0$

141. R.H. Hannink, P.M. Kelly, B.C. Muddle, Transformation toughening in zirconia-containing ceramics. J. Am. Ceram. Soc. 83(3), 461-487 (2000). https://doi. org/10.1111/j.1151-2916.2000.tb01221.x

142. B. Basu, Toughening of yttria-stabilised tetragonal zirconia ceramics. Int. Mater. Rev. 50(4), 239-256 (2005). https://doi. org/10.1179/174328005X41113

143. P.F. Becher, Microstructural design of toughened ceramics. J. Am. Ceram. Soc. 74(2), 255-269 (1991). https://doi. org/10.1111/j.1151-2916.1991.tb06872.x

144. A. Mukhopadhyay, D. Chakravarty, B. Basu, Spark plasmasintered $\mathrm{WC}-\mathrm{ZrO}_{2}-\mathrm{Co}$ nanocomposites with high fracture toughness and strength. J. Am. Ceram. Soc. 93(6), 1754-1763 (2010). https://doi.org/10.1111/j.1551-2916.2010.03685.x 
145. J. Wang, R. Stevens, Zirconia-toughened alumina (ZTA) ceramics. J. Mater. Sci. 24(10), 3421-3440 (1989). https:// doi.org/10.1007/BF02385721

146. D. Zheng, X. Li, Y. Li, S. Qu, C. Yang, Zirconia-toughened WC with/without $\mathrm{VC}$ and $\mathrm{Cr}_{3} \mathrm{C}_{2}$. Ceram. Int. 40(1), 20112016 (2014). https://doi.org/10.1016/j.ceramint.2013.07.111

147. M. Bengisu, O.T. Inal, Whisker toughening of ceramics, toughening mechanisms, fabrication, and composite properties. Annu. Rev. Mater. Sci. 24(1), 83-124 (1994). https://doi. org/10.1146/annurev.ms.24.080194.000503

148. M. Bengisu, O.T. Inal, O. Tosyali, On whisker toughening in ceramic materials. Acta Metall. Mater. 39(11), 2509-2517 (1991). https://doi.org/10.1016/0956-7151(91)90066-A

149. P.F. Becher, C.H. Hsueh, P. Angelini et al., Toughening behavior in whisker-reinforced ceramic matrix composites. J. Am. Ceram. Soc. 71(12), 1050-1061 (1988). https://doi. org/10.1111/j.1151-2916.1988.tb05791.x

150. X.B. Li, C.M. Ke, N. Li, Progress in ceramic matrix composite by $\mathrm{SiC}$ whisker toughening. Mater. Rev. 21(8), 394-397 (2007)

151. Y.J. Chao, J. Liu, Study of WC ceramic tool material by SiC whisker toughening. Rare Metals Cemented Carbides 33(4), 13-16 (2005)

152. H. Taimatsu, S. Sugiyama, M. Komatsu, Effects of $\mathrm{Cr}_{3} \mathrm{C}_{2}$ and $\mathrm{V}_{8} \mathrm{C}_{7}$ on the microstructure and mechanical properties of WC-SiC whisker ceramics. Mater. Trans. 50(10), 2435-2440 (2009). https://doi.org/10.2320/matertrans.M2009169

153. D. Zheng, X. Li, Y. Li, S. Qu, C. Yang, In-situ elongated $\beta-\mathrm{Si}_{3} \mathrm{~N}_{4}$ grains toughened WC composites prepared by one/ two-step spark plasma sintering. Mater. Sci. Eng., A 561, 445-451 (2013). https://doi.org/10.1016/j.msea.2012.10.059

154. Y. Li, D. Zheng, X. Li, S. Qu, C. Yang, $\mathrm{Cr}_{3} \mathrm{C}_{2}$ and VC doped WC- $\mathrm{Si}_{3} \mathrm{~N}_{4}$ composites prepared by spark plasma sintering. Int. J. Refract. Met. Hard Mater. 41, 540-546 (2013). https:// doi.org/10.1016/j.ijrmhm.2013.07.004

155. Y. Li, X. Li, D. Zheng, S. Qu, C. Yang, et al., Tungsten carbide composite material comprising aluminium oxide particles and silicon nitride whiskers and preparation process thereof. WO, WO/2013/020317 (2013)

156. R. Lakshminarayanan, D.K. Shetty, R.A. Cutler, Toughening of layered ceramic composites with residual surface compression. J. Am. Ceram. Soc. 79(1), 79-87 (1996). https://doi. org/10.1111/j.1151-2916.1996.tb07883.x

157. G. Blugan, R. Dobedoe, M. Lugovy, S. Koebel, J. Kuebler, $\mathrm{Si}_{3} \mathrm{~N}_{4}$-TiN based micro-laminates with rising R-curve behavior. Compos. Part B 37(6), 459-465 (2006). https://doi. org/10.1016/j.compositesb.2006.02.013

158. M. Lugovy, V. Slyunyayev, N. Orlovskaya, G. Blugan, J. Kuebler et al., Apparent fracture toughness of $\mathrm{Si}_{3} \mathrm{~N}_{4}$-based laminates with residual compressive or tensile stresses in surface layers. Acta Mater. 53(2), 289-296 (2005). https://doi. org/10.1016/j.actamat.2004.09.022

159. S. Iijima, Helical microtubules of graphitic carbon. Nature 354(6348), 56-58 (1998). https://doi.org/10.1038/354056a0
160. S.C. Tjong, Carbon Nanotube Reinforced Composites, Metal and Ceramic Matrices (Wiley, Hoboken, 2009), pp. 61-64. https://doi.org/10.1002/9783527626991

161. I.J. Shon, K.I. Na, B.R. Kim, I.Y. Ko, J.M. Doh et al., Mechanical properties and consolidation of nanostructured WC-CNT composites by high frequency induction heated sintering. Rev. Adv. Mater. Sci. 28, 9-12 (2011)

162. T. Bai, Fabrication and properties of $\mathrm{WC}-\mathrm{Al}_{2} \mathrm{O}_{3}$ cemented carbide reinforced by single-walled carbon nanotubes. Appl. Mech. Mater. 404, 91-94 (2013). https://doi.org/10.4028/ www.scientific.net/AMM.404.91

163. T. Bai, T. Xie, Fabrication and mechanical properties of WC$\mathrm{Al}_{2} \mathrm{O}_{3}$ cemented carbide reinforced by CNTs. Mater. Chem. Phys. 201, 113-119 (2017). https://doi.org/10.1016/j.match emphys.2017.08.018

164. T. Bai, T. Xie, Influence of $\mathrm{TiO}_{2}$ contents and sintering temperature on the microstructure and mechanical properties of WC- $\mathrm{Al}_{2} \mathrm{O}_{3}$ cemented carbide reinforced by multi-wall carbon nanotubes. J. Alloy. Compd. 745, 562-568 (2018). https://doi. org/10.1016/j.jallcom.2018.02.233

165. J.H. Jang, I.H. Oh, J.W. Lim, H.K. Park, Fabrication and mechanical properties of binderless-WC and WC-CNT hard materials by pulsed current activated sintering method. J. Ceram. Process. Res. 18(7), 477-482 (2017)

166. T. Cao, X. Li, J. Li, M. Zhang, H. Qiu, Effect of sintering temperature on phase constitution and mechanical properties of WC-1.0wt\% carbon nanotube composites. Ceram. Int. 44(1), 164-169 (2018). https://doi.org/10.1016/j.ceram int.2017.09.154

167. K.S. Novoselov, A.K. Geim, S. Morozov, D. Jiang, M.I. Katsnelson et al., Two-dimensional gas of massless dirac fermions in graphene. Nature 438(7065), 197-200 (2005). https://doi.org/10.1038/nature04233

168. A.K. Geim, Graphene, status and prospects. Science 324(5934), 1530-1534 (2009). https://doi.org/10.1126/scien ce. 1158877

169. O. Tapasztó, L. Tapasztó, M. Markó, F. Kern, R. Gadow et al., Dispersion patterns of graphene and carbon nanotubes in ceramic matrix composites. Chem. Phys. Lett. 511(4-6), 340-343 (2011). https://doi.org/10.1016/j.cplett.2011.06.047

170. S. Stankovich, D.A. Dikin, G.H. Dommett, K.M. Kohlhaas, E.J. Zimney et al., Graphene-based composite materials. Nature 442(7100), 282-286 (2006). https://doi.org/10.1038/ nature 04969

171. A. Nieto, D. Lahiri, A. Agarwal, Synthesis and properties of bulk graphene nanoplatelets consolidated by spark plasma sintering. Carbon 50(11), 4068-4077 (2012). https://doi. org/10.1016/j.carbon.2012.04.054

172. A. Nieto, A. Bisht, D. Lahiri, C. Zhang, A. Agarwal, Graphene reinforced metal and ceramic matrix composites, a review. Int. Mater. Rev. 62(5), 241-302 (2017). https://doi. org/10.1080/09506608.2016.1219481

173. I. Ahmad, M. Islam, T. Subhani, Y.Q. Zhou, Toughness enhancement in graphene nanoplatelet/SiC reinforced $\mathrm{Al}_{2} \mathrm{O}_{3}$ ceramic hybrid nanocomposites. Nanotechnology 
27(42), 425704 (2016). https://doi.org/10.1088/09574484/27/42/425704

174. L.S. Walker, V.R. Marotto, M.A. Rafiee, N. Koratkar, E.L. Corral, Toughening in graphene ceramic composites. ACS Nano 5(4), 3182-3190 (2011). https://doi.org/10.1021/nn200 $319 \mathrm{~d}$

175. M.S. Asl, M.G. Kakroudi, Characterization of hot-pressed graphene reinforced $\mathrm{ZrB}_{2}-\mathrm{SiC}$ composite. Mater. Sci. Eng., A 625, 385-392 (2015). https://doi.org/10.1016/j. msea.2014.12.028

176. J. Liu, H. Yan, M.J. Reece, K. Jiang, Toughening of zirconia/ alumina composites by the addition of graphene platelets. J. Eur. Ceram. Soc. 32(16), 4185-4193 (2012). https://doi. org/10.1016/j.jeurceramsoc.2012.07.007

177. A. Nieto, D. Lahiri, A. Agarwal, Graphene nano platelets reinforced tantalum carbide consolidated by spark plasma sintering. Mater. Sci. Eng., A 582, 338-346 (2013). https:// doi.org/10.1016/j.msea.2013.06.006

178. J.L. Sun, J. Zhao, M.J. Chen, Y.H. Zhou, X.Y. Ni et al., Multilayer graphene reinforced functionally graded tungsten carbide nano-composites. Mater. Des. 134, 171-180 (2017). https://doi.org/10.1016/j.matdes.2017.08.041

179. W. Tang, L. Zhang, J.F. Zhu, Y. Chen, W. Tian et al., Effect of direct current patterns on densification and mechanical properties of binderless tungsten carbides fabricated by the spark plasma sintering system. Int. J. Refract. Met. Hard Mater. 64, 90-97 (2017). https://doi.org/10.1016/j.ijrmhm.2017.01.010

180. J. Poetschke, V. Richter, A. Michaelis, Influence of small additions of $\mathrm{MeC}$ on properties of binderless tungsten carbide, in Euro PM 2014 International Conference and Exhibition, Salzburg, Austria, September 2014

181. M. Dopita, C.R. Sriram, D. Chmelik, A. Salomon, H.J. Seifert, Spark plasma sintering of nanocrystalline binderless WC hard metals, in Proceedings of Conference Nanocon 2010, Olomouc, Czech Republic. October 2010

182. H.C. Kim, J.K. Yoon, J.M. Doh, I.Y. Koa, I.J. Shon, Rapid sintering process and mechanical properties of binderless ultra fine tungsten carbide. Mater. Sci. Eng., A 435, 717-724 (2006). https://doi.org/10.1016/j.msea.2006.07.127

183. H. Kim, D. Kim, I. Ko, I.J. Shon, Sintering behavior and mechanical properties of binderless WC-TiC produced by pulsed current activated sintering. J. Ceram. Process. Res. 8(2), 91 (2007)

184. H. Engqvist, G.A. Botton, N. Axén et al., Microstructure and abrasive wear of binderless carbides. J. Am. Ceram. Soc. 83(10), 2491-2496 (2000). https://doi. org/10.1111/j.1151-2916.2000.tb01580.x

185. J. Poetschke, V. Richter, R. Holke, Influence and effectivity of $\mathrm{VC}$ and $\mathrm{Cr}_{3} \mathrm{C}_{2}$ grain growth inhibitors on sintering of binderless tungsten carbide. Int. J. Refract. Met. Hard Mater. 31, 218-223 (2012). https://doi.org/10.1016/j.ijrmh m.2011.11.006

186. X.Y. Ren, Z.J. Peng, Y. Peng, C.B. Wang, Z.Q. Fu et al., Ultrafine binderless WC-based cemented carbides with varied amounts of AIN nano-powder fabricated by spark plasma sintering. Int. J. Refract. Met. Hard Mater. 41, 308-314 (2013). https://doi.org/10.1016/j.ijrmhm.2013.05.002

187. Y. Liu, Z. Wang, Q. Sun, B. Yin, J. Chen et al., Tribological behavior and wear mechanism of pure $\mathrm{WC}$ at wide range temperature from 25 to $800^{\circ} \mathrm{C}$ in vacuum and air environment. Int. J. Refract. Met. Hard Mater. 71, 160-166 (2018). https:// doi.org/10.1016/j.ijrmhm.2017.11.024

188. H. Engqvist, N. Axén, S. Hogmark, Resistance of a binderless cemented carbide to abrasion and particle erosion. Tribol. Lett. 4(3-4), 251-258 (1998). https://doi. org/10.1023/A:1019132011439 